

\section{Public \\ JOURNAL OF Transportation}

\begin{tabular}{c}
\hline Gary L. Brosch, Editor \\
Patricia Henderson, Managing Editor \\
\hline
\end{tabular}

\section{Editorial Board}

Robert B. Cervero, Ph.D. University of California, Berkeley

Chester E. Colby MK Centennial

Gordon Fielding, Ph.D. University of California, Irvine

David J. Forkenbrock, Ph.D.

University of Iowa

José A. Gómez-Ibáñez, Ph.D. Harvard University
Naomi W. Ledé, Ph.D.

Texas Southern University

William W. Millar American Public Transit Association

Steven E. Polzin, Ph.D., P.E. University of South Florida

Sandra Rosenbloom, Ph.D.

University of Arizona

Lawrence Schulman

Orbital Sciences Corp.

George Smerk, D.B.A.

Indiana University

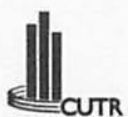

The Journal of Public Transportation (ISSN 1077-291X) is published quarterly by the Center for Urban Transportation Research (CUTR) in the College of Engineering at the University of South Florida. The contents of this document reflect the views of the authors, who are responsible for the facts and the accuracy of the information presented herein. This document is disseminated under the sponsorship of the U.S. Department of Transportation, University Research Institute Program, in the interest of information exchange. The U.S. Government assumes no liability for the contents or use thereof. Subscriptions are complimentary and may be obtained by contacting the Center for Urban Transportation Research, University of South Florida, 4202 E. Fowler Avenue, CUT 100, Tampa, FL 33620-5375, (813) 974-3120, e-mail: phenders@cutr.eng.usf.edu. 


\section{Public \\ JOURNAL OF \\ Transportation}

Volume 2, No. 3, 1999

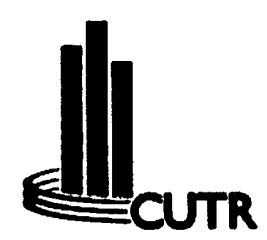

(C) 1999 Center for Urban Transportation Research

National Center for Transit Research Center for Urban Transportation Research

College of Engineering - University of South Florida

4202 E. Fowler Avenue, CUT 100, Tampa, FL 33620-5375

(813) 974-3120 • Fax (813) 974-5168

E-mail:phenders@cutr.eng.usf.edu

Web Site: http://www.cutr.eng.usf.edu 


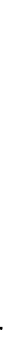




\section{Public \\ JOURNAL OF \\ Transportation}

Volume 2, No. 3, 1999

\section{Contents}

Transit Customer Acceptance of Automated Fare Collection Systems ........ 1

Peter J. Foote, Ross T. Patronsky, and Darwin G. Stuart

Assessing Transit Station Area Redevelopment:

A Case Study of the Lindbergh Station in Atlanta

Lawrence D. Frank, Mollie Stephenson Smith, and Eleanor Q. Matthews

Environmental Responsiveness in Australia's Bus and Coach

Supply Chain.

Ann M. Brewer

Transit Stations and Commercial Property Values:

A Case Study with Policy and Land-Use Implications

Arthur C. Nelson

Modeling Senior Travelers' Acceptance of New Transit Systems

Mohamed A. Abdel-Aty

Our troubled planet can no longer afford the luxury of pursuits confined to an ivory tower. Scholarship has to prove its worth. not on its own terms, but by service to the nation and the world.

- Oscar Handlin 


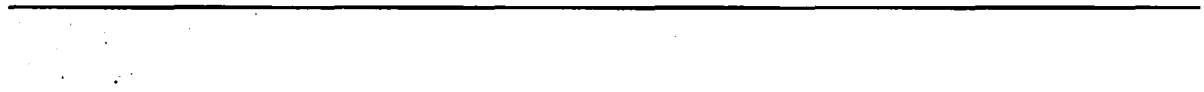




\title{
Transit Customer Acceptance of Automated Fare Collection Systems
}

\author{
Peter J. Foote, Ross T. Patronsky, Darwin G. Stuart \\ Chicago Transit Authority
}

\begin{abstract}
The Chicago Transit Authority (CTA) inaugurated an Automated Fare Collection (AFC) system in Fall 1997. More than I million daily rides now utilize AFC to access CTA's bus and rail service networks. While this represents about three-fourths of all CTA riders, many have stayed with cash or tokens (though the latter are now being phased out); monthly passes have been fully integrated with the farecard technology.

This article provides a one-year perspective on customer reactions to, acceptance of, and problems with the new AFC system. It examines "before" and "after" shifts among the various fare media options available, and discusses major differences for bus and rail customers regarding ease of purchasing automated farecards and the resultant greater usage levels for rail as compared to bus. This article also reviews behavior in purchasing precoded, fixed-value farecards; buying variable-value farecards at automated vending machines (AVMs) located at rail stations; and recharging previously purchased farecards at those AVMs. Systemwide customer satisfaction surveys conducted in 1995 and 1997 found that satisfaction ratings, particularly among bus riders, significantly improved for several different fare-related service attributes. Transactions handled by rail station customer assistants, the CTA customer service hot line, and its AFC express unit desk, in dealing with customer questions/problems
\end{abstract}


regarding the new AFC equipment, are also discussed. Typical weekday complaint levels related to $A F C$-especially those involving refund requests - are quite modest, but require sustained levels of courtesy and quick response.

\section{Introduction}

In September 1997, the CTA completed implementation of an AFC system on both its bus and rail service networks. This $\$ 106$ million project required a 27-month implementation period, with much of the investment applied to refitting CTA's 141 rail rapid transit stations with appropriate automated turnstile and farecard vending machines. Implementation on the 129-route bus system involved integrating automated transit farecard readers with computerized cash and token fare collection equipment, which remained in service. The AFC system utilizes a credit-card-size farecard with a magnetic stripe that stores its monetary value, decreased electronically by the value of every originating ride or transfer used, and increased electronically whenever dollar value is added at an AVM.

This article summarizes the impact of the AFC system on CTA's customers over a period of 13 months following full implementation. In general, an effective July 1997 multimedia marketing campaign, followed by expanded and improved customer service operations related to fare collection, helped smooth the customer acceptance process. Since AFC represented one of the most dramatic changes in day-to-day usage of the CTA system in many years, much attention was given to facilitating the transition process. Several major shifts in key CTA job positions were required, including converting former rail ticket agents into customer assistants and inoreasiog thou on ther service staff to deal specifically with rider problems encountered mising he now A FC equipment.

\section{Shift in Fofe Hedia togage}

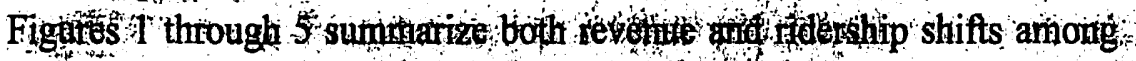

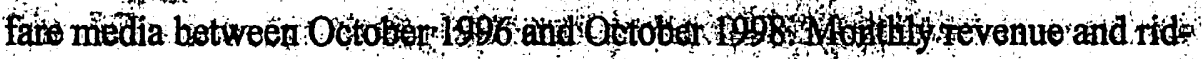

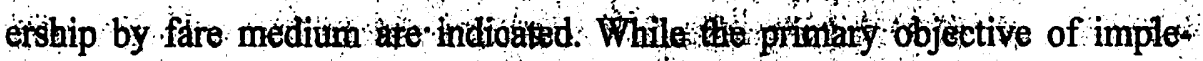

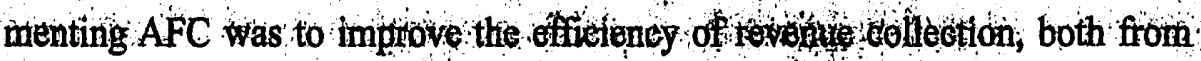

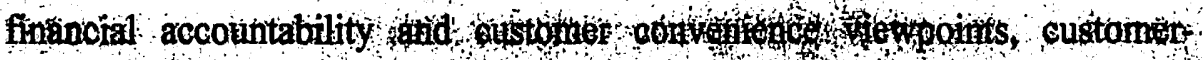


switching to the new automated farecards was not mandatory. As a result, while AFC quickly became the primary means for fare payment on the CTA system, monthly passes, tokens, and cash also continued to represent major fare payment options. Though cost-per-ride savings were offered as a primary incentive to switch to farecards, cash and tokens (with the latter no longer offering a discount, but representing only an equivalent to cash) continued to be used by many riders.

Several major impacts are suggested by Figures 1 through 5 . While unlimited ride passes were also equipped with magnetic stripes to be readable by bus and rail fare collection equipment, their price ( $\$ 88$ for full-fare riders) was unchanged, and their usage level essentially also remained unchanged. With the 11 percent discount for tokens eliminated-and essentially transferred to farecards instead - tokens dropped quickly in popularity, from about 29 percent of all riders in October 1996 to only 9 percent in October 1998. Some token users have remained loyal to this fare medium as a result of habit, continued convenience, and/or unwillingness/apprehension regarding the new automated equipment. Cash fare riders have continued at a somewhat surprisingly high level: nearly 41 percent in October 1998 of all revenue collected, and about 20 percent of all rides carried. (Transfers received, when paid for by cash, accounted for another $22 \%$ of October rides.)

As Figure 4 indicates, cash-fare customers are primarily riding CTA's bus system, where they represent 24 percent of all bus riders carried (again, transfers paid for by cash accounted for anether $25 \%$ ). This, in part, reflects the distribution of neighborhood opportunities to conveniently purchase automated farecards. In general, while these are avallable at 525 food store and currency exchange locations throughout CTA's service area, well ass at all 141 rail stations and at CTA offices, many originating bus rides apparently still find the switch to prepurchasing farecards to be-burdersome. Pat of this burden may be financial, as the 1996

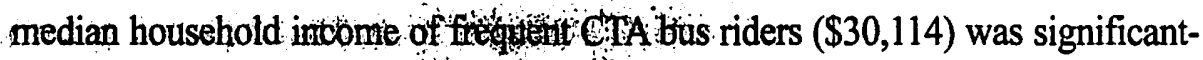
ly lower than for rail ridets ( $\$ 353038)$. I If appears that the prevalued $\$ 13.50$ and $\$ 16.50$ farecards available at noightoonthood groceries and currency exchanges are

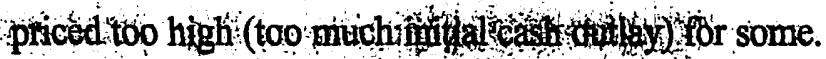

Tol, $2,10,3,109$ 


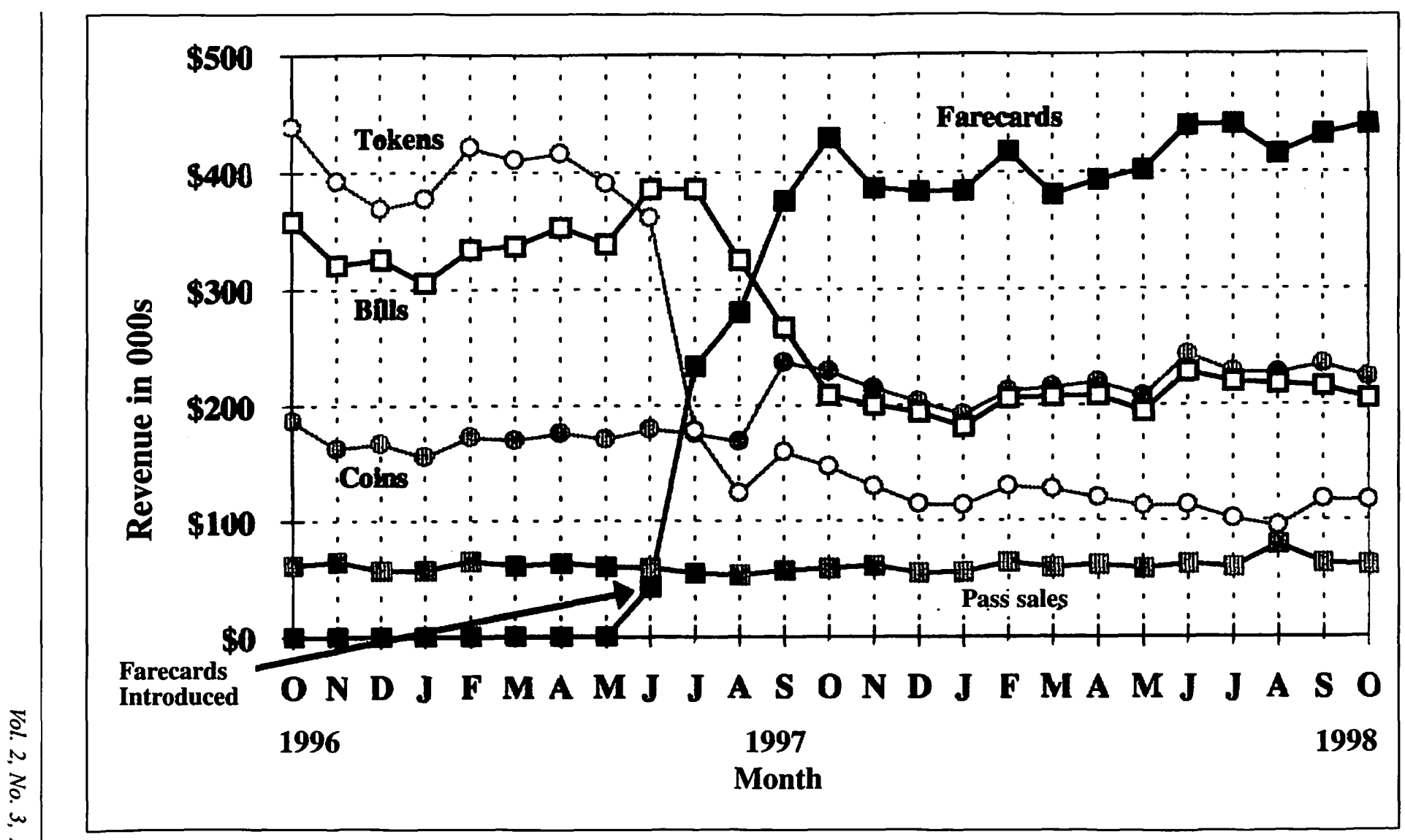

Figure 1. Average daily farebox revenue by month and fare type, 1996-1998 


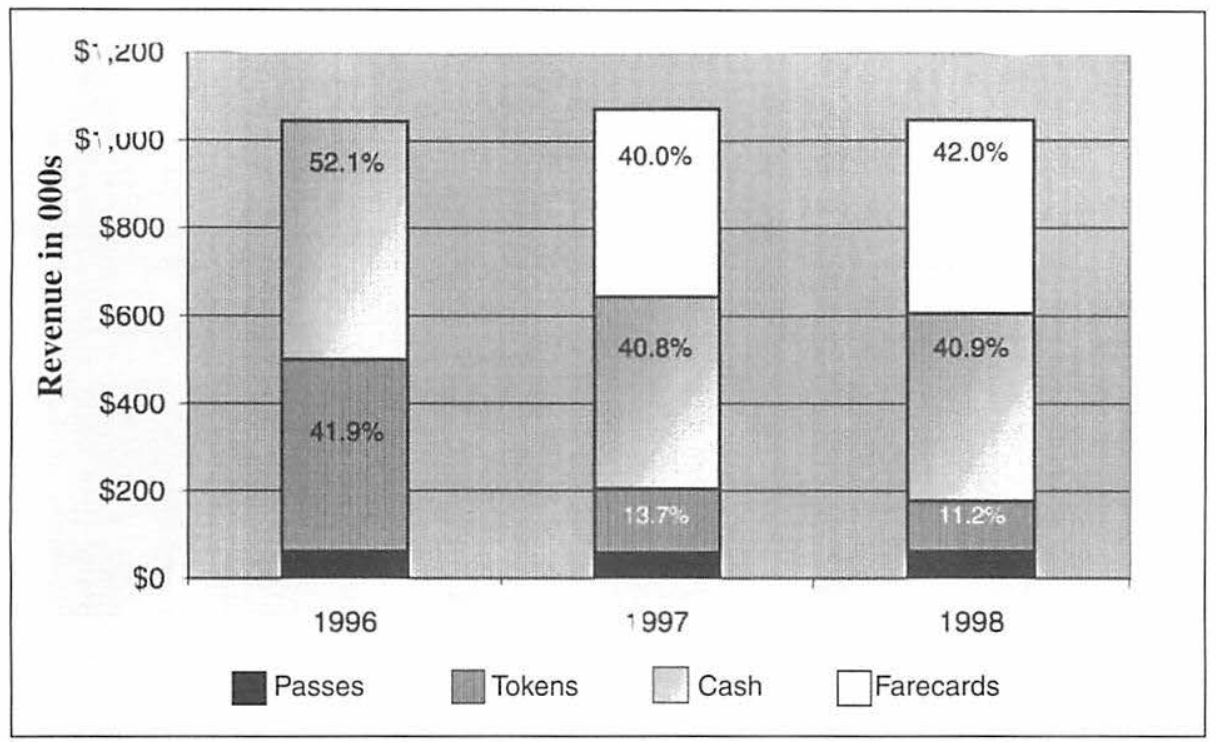

Figure 2. Average daily farebox revenue, October 1996, 1997, 1998

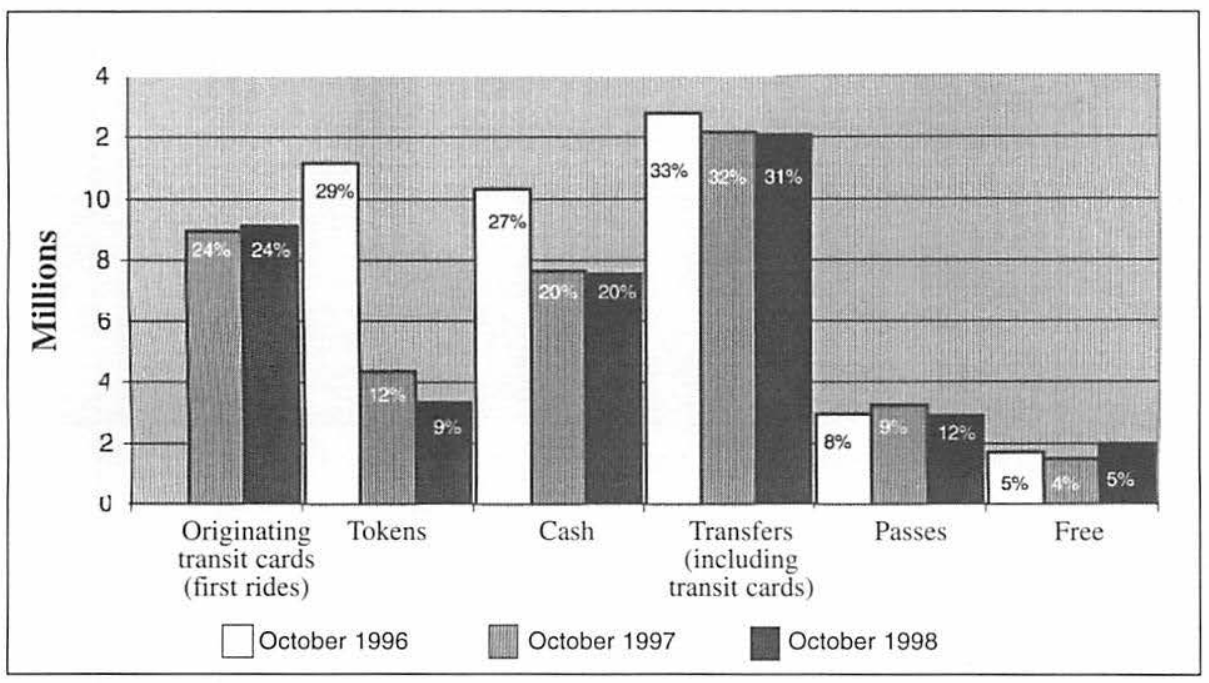

Figure 3. October monthly system ridership by fare medium, adjusted, 1996-1998 


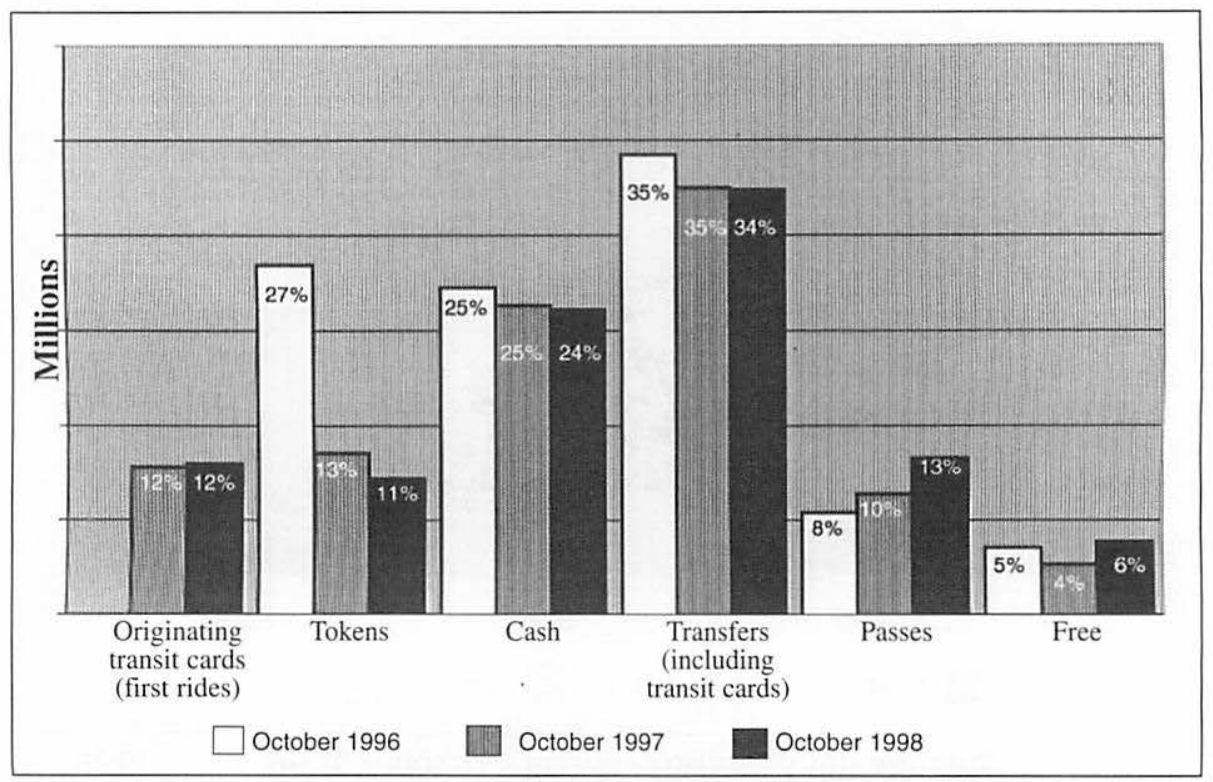

Figure 4. October monthly bus ridership by fare medium, adjusted, 1996-1998

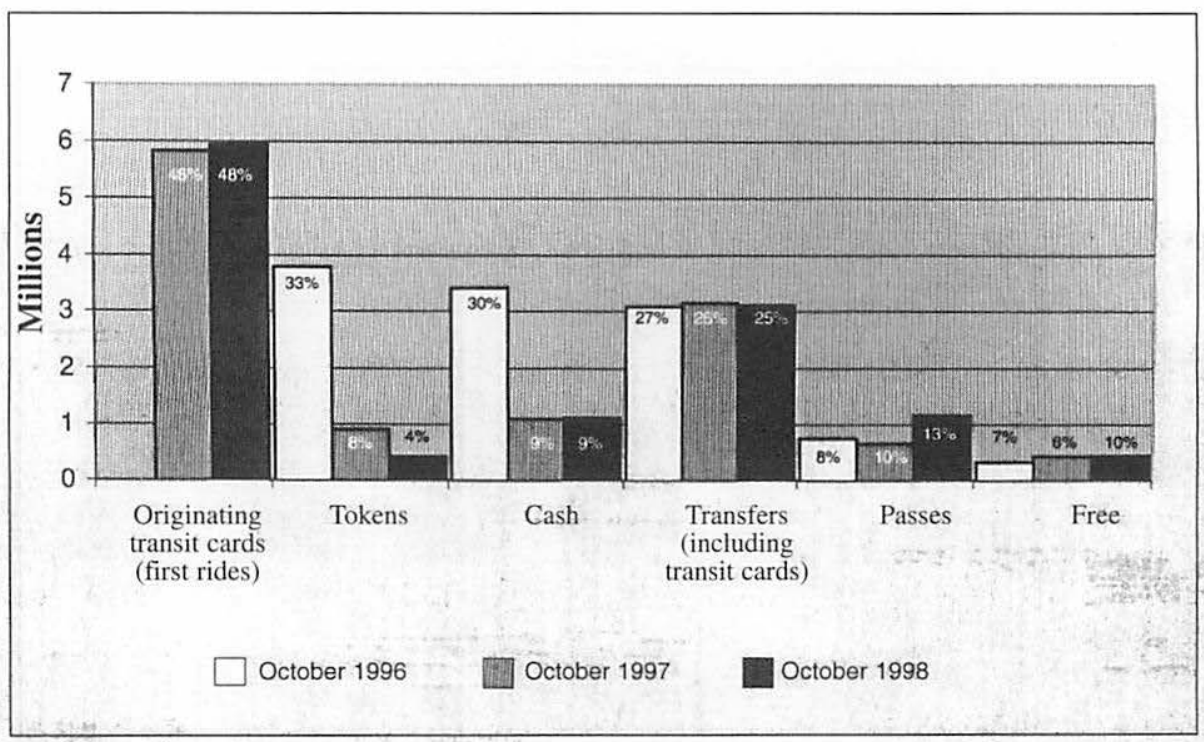

Figure 5. October monthly rail ridership by fare medium, adjusted, 1996-1998 
Bus riders paying by cash or tokens are issued an automated transfer card, if requested and with additional payment, which permits them to transfer to rail via the automated fare equipment. Because half of all CTA riders transfer between modes, offering bus-to-rail and rail-to-bus automated transferring opportunities is essential for efficient operations. It also allows many bus riders to "ignore" the AFC system, even though they may be missing an opportunity for cost savings on a per ride basis.

As indicated in Figure 5, the ready availability and convenience of AVMs for purchasing farecards at all CTA rail stations has been a primary incentive for switching to AFC. Use of tokens and cash on rail has consequently declined to only about 4 percent and 9 percent, respectively, by October 1998. (When using cash or tokens to pay for one ride at a time, rail riders may also pay for and be issued an automated transfer card to use for bus service.)

Another major incentive for rail riders to switch to AFC, in addition to convenience of farecard purchase, is that generally only one turnstile at each rail station is equipped to handle coins (no bills) or tokens. The other turnstiles handle farecards only, thereby providing "gentle persuasion" for switching to farecards-in order to avoid rush-hour lines at the one turnstile still accepting cash and tokens. This particularly applies, of course, at CTA's higher ridership rail stations, including all 17 in the central area, where four, eight, or more turnstiles are typically in operation, but only about one-fourth accept cash or tokens.

\section{Nonthly Farecard Sales Patterns}

When purchasing farecards at AVM machines located at rail stations, CTA cuistonters may either buy a new farecard or recharge an existing one. Pitơmotionat material and customer assistants encourage precharging of existTing fareards; as this allows customers to retain whatever value may remain on that card and reduces CTA costs for the farecards themselves. In addition, two types of prevalued farecards; with a fixed value of either $\$ 13.50$ or $\$ 16.50$, were intitially available at currency exchanges and food stores. Both of these farecards automatically offer a $\$ 1.50$ riding bonus; that is, the $\$ 13.50$ farecard axtrayly ofe $\$ 15,00$ in rides. AVMs also offer this bonus for multiples of 
$\$ 13.50$ in farecard purchase. (On November 1, 1998, prices were adjusted so that a $\$ 10.00$ farecard purchase received a $\$ 1.00$ riding bonus. The intent was to offer a bonus at a more convenient price, requiring, for example, only a $\$ 10.00$ bill, or two fives.)

Figures 6 and 7 summarize comparative sales characteristics for these different farecard purchase and recharge options. A total of 69 percent of all farecard purchase transactions, and 78 percent of the value of those transactions, involve recharging at AVMs. Only 6 percent of farecard purchase transactions, and 14 percent of the value of those transactions, involve prevalued farecards purchased at neighborhood (nonrail) locations.

The average initial sales and added recharge value for AVM farecard transactions are relatively low-only $\$ 6.58$ for initial sales and $\$ 5.49$ for added value. The range of variation here is extensive, however, as indicated by the large standard deviation associated with these purchase values. The relatively low cash outlays for farecard purchase at AVMs also indicate that small numbers of CTA customers qualify for the prepurchase bonus of 11 percent $(\$ 1.50$ for every $\$ 13.50$ of farecard value).

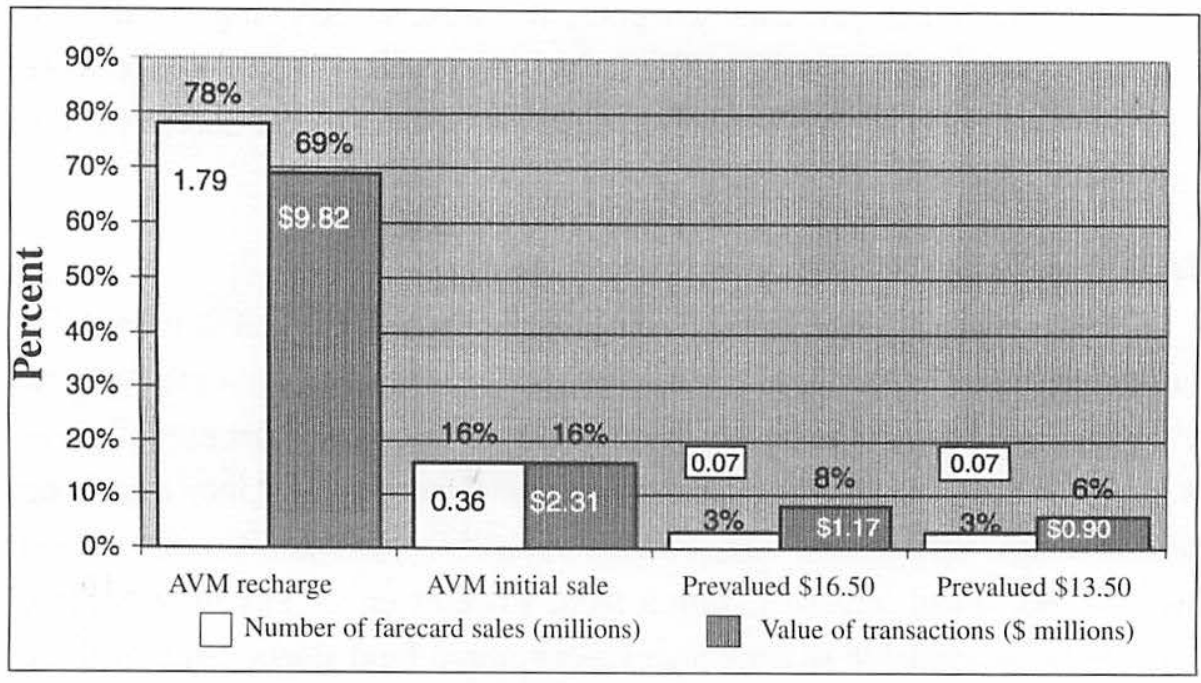

Figure 6. Monthly farecard sales vs. transactions, October 1998 


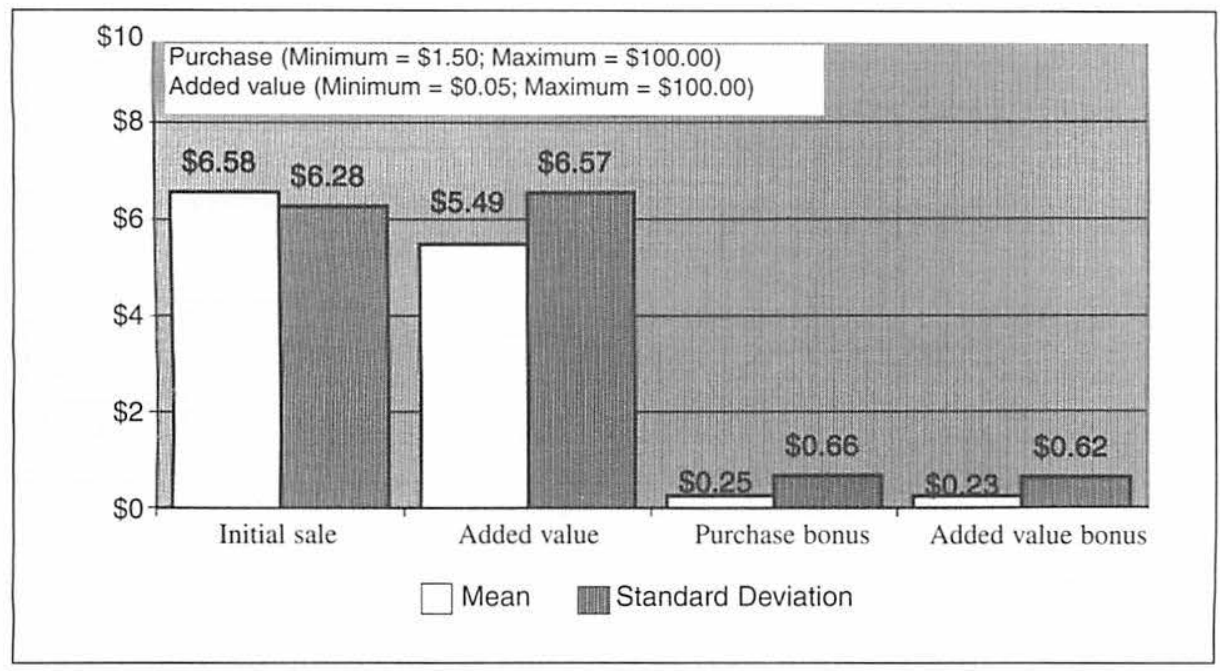

Figure 7. AVM farecard sales daily average, October 1998

\section{Bus and Rail Fare Media Transactions}

Figures 8, 9, and 10 and Table 1 summarize a typical weekday in October 1998 with regard to fare payment media. Originating fares, both full-fare and reduced-fare riders, are indicated. For transfers received, passes, and free rides, it is not possible to distinguish full- from reduced-fare riders, so combined totals are given. The bus and rail components of overall system ridership, on an average weekday, are also indicated. The relative proportion of system rides attributed to each of 10 different fare media is given, with bus vs. rail comparisons of particular interest.

Reduced-fare riders (students, seniors, disabled) show a much lower rate of conversion to AFC fare payment (Table 1). Tokens still represent their primary means for originating rides, followed by cash, with farecards a distant third. Transfer cards, issued on bus only to cash-paying and token-fare riders, represent the primary type of "transfer received." In fact, they represent 22 percent of all rides carried, compared to transfers deducted from transit cards, at 10 percent. (Transit cards cover both originating fares and up to two transfers per journey.) 


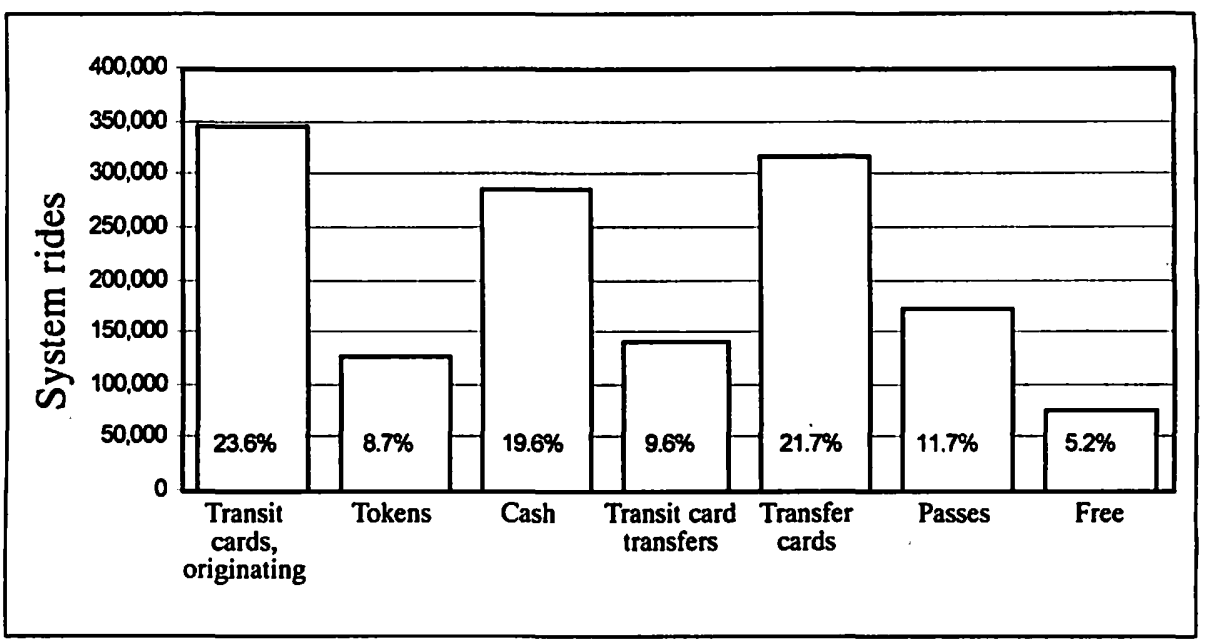

Figure 8. Typical 1988 system ridership by fare medium adjusted, October 1998

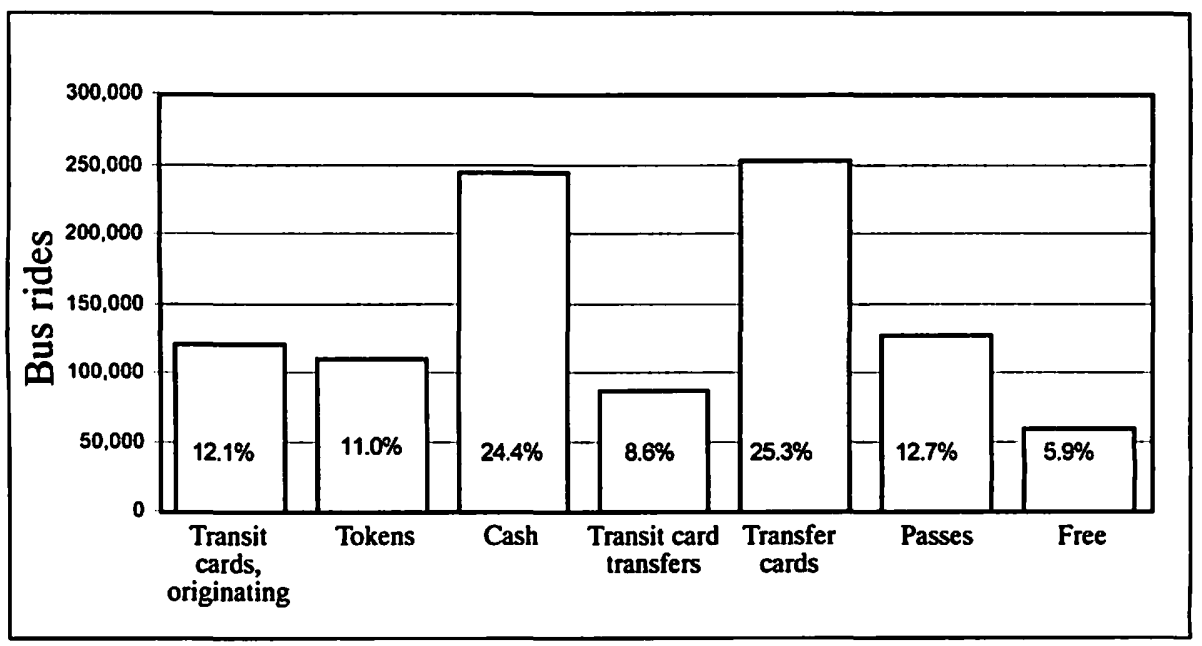

Figure 9. Typical 1988 bus ridership by fare medium adjusted, October 1998 


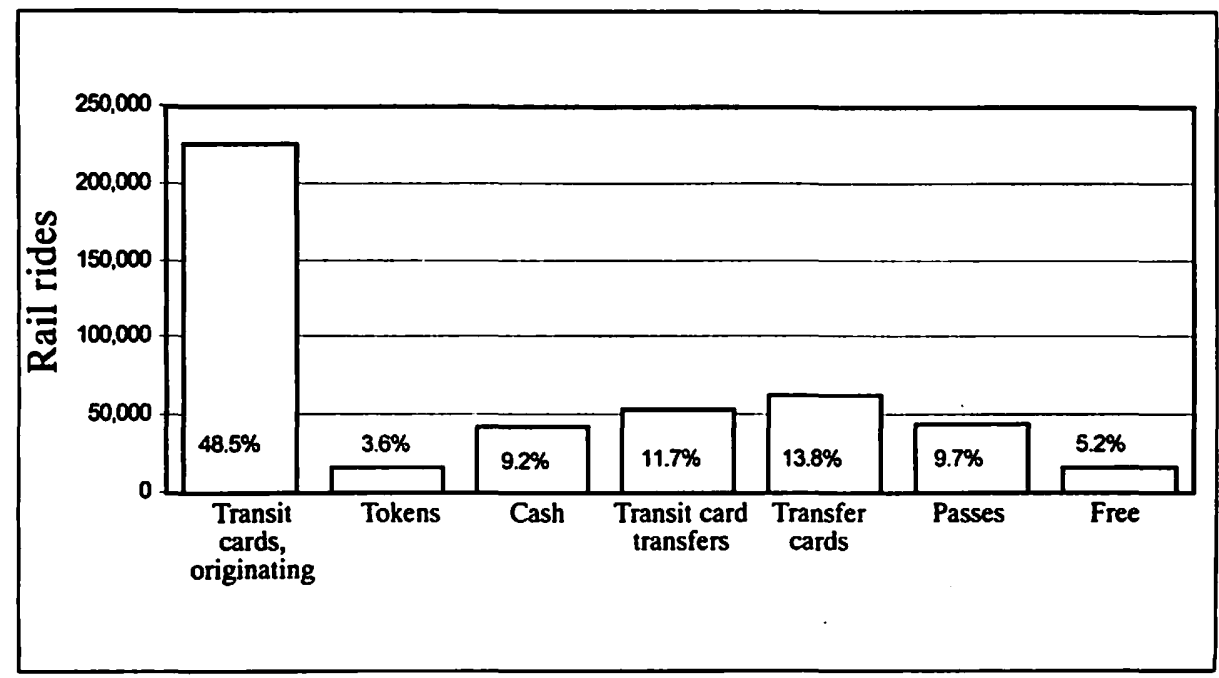

Figure 10. Typical 1988 rail ridership by fare medium adjusted, October 1998

Processing of transfer cards on buses correspondingly represents the single most prevalent type of bus rider carried, at more than one-fourth of all bus boardings. Cash-paying customers represent the second largest type of boarding bus riders, at 24 percent, followed by full-fare originating transit card users, at 12 percent. For rail, 47 percent of all boarding passengers are originating full-fare transit card users- by far the prevalent type of rider on rail. Token-fare and cash payment represent only about 4 percent and 9 percent of all rail riders, as originating fare payment customers. Even on rail, transfer cards issued to bus riders represent a significant type of fare payment-in fact, at 14 percent of all boarding rail riders, this is the second largest type of fare media presented.

\section{Bus and Rail Customer Service Transactions}

In October 1997, just one month after full implementation of the AFC system (and three months after CTA's major AFC marketing campaign, which coincided with about $95 \%$ implementation), a random digit-dial customer satisfaction survey was conducted within the CTA service area. ${ }^{2} A$ total of 44 different overall transit service quality features were investigated for both bus and rail riders, with a number of these either directly or indirectly involving fare 


\section{Table 1}

(Supplement to Figures 8, 9, and 10)

Full-Fare and Reduced-Fare Rider Components of Originating Rides

\begin{tabular}{|c|c|c|c|c|c|c|}
\hline & \multicolumn{2}{|c|}{ Transit Card } & \multicolumn{2}{|c|}{ Tokens } & \multicolumn{2}{|c|}{ Cash } \\
\hline & Full & Reduced & Full & Reduced & Full & Reduced \\
\hline Bus & $11.6 \%$ & $0.5 \%$ & $4.6 \%$ & $6.4 \%$ & $19.5 \%$ & $4.9 \%$ \\
\hline Rail & 46.8 & 1.6 & 2.8 & 0.8 & 8.3 & 0.8 \\
\hline System & 22.8 & 0.8 & 4.0 & 4.6 & 16.0 & 3.6 \\
\hline
\end{tabular}

Note: Percent of total average weekday rides.

payment. When compared with a similar survey conducted two years earlier,' it was found that bus riders, in particular, significantly improved their ratings of several fare-related service attributes. As indicated in Table 2, ease of making transfers, as well as the cost of transferring, were both rated significantly higher, as were the cost of a one-way ride and the cost of a monthly pass. Curiously, even though rail riders converted at a higher level to AFC, their ratings of these same service features did not significantly improve.

The lower perceived cost of transferring (Table 2) reflects the fact that transfer costs are now only deducted from farecards when actually used, as compared to the prior possible purchase of transfers (and transfer cards) that are ultimately never used, because an intended bus is late in arriving or for other

Table 2

Changes in CTA Customer Satisfaction of CTA Bus (November 1995-November 1997) (\%)

\begin{tabular}{lll}
\hline Attribute & 1995 & 1997 \\
\hline Value of service for fare paid & 3.35 & 3.55 \\
Cost of one-way ride & 3.04 & 3.36 \\
Cost of monthly pass & 2.48 & 3.05 \\
Cost of transferring & 3.12 & 3.48 \\
Ease of making transfers & 3.64 & 3.79 \\
$(p<.05)$ & & \\
\hline
\end{tabular}


reasons. Perceived improvement in the cost of the monthly pass probably reflects a misinterpretation on the part of some bus riders of the automated farecard as a kind of "pass," even though the cost of each ride is individually deducted, rather than allowing unlimited rides. Perceived reduction in the cost of a one-way bus ride most likely reflects the "bonus ride" associated with purchasing farecards in multiples of $\$ 13.50$. As noted earlier, the lower median household incomes of CTA bus riders may also be a factor in this increased perception and significance of modest fare reductions.

CTA's Customer Service Division was reorganized and expanded in early 1997 as part of a renewed emphasis on increasing customer satisfaction. Implementation of AFC as a major new technology upgrade for collecting fares from most CTA riders was initially viewed with some trepidation by this group. The group was concerned that, given the potential for even small rates of equipment failure, across a million or more fare transactions daily, the daily complaint rate would be extremely high. In anticipation of potentially large increases in both inquiries regarding how the AFC system works, as well as complaints regarding AFC equipment failure (incorrect amounts deducted from farecards, refunds requested, etc.) the customer service staff received special training in AFC operations.

As indicated in the 15-month graphs given in Figures 11 and 12, calls to the CTA customer service "hot line" telephone number regarding AFC did increase dramatically. However, calls that represented either AFC inquiries or complaints reached initial levels consistent with other types of inquiries and/or complaints, but did not overwhelm CTA staff.

These two figures indicate that the peak number of inquiries regarding AFC/fares understandably occurred during its first "official" month, July 1997, and reached about 2,500 calls for that month. These calls generally declined on an ongoing basis over the following year, reaching a low of only 109 calls in July 1998. Other types of calls to the hot line center also regularly exceed 2,000 per month, including travel information requests (how do I get from A to B?), as well as general inquiries regarding various CTA matters (including service changes on specific routes) and overall complaints of several different types. 


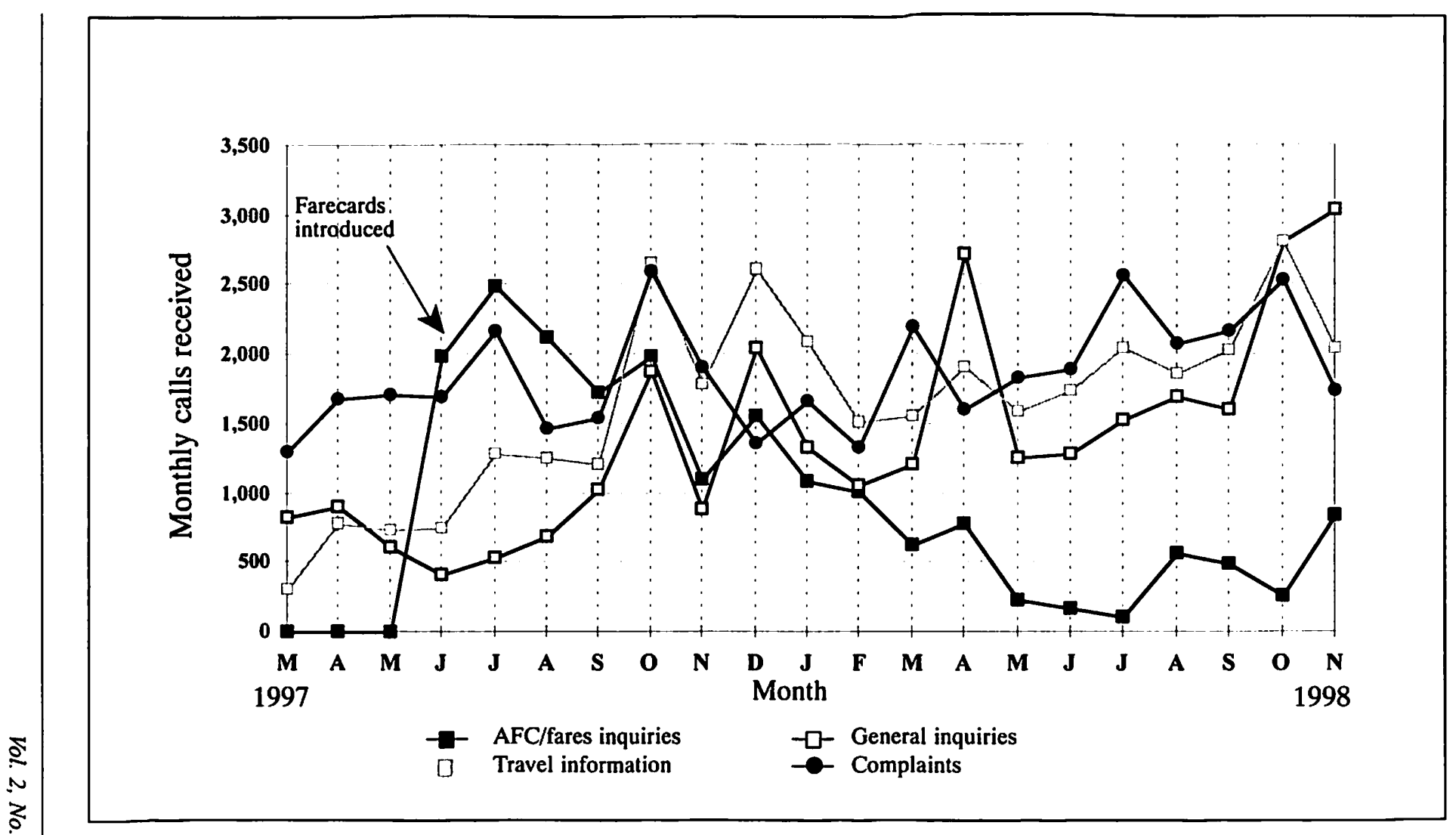

Figure 11. Calls to 1-888-Your-CTA by call type, March 1997-November 1998 


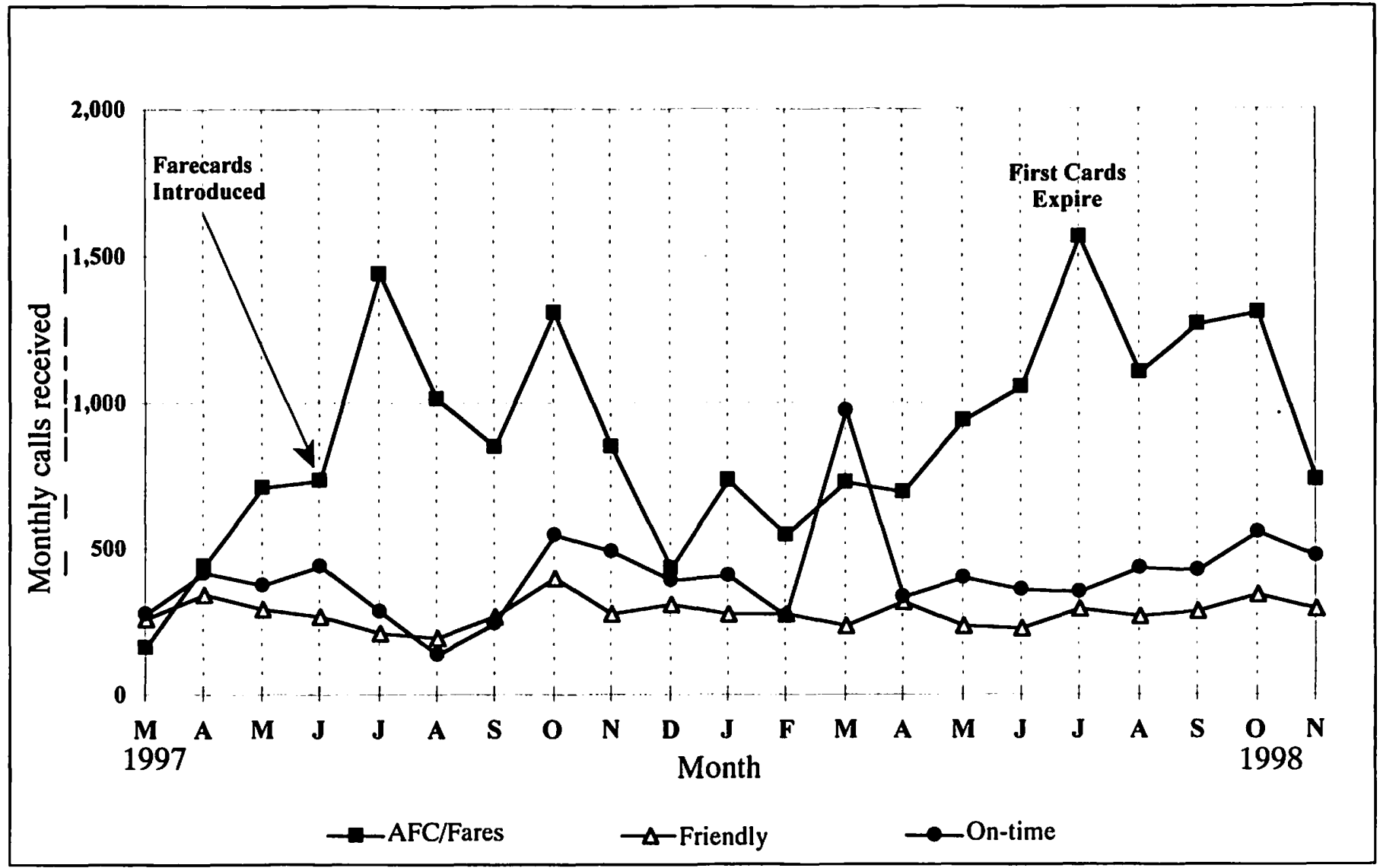

Figure 12. Complaint calls to 1-888-Your-CTA by call type, March 1997-November 1998 
As shown in Figure 12, the number of complaints (in general, refund requests) associated with the new $\mathrm{AFC}$ system was high in its initial month, at nearly 1,500, but then declined gradually to a low of under 450 in December 1997. Since then, however, complaints have gradually increased, to reach a new high of over 1,500 in July 1998 . Reasons for these increases in AFC/fares complaints over the spring and summer of 1998 are not clear, though they again began to decline in the fall. For infrequent travelers, the one-year validity of farecards purchased at the onset of AFC implementation began to expire in mid-1998 and partially contributed to increased complaints. New users generated over the spring and summer could also be a major underlying factor.

During the fall and winter months of 1997 to 1998, AFC/fares complaints began to fall to a level consistent with the other two primary categories of CTA customer complaints, on-time performance and friendliness/courtesy of operators. For example, in February 1998, AFC/fares complaints were roughly only twice the volume (546) of each of the other two complaint categories. Prior to AFC, fare-related complaints were typically well below on-time and courtesy concerns.

A special unit, established to exclusively handle AFC refund transactions, was readily accessible at the main offices of CTA in downtown Chicago. Its activities were examined for a typical weekday in October 1998. Activity levels were also compared against a typical weekday for CTA rail customer assistants, who represent CTA's primary face-to-face interaction-along with individual CTA bus operators-with customers regarding fare payment.

In general, the AFC express unit deals with five different activities: processing fare discrepancy reports that are forwarded to them from rail customer assistants (meaning that the rail customer assistant was not able to resolve a fare discrepancy on the spot, being empowered to issue immediate replacement farecards, in denominations of $\$ 3.60, \$ 10.00$, and $\$ 20.00$ ), processing similar bus-fare discrepancy reports from bus operators and bus garage supervisors, handling walk-in refund requests, mailing refunds generated from all three previous sources, and handling phone calls regarding refunds or the status of prior refund requests. 
Comparisons of customer interactions indicate that typical weekday activity levels at CTA offices regarding the most troublesome type of customer complaint related to AFC-requesting a refund-are quite modest: about 30 fare discrepancy reports (from bus and rail) handled daily, together with 25 walk-in refund requests, and 50 phone calls.

The daily volume of rail-fare discrepancy reports prepared by customer assistants was also examined. These involve all rail customer AFC discrepancy interactions, both those settled on the spot by the customer assistant as well as those forwarded to the AFC customer service express unit for follow-up. These figures again show that most customers experience AFC problems with the AVMs that take their cash and issue farecards. About 125 to 135 AVM incidents are handled per day, with 75 percent of these involving "lost value on farecard." At rail turnstiles, only about 10 incidents per day are reported, with damaged farecard and double deduction of fare the most frequently reported malfunctions.

Customer assistants typically handle an average refund transaction of under $\$ 10$, for both AVM problems as well as turnstile malfunctions. The average refund handled at the AFC express unit is typically much larger, with walk-ins the highest at over $\$ 25$ per refund, and with somewhat lower levels associated with mailed check refunds, as well as with mailed replacement farecards.

As indicated in Table 3, these different levels of AFC-related customer transactions-with the CTA call center, AFC express unit, and rail customer assistants-together yield a manageable systemwide level of about 260 daily customer transactions. This converts to a daily "problem incidence rate" of about 2.3 per $10,000 \mathrm{AFC}$ transactions.

\section{Conclusions}

The following conclusions were drawn from the examination of "before" and "after" shifts in available fare media options:

- Though AFCs are technologically advanced, and somewhat intimidating (at least at first) for many transit riders, careful implementation 


\begin{tabular}{|c|c|c|}
\hline \multicolumn{3}{|c|}{$\begin{array}{c}\text { Table } 3 \\
\text { Summary of Daily AFC-Related Customer Service Transactions }\end{array}$} \\
\hline Customer Service Group & $\begin{array}{l}\text { AFC-Related Customer } \\
\text { Service Transactions } \\
\end{array}$ & $\begin{array}{c}\text { Average Number of Weekday } \\
\text { Customer Transactions } \\
\text { (October 1998) }\end{array}$ \\
\hline Customer service call center & $\begin{array}{l}\text { - Inquiries } \\
\text { - Complaints, problems, } \\
\text { refund requests } \\
\end{array}$ & $\begin{array}{l}10 \\
52 \\
\end{array}$ \\
\hline $\begin{array}{l}\text { Customer service } \\
\text { AFC express unit }\end{array}$ & $\begin{array}{l}\text { - Bus FDRsa } \\
\text { - Rail FDRs } \\
\text { - Walk-in refunds } \\
\end{array}$ & $\begin{array}{l}19 \\
12 \\
25 \\
\end{array}$ \\
\hline $\begin{array}{l}\text { Rail station } \\
\text { Customer assistants }\end{array}$ & $\begin{array}{l}\text { - AVM problems, } \\
\text { refund requests } \\
\text { - Turnstile problems, } \\
\text { refund requests }\end{array}$ & $\begin{array}{r}131 \\
11\end{array}$ \\
\hline \multicolumn{3}{|r|}{ Total $=260^{b}$} \\
\hline $\begin{array}{l}\text { Typical overall number of AFC } \\
\text { equipment weekday operations, } \\
\text { October } 1998\end{array}$ & $\begin{array}{l}\text { - Rides processed } \\
\text { - Farecards issued or } \\
\text { revalued, AVMs }\end{array}$ & $\begin{array}{r}1,053,700 \\
92,500\end{array}$ \\
\hline \multicolumn{3}{|r|}{ Total $=1,146,200$} \\
\hline
\end{tabular}

a. Fare discrepancy reports.

b. Some double counting among categories is likely.

c. Bus farecard processing units, rail turnstiles.

Note: Not included are other AFC equipment servicing and maintenance operations, which otherwise did not result in customer farecard revenue loss or related complaint, such as miscellaneous repair of inoperable turnstiles.

and effective marketing can result in their successful inauguration and being well-received by customers.

- The keys to successful implementation of an AFC system are convenience of purchase and ready availability of AVMs for flexible-price purchasing of farecards. This was clearly reflected in the much lower acceptance of AFC farecards by CTA bus riders, whose access to AVMs was more limited.

- Implementation of CTA's AFC system was an important component, involving several fare-related service attributes, in improved overall customer satisfaction between 1995 and 1997. 
- Even within well-designed and implemented AFC systems, cash is likely to still be a significant fare medium, if allowed. Customers who prefer cash are generally not price sensitive, ${ }^{4}$ and may also be relatively infrequent riders who, partially through unfamiliarity with the equipment, continue to prefer cash.

- Customers readily accept the idea of recharging farecards already in their possession. This allows them to retain whatever value may remain on a farecard, and also helps the transit operator reduce the costs of printing, encoding, and issuing new farecards.

- Major technology advances such as AFC will likely produce a whole new area of customer inquiries, problems, and complaints. While this new area of customer interactions may become more frequent than others (such as complaints over on-time performance and operator courtesy), it need not overwhelm the staff.

- AFC can significantly increase both the flexibility and control necessary to more readily allow multiple fare options. In fact, CTA recently introduced several pricing revisions in its fare structure that involve adjusting downward the farecard purchase price at which a 10 percent bonus is awarded, and lower priced 30-day passes that become effective on the first day of use.

- AFC can also facilitate fare policy innovations designed to increase ridership and/or revenue. For example, CTA recently implemented a discounted University Pass Program (U-Pass) for full-time university students at 14 different colleges and universities within its service area. The program relies on AFC technology to uniquely encode each U-Pass farecard with school and student serial number and specific term/semester validity dates.

- AFC allows a major leap forward in the quality of ridership data available for service planning and analysis (by bus route, rapid transit line and station, time of day, fare media utilized, etc.). Such improvements continue to be actively employed by the CTA planning staff to facilitate operations. 


\section{Endnotes}

1. Northwest Research Group, Customer satisfaction survey of Chicago Transit Authority riders, Chicago Transit Authority, December 1997.

2. Ibid.

3. Northwest Research Group, Customer satisfaction survey of Chicago Transit Authority riders, Regional Transportation Authority, December 1995.

4. Multisystems, Stored-value farecard pricing survey and ridership/revenue model, Chicago Transit Authority, December 1995.

\section{About the Authors}

Peter J. Foote is a senior transit research analyst in the CTA's market research department. He has been engaged in transportation research since joining the CTA in 1987, where he has been project manager of a wide variety of customer-focused on-board, telephone, and mail surveys. He is active in the Transportation Research Board's (TRB) Marketing and Fare Policy Committee.

Ross Patronsky is manager of data services and development at the CTA, and is responsible for reporting and analyzing ridership. He has devoted more than 20 years to the transit industry, including stints in Madison, Wisconsin, and Ann Arbor, Michigan. He holds master's degrees from the University of Michigan, and has been active in the Chicago Chapter of the American Statistical Association.

DARWIN G. STUART is manager of market research at the CTA, where he has been responsible for a variety of system planing, corporate planning, and market analysis activities. He has also worked as a private transportation and transit planning consultant and has been active with TRB committee and research panel efforts. He holds a doctorate degree from Northwestern University. 


\title{
Assessing Transit Station Area Redevelopment: A Case Study of the Lindbergh Station in Atlanta
}

\author{
Lawrence D. Frank, Georgia Institute of Technology \\ Mollie Stephenson Smith, CRA Associated, Inc. \\ Eleanor Q. Matthews, MARKETEK, Inc.
}

\begin{abstract}
$\overline{\text { Abstract }}$
This article assesses the land-use, demographic, circulation, and economic development attributes of transit station area development. Findings from this assessment are applied to the Lindbergh Metropolitan Atlanta Rapid Transit Authority (MARTA) Station area in Atlanta, Georgia, for which a private-public partnership is currently being negotiated. Recommendations for the redevelopment of the Lindbergh Station area are provided, including a schematic design that integrates those recommendations. The resulting recommendations are intended to maximize the likelihood for transit ridership and economic benefit while offsetting traffic congestion and vehicle emissions-in keeping with the objectives of the Federal Transit Administration's Livable Communities Initiative. A safe and inviting walking environment throughout a station area-extending well beyond the area of physical redevelopment itself-is fundamental to achieving these objectives. Existing barrier effects and lack of pedestrian
\end{abstract}


connectivity associated with major transportation corridors within the Lindbergh Station area will significantly offset transportation and environmental benefits on which public investment in the redevelopment is predicated. Solutions are required that provide not only safer street crossings, but a larger proportion of rights-of-way devoted to pedestrian movement and the development of a "street life." Priority should be given to pedestrian improvements that increase access to transit for traditionally underserved populations. Finally, open space is required to effectively compete with other more auto-dependent areas and to draw higher income populations to transit station areas.

\section{Introduction}

Many growing metropolitan areas throughout the nation are faced with increasing levels of traffic congestion, sprawling development, socially isolated communities, and poor air quality. Development patterns and transportation investments collectively shape not only the arrangement of activities in the urban landscape, but also determine the relative ease of travel by mode. An obvious alternative to auto-dependent "green-field" development is the reinvestment within existing centers. This article explores the potential for reinvestment around transit stations, in particular where walking and transit should be viable options to the automobile. Assessing the likely implications of alternative approaches to redeveloping transit station areas can be supported through a holistic approach at addressing the creation of a set of criteria or performance measures that address circulation, land- use, demographic, and economic development concerns. Past research also suggests that significant coordination is required among federal, state, regional, and local agencies to implement strategies aimed at confronting urban problems that extend to a regional scale. Institutional mechanisms are required to prioritize nonmotorized circulation within station areas. This requires an investment program that extends well beyond those parcels that are under redevelopment.

The Atlanta region is currently without a long-range transportation plan that conforms with national air quality requirements specified in the Clean Air Act and detailed in the National Ambient Air Quality Standards. This means that the region is currently without an adopted strategy capable of achieving 
compliance with federal air quality mandates. Underpinning the inability to develop a conforming transportation plan is the allocation of growth, in terms of the specified location of future households and jobs, that has been modeled by the Atlanta Regional Commission. As currently modeled, the vast majority of growth would go to the urban fringe-and the modeling results suggest that this, among other factors, leads to ever increasing auto dependence and bad air. One alternative to this scenario is to focus a portion of the growth into locations where alternatives to the single-occupant vehicle (SOV) exist.' This article explores the redevelopment of an existing transit station area as a case study to evaluate the potential for improving regional air quality and transportation conditions by capitalizing on existing transit investments.

\section{Transit Supportive Development}

An extensive literature defining transit-oriented development (TOD) currently exists. This article applies the empirical research embedded in this literature through the development of a system of land-use, demographic, circulation, and economic development attributes that interactively define a program for redevelopment. The conceptual model for this system is depicted in Figure 1.

The figure illustrates specific attributes that need to be addressed within an effective redevelopment plan. It is critical to have a program for redevelopment that defines the appropriate combination of land-use and demographic mix and supportive circulation improvements, confirmed against a carefully researched economic development program. Transit-supportive development refers to an urban environment characterized by moderate- to high-density residential, and a mix of commercial and retail uses, all in close proximity to the local or regional transit system. In addition to simply accommodating projected growth, the goals of TOD are to increase transit ridership, improve the quality of life in urban areas, and enhance economic vitality. Related objectives include:

1. using infill and redevelopment to maximize the use of existing urbanized areas already accessible to transit;

2. employing land-use strategies to reinforce transit use; 


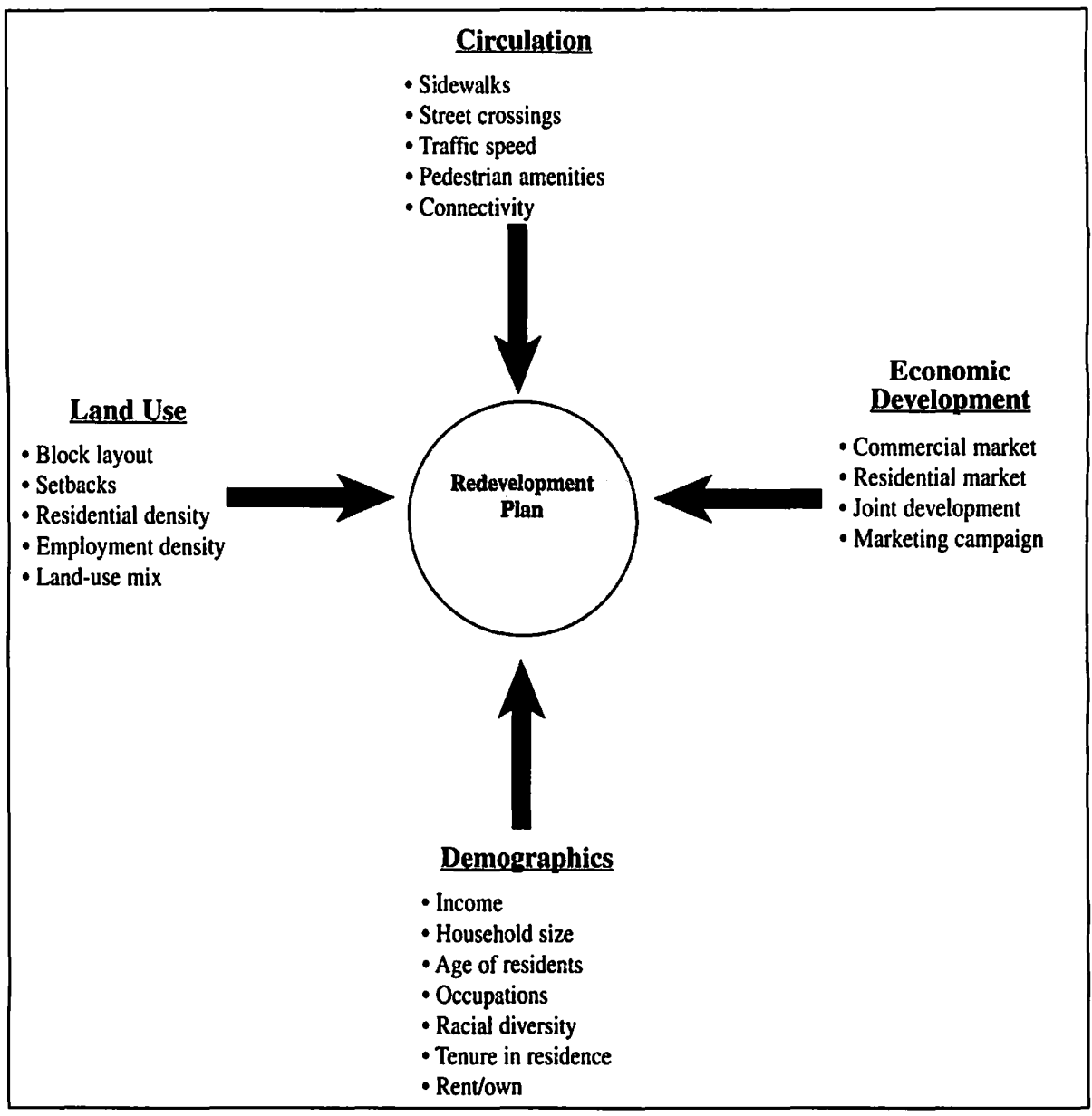

\section{Figure 1. Attributes of transit-oriented development}

3. creating an environment that presents numerous opportunities to walk and bike, thereby reducing the number of automobile trips and vehicle miles traveled in the immediate area and larger region; and

4. fostering a 24-hour community that is more vital, interactive, and secure than many of today's typical neighborhoods.

These benefits, however, are contingent on successful implementation. For example, transit-supportive development requires coordination between agencies and all levels of government, along with partnerships between and among developers, neighborhoods, transit authorities, and local government. 
Success of these relationships also requires understanding of available funding sources. ${ }^{2}$

\section{Land-Use Considerations}

The literature on TOD establishes several key conceptual components. Many researchers have focused on the importance of land use, particularly on the effect of intermixing uses, the compactness of development, and street connectivity. The geographic scale at which uses are intermixed impacts the distances that need to be traversed to reach a complementary use (e.g., a store from home or work). The compactness of development, most often measured as the density or numbers of households and jobs per unit of area, captures a multitude of demographic and urban form factors associated with travel choice. The degree to which the street network is interconnected, ranging between a gridiron plan (most connected) to a cul-de-sac form (disconnected) determines the level of ease that destinations can be reached. These land-use measures interact. A measure of land-se mix may indicate that a neighborhood has a wide variety of uses all within short crow-fly walking distances-but few people are walking due to the lack of direct pedestrian linkages between these different land uses (Frank 1998).

The question of what uses should be included, and in what proportion, is more complex. Calthorpe (1993) defines the ideal land-use mix for neighborhood TODs as 10 percent to 15 percent public use, 10 percent to 40 percent core/employment, and 50 percent to 80 percent housing. Others stress the importance of retail uses, claiming they can yield almost as many transportation benefits in residential neighborhoods as can higher densities (Bernick and Cervero 1997), a second important factor in encouraging transit and pedestrian activity.

Numerous studies document that density is a critical component of a set of factors that are required to facilitate transit ridership. In Urban Rail in America, Pushkarev, Zupan, and Camella (1982) note the importance of transit-supportive development patterns at both trip origins and destinations. More specifically, they note the need for a minimum level of residential density at the production end and a critical mass of development at the destination or employment trip end for transit to be efficient and competitive. In an exami- 
nation of six metropolitan areas, ranging from Springfield, Massachusetts, to New York City, transit ridership rose marginally when residential densities were increased from 7 dwelling units per acre to 16 (Bernick and Cervero 1997). Density of workplaces has also been found to lead to increased transit use. A study of Bellevue, Washington, a city having a mean workplace floor area ratio of 7.4 , found that 27 percent of its employees reached the office by bus, carpool, or vanpool (Cervero and Gorham 1995). This is a relatively high modal share for transit for a modern suburban center of moderate development densities. The higher level of transit usage can be explained by regional congestion, aggressive transportation demand management efforts pursuant to Commute Trip Reduction efforts, and a high-quality transit service that includes regional express service often operating on less clogged high-occupant vehicle facilities. Another study of the Seattle metropolitan region found that auto use decreased and transit and walk trips increased when employment densities of more than 75 workers per acre were reached (Frank and Pivo 1994). These shifts in travel from the personal vehicle to transit and walking associated here with higher levels of employment density reflect other market forces that occur with higher concentrations of development-namely the increased cost and the reduced availability of parking.

Other important land-use factors focus on design issues such as block size, connectivity, and building setbacks. Downtown Portland, Oregon, is an often-cited example of how a uniformly small block size has helped to create a pedestrian- and transit-supportive environment (City of Portland 1980). A street pattern that uses an interconnected grid, where adjacent developments are linked together, allows for a number of alternative routes for both pedestrian and vehicular traffic. This adds variety for pedestrians, who, as a result, have more paths to travel between activities (Calthorpe 1993). It also allows local trips between the home and nearby attractions to be made without using the major arterial street network (Metro 1997). This is a very important safety consideration for families with younger children.

Calthorpe (1993) also observes that minimal setbacks encourage pedestrian activity by bringing buildings close to the street. Buildings should be as close 
to the street as possible, although setbacks of up to 20 feet can be allowed for larger office buildings in commercial areas. The closeness of the buildings to the street also serves to narrow the street and helps to slow traffic; the planting of trees in planting strips (if there is enough room) or on the median of a street can have the same effect. In residential areas the setback should be 10 feet to 15 feet, allowing some privacy while keeping the buildings close to the street.

\section{Demographic Considerations}

A variety of studies illustrate that land use and the level of transit service are not the sole factors that impact travel choice; and, in some instances, are regarded as having a relatively inconsequential influence when compared with household demographics. Household demographic characteristics that explain travel behavior include income, life cycle stage, automobile availability, household size, and ownership (Ewing, Haliyur, and Page 1994; Cervero and Kockelman 1997). Most people that inhabit successful TODs are between 25 and 34 years old, and 65 years old and over. While median household income tends to be relatively low compared with many suburban communities, there is an increasing demand for high-quality housing located within close proximity to transit. Childless households and in-migrants from foreign countries are other important demographic candidates for transit-oriented living (Cervero and Kockelman 1997). These households tend to be small, occupy less space, and are more inclined toward multifamily settings.

Clearly, the ideal population of a transit-oriented community can best be characterized by its diversity. However, in areas where retrofit is taking place, efforts to preserve the area's diversity are essential. This is a very important consideration within the Lindbergh Station area in Atlanta, which has concentrations of white, black, Hispanic, and Asian populations within close proximity. ${ }^{3}$ The level of automobile ownership is also a reliable indicator of a household's degree of attraction to transit-supportive development. Most rail-served apartments and condominiums are small in size with relatively low vehicle ownership (Bernick and Cervero 1997). Conversely, several studies have further documented that increasing levels of auto ownership are associated with reduced transit ridership (Frank 1999; Schimek 1996). Finally, it has been 
found that the population of transit-based housing should have large concentrations of managerial and professional workers. Only a few residents of transit-based housing work in sales, service, and other occupations (Bernick and Cervero 1997).

\section{Circulation Patterns}

While the importance of land use cannot be overstated, characteristics of the transportation network itself play an enormous role in a successful TOD. A fundamental criterion of TOD is the ease and degree of attractiveness for local travel on foot. Utilitarian factors, such as the ease of street crossings, sidewalk continuity, signal placement, local street characteristics, and topography (Parsons, Brinckerhoff, Quade, and Douglas Inc. 1993; Florida Department of Transportation 1995) must be considered during planning stages of the TOD. Other important elements are aesthetic in nature, including the presence of lighting, landscaping, and street furniture. People are attracted to places that are quiet, well maintained, and conducive to relaxation and social contact (Untermann 1984). Antoniou (1971) provides a very thorough description of factors that must be considered when planning for the pedestrian, including facilities and amenities, maintenance, and the provision of public utilities to the area under consideration. Sidewalk widths should be large enough to easily accommodate the expected pedestrian flow; lighting should be sufficient for both safety and attractiveness; and amenities should be chosen and placed based on expected flow and usage.

Moudon et al. (1996) theorized that the low incidence of pedestrian travel in mixed-use, medium-density environments located in many suburban settings is due to inadequate site design. Even in areas spatially conducive to walking, a lack of direct, continuous, and safe pedestrian systems will prevent people from choosing to walk. This condition is termed "low connectivity." Though empirical evidence relating pedestrian behavior to site design in medium-density settings is scarce, it does suggest that pedestrian travel is a viable alternative to the SOV for a portion of the population under specific circumstances. Isolating those circumstances and then ensuring their provision is therefore key to providing for a successful pedestrian environment. 
An obvious component of the circulation network is the flow of vehicular traffic on the roadway system. One way that traffic flow can be structured to allow for pedestrian access while maintaining vehicle capacity involves the formation of directional couplets resulting in a narrower vehicular right-ofway between pedestrian refuges. ${ }^{4}$ Other practices that often result in the reduction of traffic volume and speed include the elimination or rerouting of through traffic, provision of midblock crossings, and development of internal pedestrian shopping areas (Untermann 1984). One measure of the degree of pedestrian friendliness is the proportion of the right-of-way devoted to pedestrian movement. The Florida Department of Transportation (1995) suggests an ideal overall ratio of 50:50 of pedestrian space to vehicle space on targeted corridors within TODs.

Many other considerations are necessary when planning pedestrian facilities in areas of substantial automobile traffic. Intersections are one of the most obvious areas of concern and should be clearly designed for ease of pedestrian crossing and maneuverability. Geometry of the roadway should be designed in order to slow traffic and allow pedestrians to safely share the facility; signal placement should be easily seen by the pedestrian; and sidewalks and crosswalks at or near intersections should be well lit. Raised medians should be provided so that pedestrians are given opportunity for refuge midway through the street crossing (Florida Department of Transportation 1995).

\section{Economic Development}

Economic development has not been as well researched as other aspects of TOD. Newman and Kenworthy (1996) point out that transit investment can have twice the economic benefit to a city as highway investment. Transit focuses access in a manner that enables higher densities, which in turn creates more efficient subcenters, which can offset sprawl. In addition, transit enables a region to become more corridor oriented, making the provision of infrastructure easier and less expensive (Burchell and Listoken 1974). The economic development point of view should be carefully considered when assessing an area's potential for successful TOD. However, it should be addressed within the larger context of the other issues outlined here as well. Berechman (1995) 
states that in evaluating the economic development potential of a transit station area, it is necessary to consider the travel and socioeconomic characteristics of the area, the transport attributes of the project, and its relationship to the wider transport network.

The ability of a project to maximize its potential requires a careful assessment of the residential and commercial land markets within a defined competitive trade area. Residential location is a complex decision process underpinned by a set of attributes. The ability to maximize the attractiveness of a station area as a residential location requires knowing the market. For example, the ability to attract high-end clientele will require understanding of the amount and character of open space that is perceived as a competitive amenity to having one's own yard. For low-income residents, the proximity to transit may help a great deal, but given the high rate of vehicle ownership, even among low-income households, a competitive rental price will often remain an overriding factor.

An integrated approach to assessing the transportation, land-use, and economic development attributes of station area development is not typically undertaken during the assessment and planning phases of TOD. Economic development interests are indeed the most common foundation of land development and transportation actions. However, a careful assessment of the underlying market forces driving the demand for an assumed real estate product is often omitted from the transportation planning process. The following case study of the Lindbergh Station area redevelopment suggests that transit operators, developers, and environmentalists may find themselves with very closely allied objectives. Where travel by transit or on foot is highly sensitive to a certain level of density or compactness, the same holds true for the developer whose profit is contingent upon the number of sellable units that are created within a project.

\section{The Lindbergh Station Area}

This case study began as an assessment of redevelopment plans for the area surrounding Lindbergh Station, an intown stop on the MARTA rail system 
(Figure 2). The goal of the study was to create a set of measures and design tools that could be used to guide the final redevelopment program. Recommendations were developed in partnership with the City of Atlanta's Planning Bureau and MARTA.

The project expanded on the Transit Station Area Development (TSAD) Study for the Lindbergh Station area, which was completed by a team of consultants in January 1998. The City of Atlanta wanted to supplement the TSAD effort with more in-depth information on the travel behavior, air quality, pedestrian accessibility, and economic development potentials of various approaches to redevelopment. Additional research was conducted, literature reviews of relevant case studies were performed, and transit-supportive development recommendations were specified for the area. These will be used by the City in

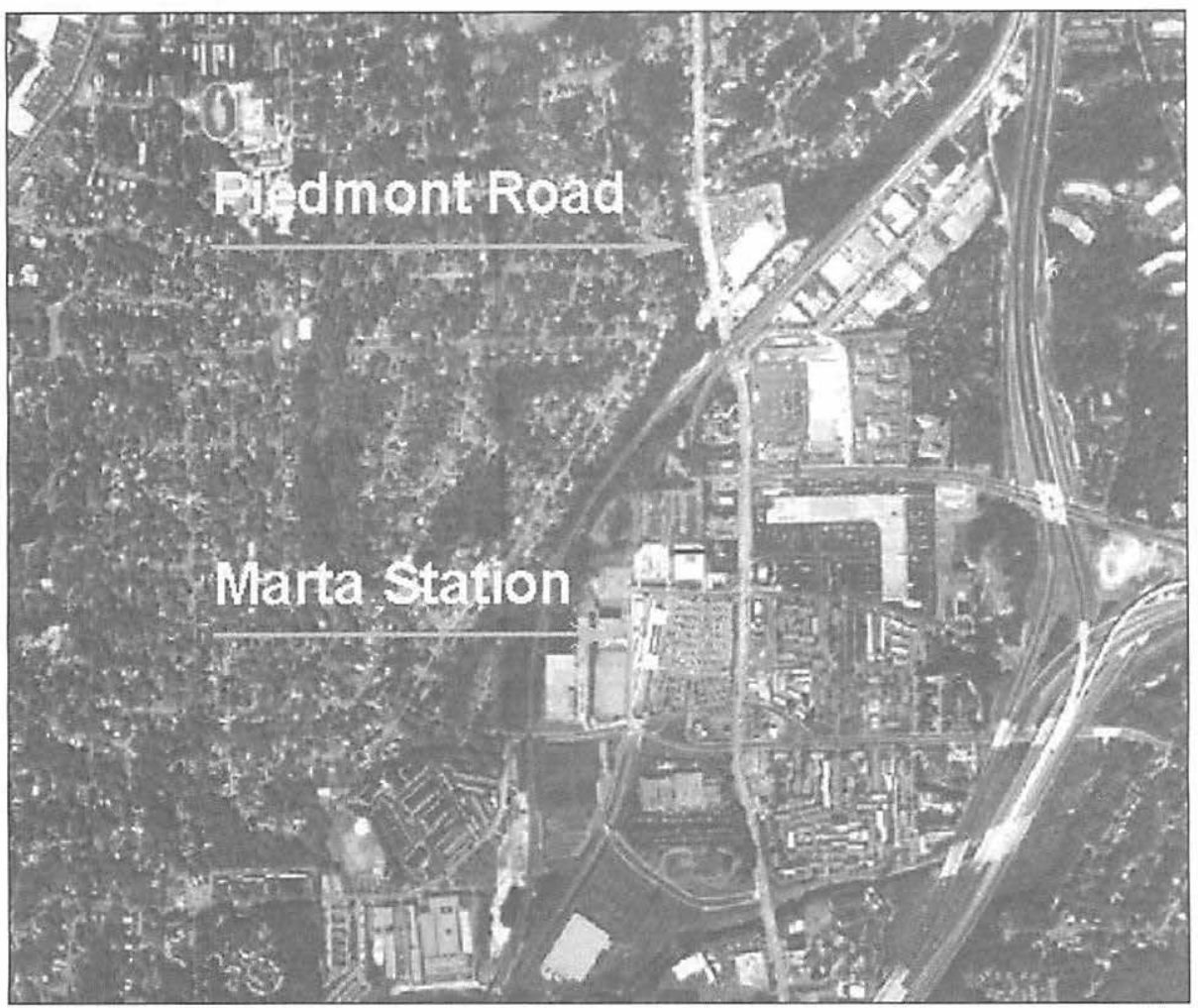

Figure 2. Existing land-use and circulation conditions at Lindbergh Station 
evaluating the environmental and transportation benefits associated with current and future redevelopment proposals. The information gathered has been used by local neighborhoods in their efforts to minimize the negative traffic impacts associated with more concentrated development.

The three goals for the redevelopment of the Lindbergh Station area, as stated by MARTA and the City of Atlanta, are to: (1) increase transit ridership (2) foster economic development, and (3) establish a sense of community. These three goals are roughly aligned with those of the Federal Transit Administration's (FTA) Livable Communities Initiative. ${ }^{5}$ Establishing a "livable community" that offers alternatives to auto-dependent land-use patterns found elsewhere in the Atlanta region also offers an important promise for the reduction of vehicle emissions. Given the air quality problems faced within the Atlanta region, a fourth goal was added for the redevelopment effort: implement a model development pattern that supports multimodal accessibility, reduced auto dependence, and decreased air pollution.

These goals were addressed in the project through four specific task areas, defined in Figure 1: land use, demographics, transportation, and economic development.

\section{Station Area Analysis}

An analysis of existing land-use and demographic conditions was performed using census data, employment security data, and assessors' parcellevel data at the block and block-group levels. Factors included in the analysis were age, income, employment, ethnicity, tenure in residence, housing value, and other household characteristics. Current levels of land-use intensity (both employment and residential density), mix, and connectivity were also assessed.

Land Use. An examination of land-use conditions showed that the Lindbergh study area contains 91 blocks and 576 hectares (approximately 1,422 acres). The average block is more than 15 acres in size - far higher than what might be considered a more walkable scale at between 2 and 5 acres (City of Portland 1980). The western portion of the study area is predominantly singlefamily residential, while other portions include more multifamily apartment buildings. Within the last year, formerly vacant land near MARTA's north-south 
line has been developed into an upscale multifamily apartment complex of 396 residential units. ${ }^{6}$ Much of the land in the study area is owned by MARTA and is used for the Lindbergh MARTA Station, the MARTA headquarters building, and parking. The remaining land in the study area is used for various forms of commercial development. Figure 2 conveys the layout of existing development in the station area including single-family residential to the east and high-density commercial develop along the Piedmont Road corridor.

Demographics. Racial distribution and placement within the study area were examined. White residents make up 72.4 percent of the Lindbergh study area and are evenly distributed throughout. Most of the remainder is either Hispanic (10.1\%) or black (10.9\%), and 3.7 percent are Asian. Nearly all of the minority concentrations are located in the eastern portion of the study areato the east of Piedmont Road. Overall, the population in the study area is fairly well educated, with 33 percent having earned a bachelor's degree, 20 percent having some college but no degree, and 17 percent having a graduate or professional degree. The largest percent of occupants in the study area works in the managerial/professional sector, comprising about 44 percent of the study area's workforce. Many residents (29\%) also work in sales/services. Most block groups east of the MARTA station have a median income of less than $\$ 20,000$. Block groups south of the MARTA station have median incomes between $\$ 20,000$ and $\$ 40,000$. The more affluent residents tend to live to the north and west of the MARTA station and have median incomes ranging from $\$ 40,000$ to $\$ 60,000$ - consistent with the racial distribution noted above. The mean number of vehicles per household in the Lindbergh area is 2.79 . Thirtyseven percent of the residences in the study area are owner-occupied.' A majority of these were detached, single-family houses. The remaining 63 percent of the housing supply, in the form of rental units, are low-rise, two-story units, located along Piedmont and Lindbergh Roads and at the eastern boundary of the study area. There is no significant supply of attached, owner-occupied housing in the study area at present. The median house value is in the range of $\$ 175,000$ to $\$ 199,000$. $^{8}$ Approximately 70 percent of the housing values are more than $\$ 150,000$. 


\section{Transportation}

The initial assessment of circulation conditions examined vehicular access, pedestrian access, transit access, and safety. Deficiencies in the existing pedestrian network were cataloged, including sidewalk disconnects, driveways, and facilities for the disabled. Parking data obtained from MARTA were supplemented by conducting a three-day parking study to assess the utilization of surface lots in the study area. Within the Lindbergh Center area, as in most of the Atlanta region, the predominant mode of travel is the automobile. Piedmont Road, a six-lane state route, divides the study area into eastern and western portions and allows a heavy volume of traffic to traverse the study area at high speeds. The fact that most of the traffic is "cut through" is indicated by the peak traffic times, which are 8 A.M. and 5:15 P.M. Lack of on-street parking, the visual effect of existing land uses, scale of signage, and signal timing all play an additional part in the high speeds observed on Piedmont Road. The posted speed limit on Piedmont Road is 40 miles per hour. While no formal speed studies were undertaken, simply driving through the area made it apparent that average speeds are much higher than the speed limit. This is not too surprising given that every step is taken to maximize vehicle traffic flow and the high-design speed along this thoroughfare.

An origin-destination study of the Lindbergh MARTA Station park-andride patrons confirms a high proportion of drive-alones and those using MARTA to avoid the inbound traffic on the downtown freeway. Most of these trips terminate at locations outside the study area-mainly downtown-suggesting that the study area is basically a transfer point instead of a destination.' Surface parking comprises 65 acres, corresponding with a significant proportion of the study area (Figure 2). The monthly utilization of the MARTA surface lot, which is free of charge, averages 77 percent. The MARTA employee deck, for which a parking fee is charged (\$3), averages a 75 percent utilization rate. The parking utilization for the area's two shopping centers, located to the east of Piedmont, is not as high. Estimates performed over a three-day period indicated that these lots are heavily underutilized, especially during the weekday, when utilization rates ranging between 25 percent and 50 percent were 
observed. Collectively, the lots have a 35 percent utilization rate based on the three-day average. Conditions for pedestrians within the Lindbergh Station area are hazardous and unpleasant. The intersection of Piedmont and Lindbergh Roads has been the scene of numerous pedestrian-vehicle conflicts. Figure 3 conveys the characteristics of the pedestrian environment of the Lindbergh Station area, and Table 1 details the incidents involving pedestrians that took place in the area in 1995.

Piedmont Road, the area's main roadway, has a daily traffic volume of more than 42,000 vehicles. Five motor vehicle incidents involving pedestrians took place in the study area during 1995. All but one of those occurred on Piedmont Road. During site visits, the area's pedestrian network was mapped, focusing primarily on pedestrians and Americans with Disabilities Act (ADA) disconnects. In addition to sidewalks that abruptly stop, many areas do not have the curb cuts or sidewalk width mandated by the ADA of 1990 . Of greatest concern is the fact that several intersections have handicapped ramps on one corner but not on the other, essentially trapping the wheelchair-bound person who ventures into the intersection without surveying the far side. Another pedestrian issue is the difficulty involved in safely crossing Piedmont Road. Currently, inadequate crosswalks and signal timing make it a hazardous traverse. The width of the crosswalks does not adequately accommodate peak pedestrian flows. The narrow, mountable medians on Piedmont Road are also inadequate and terminate a significant distance before each intersection. The protection provided by the medians is also limited by their low height, as motorists can easily drive up and over these curbs.

Transportation recommendations resulting from this analysis focused on pedestrian facilities-especially sidewalks and crosswalks.

- "Collector" sidewalks should not be less than 3 meters in width; all other sidewalks should not be less than 2 meters in width.

- Pedestrians should be able to cross all local streets at every logical crossing point, and each intersection should have a clearly defined crosswalk with (1) pavement striping and (2) pedestrian buttons and signal displays. 


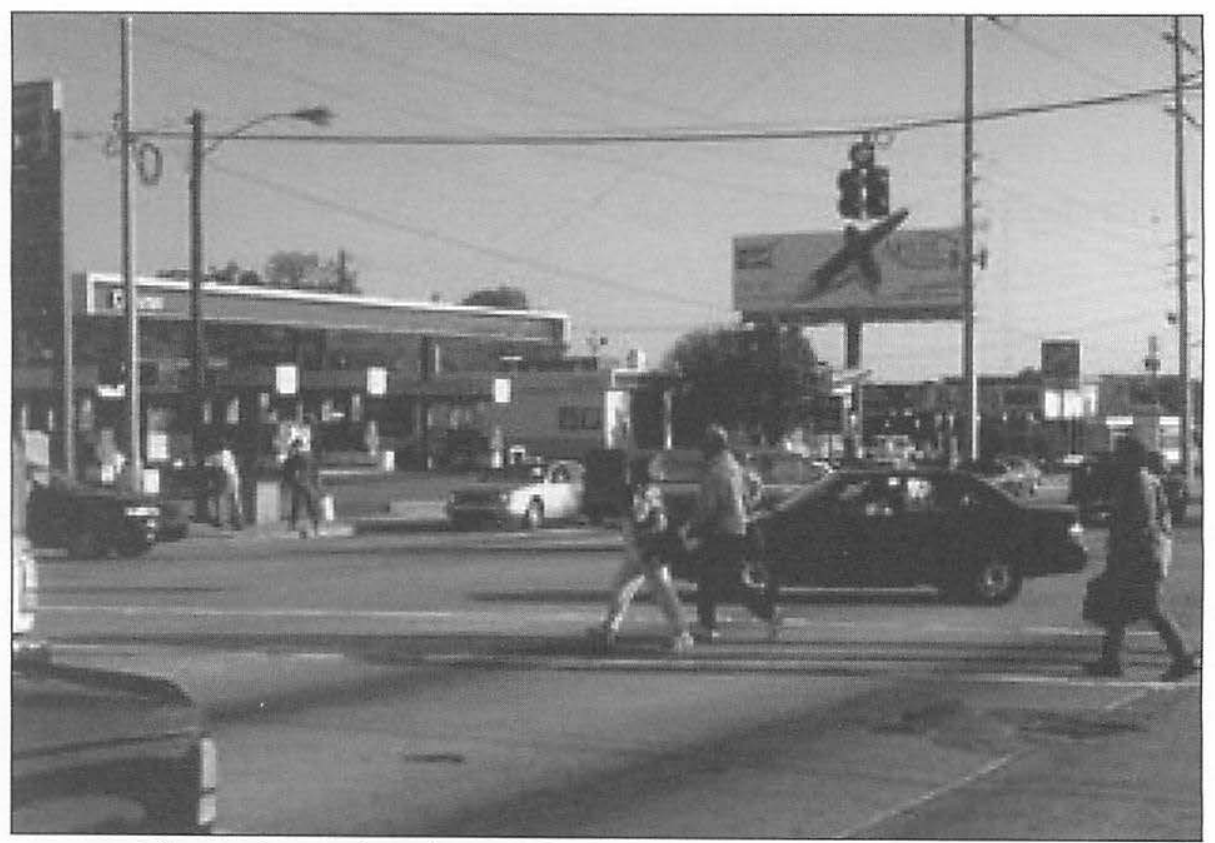

Figure 3. "Pedestrian environment" along Piedmont Road

\begin{tabular}{|c|l|l|l|l|l|l|}
\hline \multicolumn{2}{|c|}{ Intersection } & & $\begin{array}{l}\text { Vehicle } \\
\text { Maneuver }\end{array}$ & $\begin{array}{l}\text { Pedestrian } \\
\text { Maneuver }\end{array}$ & $\begin{array}{l}\text { Contributing } \\
\text { Factor }\end{array}$ & $\begin{array}{l}\text { Traffic } \\
\text { Control }\end{array}$ \\
\hline 1 & Piedmont Road & Morosgo Drive & Straight & $\begin{array}{l}\text { Crossing at } \\
\text { crosswalk }\end{array}$ & $\begin{array}{l}\text { Disregard stop } \\
\text { sign/signal }\end{array}$ & $\begin{array}{l}\text { Traffic } \\
\text { signal }\end{array}$ \\
\hline 2 & Lindbergh Drive & Adina Drive & - & $\begin{array}{l}\text { Crossing, } \\
\text { not at } \\
\text { crosswalk }\end{array}$ & - & - \\
\hline 3 & Piedmont Road & $\begin{array}{l}\text { Sydney Marcus } \\
\text { Boulevard }\end{array}$ & $\begin{array}{l}\text { Turning } \\
\text { left }\end{array}$ & $\begin{array}{l}\text { Crossing, } \\
\text { not at } \\
\text { crosswalk }\end{array}$ & Failed to & $\begin{array}{l}\text { Traffic } \\
\text { signal }\end{array}$ \\
\hline 4 & Piedmont Road & Miami Circle & $\begin{array}{l}\text { Turning } \\
\text { right }\end{array}$ & $\begin{array}{l}\text { Crossing, } \\
\text { not at } \\
\text { crosswalk }\end{array}$ & - & $\begin{array}{l}\text { Stop or } \\
\text { yield } \\
\text { sign }\end{array}$ \\
\hline 5 & Piedmont Road & Miami Circle & $\begin{array}{l}\text { Entering/ } \\
\text { leaving } \\
\text { driveway }\end{array}$ & $\begin{array}{l}\text { Crossing at } \\
\text { crosswalk }\end{array}$ & - & Lanes \\
\hline
\end{tabular}

Table 1. 1995 Pedestrian Incidents 
- Wheelchair ramps should be provided at each side of each intersection as well as at both sides of all medians. Pedestrian buttons should be well within the reach of a person in a wheelchair.

- Signal phasing should provide one second of protected crossing time per each meter of street width.

- Roadways of four or more lanes should have raised medians that extend to the edge of denoted crosswalks.

- Where sidewalks run directly parallel to roadways, a buffer should be provided to shield the pedestrians from the sights and sounds of traffic and to diminish the opportunity for pedestrian-vehicle incidents to occur. Vehicles parked on the street can serve as a buffer between moving traffic and sidewalks and this is noted as a logical solution within the literature.

The circulation recommendations for the Lindbergh Station area include specific steps necessary to improve the pedestrian orientation of the area. However, additional changes to the transportation system are required to accommodate these solutions while still maintaining adequate vehicular flow levels. Three primary design components to be executed in the first phase of the overall redevelopment scheme were identified and are shown in Figure 4 (north is up).

These changes to the transportation system include an extension of Sidney Marcus Boulevard, one of the area's primary roadways, which extends from Piedmont Road to Lindbergh Drive. This will result in the formation of a parallel north-south corridor to the west of Piedmont Road in the study area. This plan includes the conversion of Piedmont Road between Lindbergh Drive and Sidney Marcus Boulevard to a one-way boulevard for northbound traffic. ${ }^{10}$ As a result, the overall vehicle-moving capacity of the Piedmont Road corridor is maintained through the study area while effectively reducing the crossing distance for pedestrians for each direction of travel. Finally, Morosgo Drive, a secondary north-south street to the east of Piedmont Road, should be restricted to transit buses and service vehicles. 


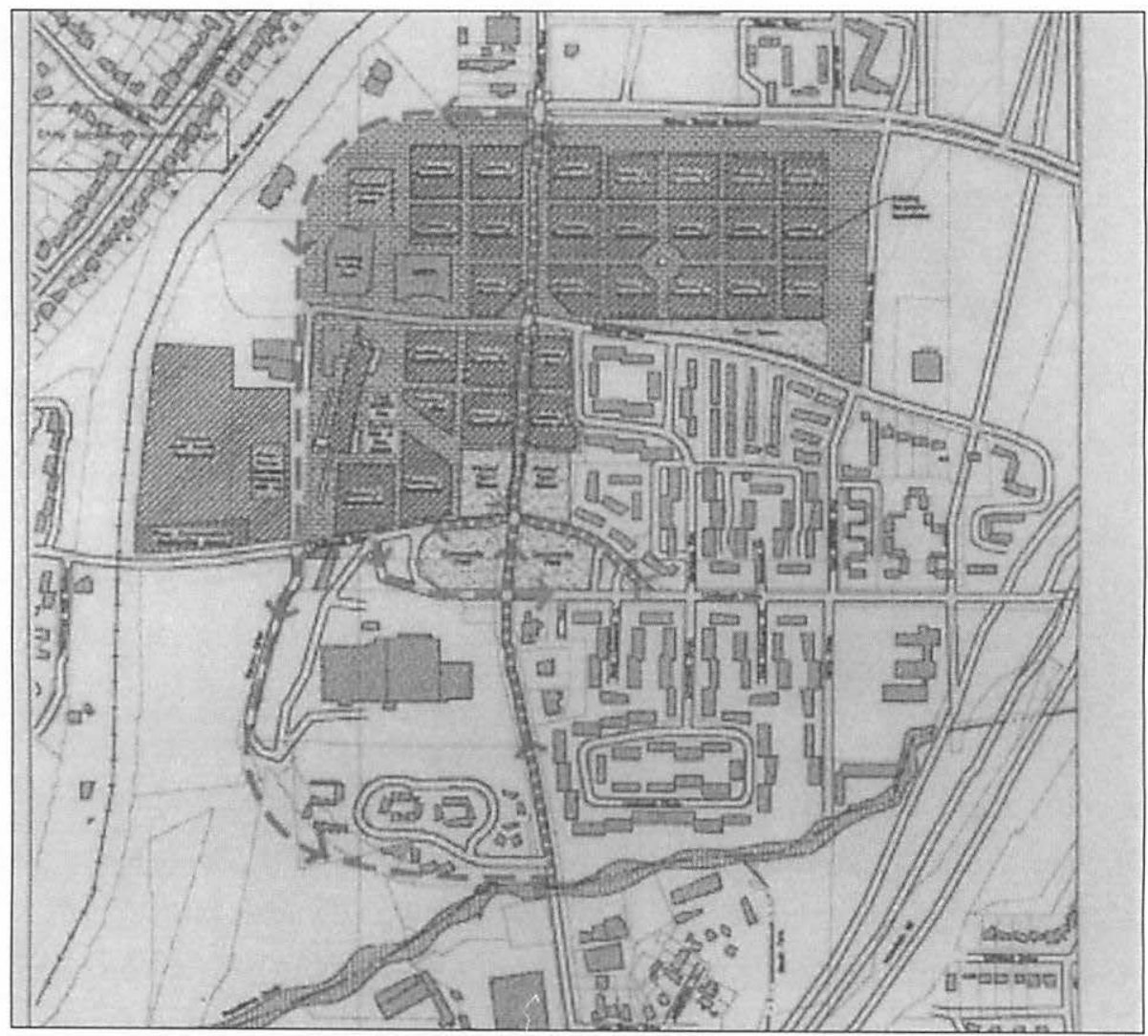

Figure 4. Proposed schematic design

These recommendations were designed to relieve congestion and improve pedestrian safety within the station area. The recommendation also stipulated special treatment of intersections, including the use of bulb-outs at the end of the parking lanes and brick or colored pavers to communicate the unique identity of the Lindbergh Station area and alert drivers that they are entering a heavily pedestrian-oriented zone. The final transportation-related recommendation was to remedy the numerous pedestrian disconnects within the station area. ${ }^{\prime \prime}$ These strategies will improve the pedestrian orientation of the area while maintaining adequate vehicular flow levels.

\section{Economic Development}

Land-use and transportation issues are, to some degree, necessary components of the TOD planning process. These issues are usually considered 
when planning such projects, although the depth of analysis varies. Economic development, however, is not always an element of TOD planning and design processes, an omission that can risk the marketability and economic viability of the final project. The concepts of physical and demographic market identification have been incorporated into this assessment of the Lindbergh Station area, resulting in a final analysis that is more thorough and practical than if undertaken with only a physical-planning orientation. An examination was made of the current conditions and potential demand in the Lindbergh/Piedmont market areas--both residential and commercial—and recommendations were made for meeting this demand.

Estimating Residential Demand. First, a primary market area was delineated to serve as the geographic base for the evaluation of potential market support for rental and for-sale residential uses at the Lindbergh Station site. The primary market area is generally defined as that geographic area from which the majority of buyers or renters will be drawn. Figure 5 shows the primary market area that was defined for residential product, bounded on the north by I-285; on the south by the Georgia Railroad; on the east by I-285; and on the west by the Chattahoochee River, Marietta Boulevard, and the Southern Railroad.

Next, a demographic profile for the primary market area was created using the Demographic and Income Forecast provided by CACI Marketing Systems, Inc., including population and household growth trends, age and household income distributions, and race and ethnicity trends. Data for the primary market area were compared with the same data for the Atlanta metropolitan area. A potential demand analysis was performed for the primary market area to estimate the market depth for rental apartments targeted at households with annual incomes from $\$ 25,000$ to $\$ 50,000$. The income categories used for potential homeowners are those in excess of $\$ 35,000$ and assume monthly housing costs for both renter- and owner-occupied units that average 30 percent of monthly gross household income.

The two main sources of demand for housing within the primary market area are new household growth and renter or owner turnover. New household growth is traditionally used to project market growth and is based on popula- 


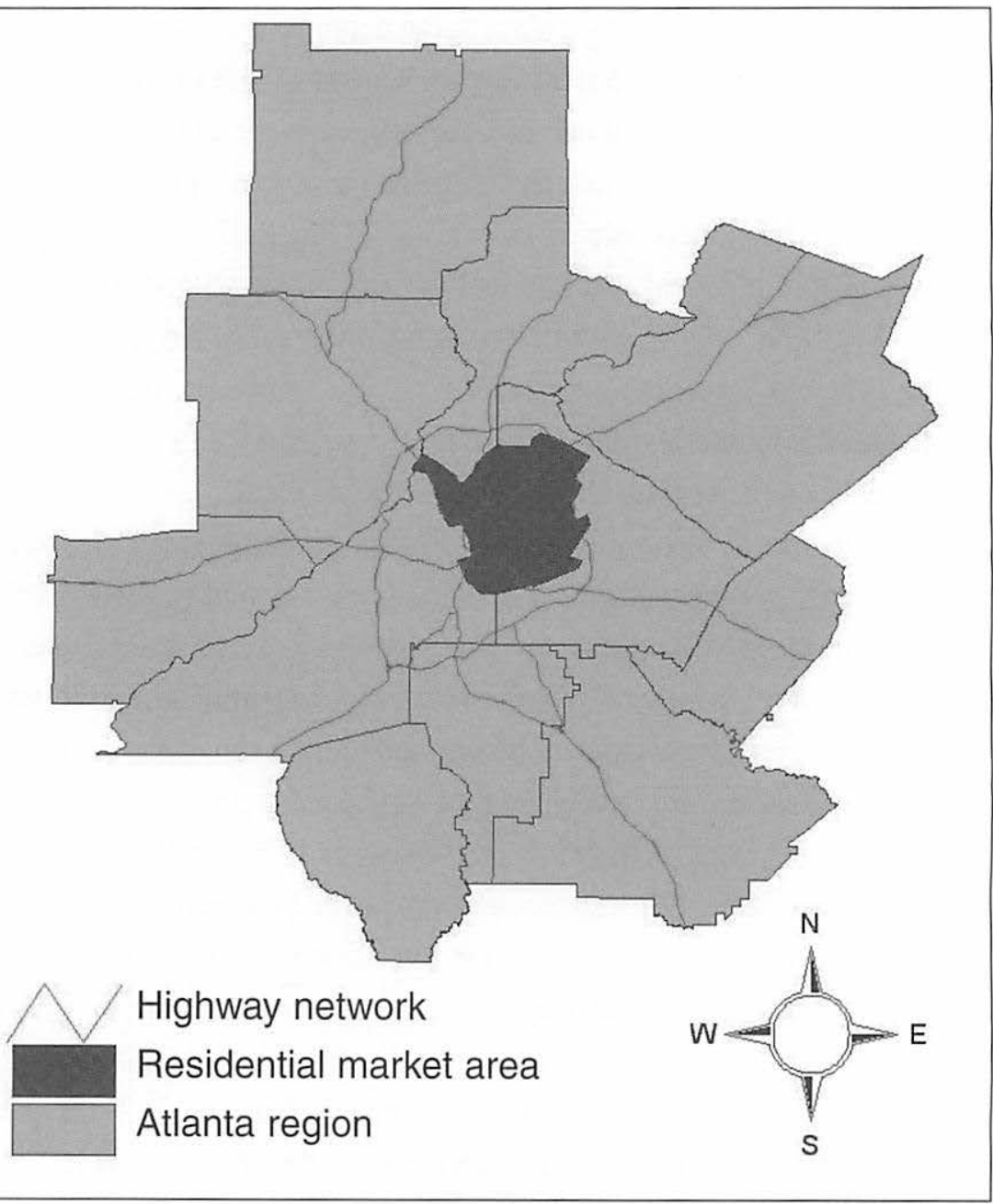

Figure 5. Residential market area

tion and household growth projections. Estimates of occupied housing units by tenure provide the base for estimating the number of households that will be renters or owners. Renter or owner turnover is a more quantitatively significant source of demand and is based on the estimated number of renter or owneroccupied units that will exist within the market area during the next five years.

The data sources for the potential demand analysis included population estimates and projections and age and income distributions provided by $\mathrm{CACI}$ 
Marketing Systems, Inc., and housing characteristics contained in the 1990 census. Even though the potential demand analysis used finite numbers, its end result (i.e., potential market support) was interpreted as an approximation of market depth that was balanced with the results of an analysis of the competitive supply. The supply analysis was used to support both quantitative and qualitative aspects of the recommended product program.

The geographic base for the analysis of the housing supply was the competitive market area, defined as the geographic area within which similar projects compete with one another on an approximately equal basis (Figure 5). The competitive residential market area used for this project is bounded on the north by Dresden Drive, on the south by Ponce de Leon Avenue, on the east by Clairmont Road, and on the west by Piedmont Road. Within the competitive market area, seven submarkets were identified based on the types and quality of housing prevailing in each. These submarkets were surveyed to obtain age of project, unit types, unit mix, rental rates/sales prices, value ratios (dollars per square foot), occupancy rates, absorption histories, amenities, and renter/owner profiles.

The final result of the potential demand analysis for renter and owneroccupied housing provided an estimate of annual market support for new housing in the primary market area. A recommended residential development program for both rental and for-sale product at the Lindbergh Station site was then created based on potential market support, the results of the analysis of the existing supply of rental housing, the availability of land, and the desired scale of the project. These figures may be conservative given the recent announcement by a major area employer, BellSouth, to relocate within the Lindbergh Station area, which may serve to accelerate the absorption of residential property, and particularly owner-occupied units.

Results. Population estimates for the area indicated average annual growth of 1.12 percent, which was significantly below the Atlanta metropoli$\tan$ area growth rate of 3.06 percent per year for the years 1990 to 1997 . Projections for the years 1997 to 2002 indicated an even slower growth rate. In addition, the population of the residential market area is significantly "older" 
than that of the Atlanta metro area. Of the total population, 13 percent was younger than 15 years old in 1997, compared with 22 percent in the metro area. The proportion of the population that was 65 years of age and older was almost 15 percent in the market area, compared with 9 percent metrowide. Median age in the market area had been increasing since 1990, from 34.1 years to 36.7 years in 1997. Comparable figures for the Atlanta metropolitan area were 31.5 years and 33.8 years, respectively.

The potential demand analysis for the entire residential market area estimated a total demand of 8,432 market-rate rental units and 7,125 market-rate, for-sale units during the years 1997 to 2002 . Renter households qualify for these units with annual incomes of $\$ 25,000$ to $\$ 50,000$, and qualified buyers have annual incomes of $\$ 35,000$ or more. Under the 20 -year residential development program proposed for the Lindbergh Station site, 4,500 new rental units and 975 new owner-occupied units would be planned. The required capture rates for this development program at the Lindbergh Station site are 0.03 percent of total demand for rental product and 0.005 percent of demand for forsale product within the residential market area. ${ }^{12}$

Based on these results, the development proposal recommends that an average of 225 rental units be built each year of the 20 -year build-out schedule. The unit mix of the proposed rental housing program should be one-, two-, and threebedroom units. Approximately 40 percent (1,800 units) of new rental housing should be one-bedroom units with a median area of 750 square feet. The primary target market for the one-bedroom units are singles who have the financial capacity to live alone. Two-bedroom rental units should average 900 square feet and comprise 45 percent $(2,025$ units) of total rental housing. Primary target markets for these units include roommates, young couples, empty nesters, and retirees. Applying the same methodology to assess residential demand across product type suggests a smaller demand for larger, three-bedroom units. Specifically, this analysis suggested that the remaining 15 percent (675 units) of the rental housing program should be three-bedroom units averaging 1,200 square feet. These units will be primarily targeted at younger families and roommates. As indicated above, it is critical to provide a variety of housing types at a variety of rental prices. However, this assessment of the demand for various 
types of residential product suggests that a limited amount of demand exists for larger, more expensive units.

The fact that only 18 percent of the proposed residential program for the Lindbergh Station site is targeted at potential owners is based on the observation that attached for-sale units are absorbed more slowly than rentals in this housing market. Absorption of rental units is consistently strong in this market, averaging from 12 to 20 units per month. On the other hand, the sale of attached for-sale units in this market has historically been slow, primarily due to the wide range of housing choices available to potential homeowners. In the competitive product survey conducted for this research, the average absorption of owner-occupied, attached housing was 1.0 unit per month or less.

Therefore, this analysis indicates that an average of 34 attached for-sale units per year should be scheduled for the Lindbergh Station site. Approximately 35 percent of the units should be one bedroom; 60 percent, two bedroom; and 5 percent, three bedroom. Based on competitive products elsewhere within the competitive market area, the suggested average size should be larger in comparison with the rental units-800, 950, and 1,400 square feet, respectively. A key issue for TOD in the area is the provision of owner-occupied housing in the $\$ 130,000$ to $\$ 170,000$ range. The analysis of the residential-owner market found that few units are for sale in this range, and recent projects have had trouble meeting sales goals, resorting to gap financing. No unit in the area is priced below $\$ 150,000$, and the majority are priced much higher.

Estimating Commercial Demand. For the retail market analysis and proposal, a primary retail trade area was defined for the Lindbergh Station site (Figure 6). The primary trade area is the geographic area from which the great majority (approximately $80 \%$ ) of customers originate. The delineation of the retail trade area is based on drive-time estimates, geographic boundaries, and the location of existing shopping centers. The primary trade area for the Lindbergh project is bounded by West Wieuca Road, Nancy Creek Road, and Harts Mill Road on the north; the Georgia Railroad on the south; I-285, Oak Grove Road, and the Lawrenceville Highway on the east; and Northside Drive, Marietta Boulevard, and the Southern Railroad on the west. 


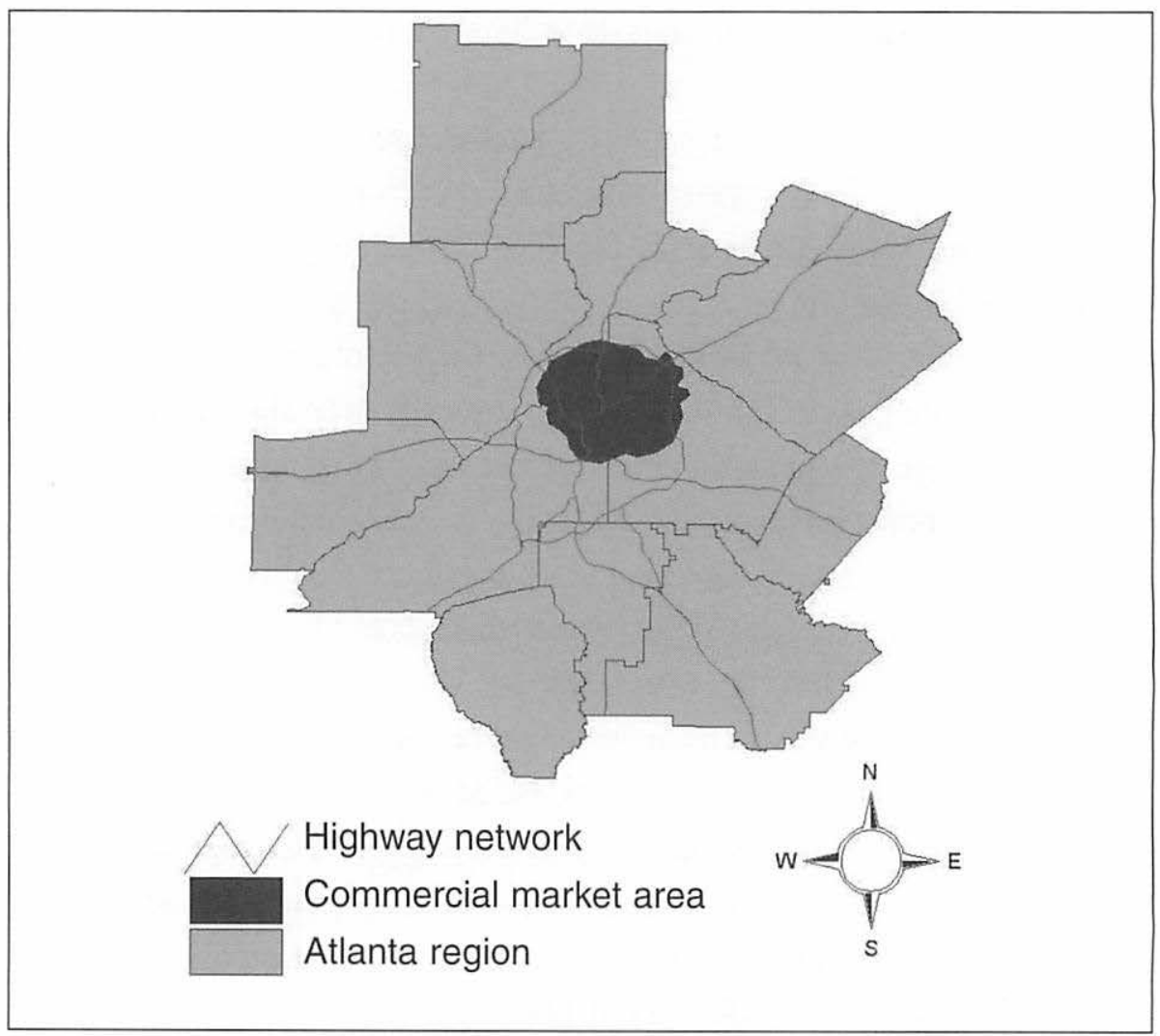

Figure 6. Commercial market area

Although a full demographic and income profile was not completed for the retail trade area, psychographic data from CACI Marketing Systems' ACORN were analyzed to provide a "lifestyle" profile of area households. Since people who share the same demographic characteristics and have similar needs may have widely divergent wants and preferences, these data are considered useful market analysis tools. In this analysis, households within the trade area are grouped into clusters or segments that bear descriptive names meant to convey a type of neighborhood or lifestyle.

To reinforce the ACORN data, CACI estimates of retail "market activity" for specific goods and services were evaluated. While there is no statistical relationship between the market activity data and psychographic data provided by ACORN, inferences may be drawn to identify market opportunities. The 
Purchase Potential Index (PPI) and the Spending Potential Index (SPI) are measures of market activity developed by CACI Marketing Systems. The PPI measures the consumer's tendency to buy certain goods and services, and the SPI denotes actual dollars spent on these goods and services. When the PPI or SPI is equal to 100 for a specific type of merchandise, it indicates that consumers are buying at a rate equal to the national average for that category. A PPI or SPI greater than 100 indicates that consumers are buying or spending above the national average. In other words, the PPI indicates if demand for a product or service in the trade area is higher or lower than average, while the SPI indicates what prices consumers will actually pay. In addition, 10 competitive shopping centers located within the primary retail trade area were surveyed to obtain information on occupancy levels, lease rates, and general character. All the shopping centers surveyed were strip centers.

Results. The population of the commercial trade area was 227,715 , comprising 110,561 households. The median age of the trade area population was 35.9 years, with a median household income of $\$ 41,469$. The trade area population was somewhat older than that of the Atlanta metropolitan area (35.9 years, compared to 33.8 years), as well as less affluent ( $\$ 41,469$ median household income, compared with $\$ 46,765)$. According to the ACORN data described above, the top consumer groups in the retail trade area are high-rise renters $(25.7 \%)$, enterprising young singles (17.4\%), urban professional couples $(13.0 \%)$, active senior singles $(9.3 \%)$, and twentysomethings $(7.9 \%)$.

The top two lifestyle segments, high-rise renters and enterprising young singles, are in the "up-and-coming-singles" group. They have money and they are willing to spend it. They are active, ambitious, and well educated. The third ranking segment, urban professional couples, is in the "upscale households" group. Most are married couples approaching or at middle age. They spend money on vacations, home furnishings and improvements, the theater, concerts, and dining out. The active senior singles segment is comprised of middle-income seniors who are active and well educated. They use coupons and spend money on specialty food items and books. Finally, the twentysomethings are young, active, and urban. Most are single and well educated. 
Overall, the market activity data indicate that trade area residents buy merchandise and services at rates that are higher than the national average. With only a few exceptions, they spend at a level that is also above average. For example, consumers in the trade area buy entertainment at a rate 3 percent above the national average ( $\mathrm{PPI}=103)$ and spend 13 percent above average (SPI=113) on entertainment. Within the entertainment category, concerts and theater had a PPI of 138 and an SPI of 106. While consumer demand for apparel in the trade area is at the national average (PPI $=100)$, consumers spend 7 percent above average (SPI=107) on apparel. Similar retail activity is seen in the household furnishings category, where the PPI=100 and the SPI=106. Consumers eat in restaurants at a rate of 11 percent above the national average (PPI=111) and spend 8 percent above the national average (SPI=108).

A Program for Commercial Development. A recommended commercial development schedule for the Lindbergh Station site was created based on the results of this analysis, the availability of development sites for commercial use, and the desired theme and scale of the Lindbergh redevelopment project. The development program for the Lindbergh Station site envisions a total of 345,000 square feet of retail space by the year 2017. Approximately 18 percent of this space should be allocated to a central market built early in the schedule to serve as an anchor for the remaining retail and service space. Such a market should include shops, eateries, arts and crafts, fresh produce, and gourmet food items. These storefronts are intended to have the appeal of New York City vendors with decorative awnings and lots of space available for product display. The market itself should encompass 70,000 square feet and serve as an anchor for almost four times as much additional retail, focusing particularly on restaurants and theaters. These economic development initiatives will require a strong partnership between the neighborhood, developer, and transit authority, as well as a public relations and marketing campaign to improve the perception of the public and attract transit users to the development.

The recent announcement by BellSouth to participate in the redevelopment will serve to anchor the station area as an emerging employment center. BellSouth's plan to locate $1,000,000$ square feet of office space at the 
Lindbergh Station will be in the form of two 17-story office towers. If realized, this may serve to increase the demand for housing and retail services above the more conservative estimates reflected in the analysis.

\section{Summary and Recommendations}

The analysis of the Lindbergh Station area TOD bridges physical planning and economic development considerations. This approach is applicable elsewhere and represents an incremental improvement over assessments that do not integrate these dimensions. If TODs continue to be considered both as pleasant alternatives to standard developments and as partial solutions to the urban problems of congestion and poor air quality, the approach described here, which effectively incorporates market demand, should be further cultivated and seriously considered by developers and municipalities. It begins to provide direction for communities that do more than simply serve as physical models of this type of development. Based on this level of analysis, a transit authority, municipality, and local neighborhoods have the ability to understand the types of residents, businesses, and shoppers that can be attracted to the area. This enables the translation of models into a reality that can begin to give shape to a physical plan for redevelopment.

The analyses and recommendations produced by the approach described here provide an essential foundation for effective analysis of TOD plans, but remain ineffective in the absence of some key ingredients of the implementation phase of development. The Lindbergh Station area project provides a good illustration of the importance of these components to successful completion of TODs that remain true to their underlying purpose and concept. Figure 4 provides a schematic design developed for the study area that integrates the physical project recommendations from each of the four focus areas.

It is recommended that the first phase of redevelopment take place on land owned by MARTA that is currently occupied by the parking lot for the transit station. This parking lot creates an unattractive barrier for pedestrian movement between Piedmont Road and the station itself. Furthermore, this parking facility is a large underdeveloped space in the center of an area that offers high potential for value capture. Based on the research, the area should be 
redesigned as a mixed-use area to include some housing above first-floor retail or restaurant uses. Owner-occupied housing should be located above the transit station itself where transit access is greatest. The design for the area should build on a grid system of streets, including a wide pedestrian walkway linking the station with a plaza or other open space at the intersection of Lindbergh and Piedmont Roads (see Figure 2). The streets to be constructed in this area should be narrow but should provide vehicular access. The network of streets with a grid pattern should be continued across Piedmont Road in the area currently occupied by a large commercial parking lot. Finally, a series of pocket parks and plazas should be constructed to physically and visually link the various parts of the district and provide nodes to pedestrian routes and crossing points.

While Figure 4 outlines a circulation and layout concept for the proposed redevelopment, it does not attempt to allocate the commercial and residential growth over time in the study area. In addition, current resistance on the part of the neighborhood groups, even in light of the significant effort placed on outreach, suggests the significant need for resources targeted at cultivating a workable plan that the local community can embrace. In the case of the Lindbergh Station area redevelopment, work is required to overcome the existing pedestrian barriers that are created by Lindbergh and Piedmont Roads. To resolve issues that extend beyond the confines of the MARTA property under immediate attention for redevelopment are the issues associated with the larger area that defines the "station area."

This is particularly important for the transit-dependent populations located across Piedmont Road to the east. At play are conflicting institutional concerns governing transportation funding priorities and agency mandates.

These large-scale issues, which extend beyond the immediate area of redevelopment, are critical for the project to be able to achieve the goals of a livable community and to provide a model for the region of transit-supportive development that can assist in meeting air quality objectives. ${ }^{13}$ While neighborhood groups are highly aware and somewhat supportive of the project, they have recently been voicing major opposition regarding traffic impacts and lack of sidewalk connections associated with the project along these corridors.

Partnerships must be built between and among MARTA, the developer, the 
neighborhood, the City of Atlanta, and the federal government. Each of these parties is currently involved in the project in some way, but coordination and cooperation is insufficient to assign responsibility that otherwise falls between parties. The FTA, for example, has contributed funding for the project under the Livable Communities Initiative and expects development of the area to follow the guidelines set forth by that program that are reflected in the goals noted earlier in this article. If those principles are not followed, the larger community, defined here to include the neighborhoods that surround the redevelopment area, stand to lose the opportunity of effectively benefiting from the redevelopment.

The full range of potential funding sources must be understood and utilized. Possible avenues for funding currently include the Transportation Enhancement Activity portion of TEA-21 funding; Congestion Mitigation and Air Quality funds; and 33C monies. ${ }^{14}$ Again, it is absolutely essential for partnerships to form early in the process and focus cooperatively on the task at hand: developing the MARTA acreage in a transit-oriented fashion that facilitates and encourages additional interconnected redevelopment of surrounding areas. This task cannot be effectively approached without adequate funding, and the range of sources available can be complex and confusing.

The Lindbergh project is in danger of falling into the common trap of tunnel vision. Many redevelopment efforts of this type tend to focus exclusively on a single parcel, ignoring the larger geographic context. Instead, planners and developers must include the corridor and community as a whole if their plans are to succeed. For example, the immediate area around the Lindbergh Station is separated from the surrounding community by railroad tracks on one side and Piedmont Road on the other. In cases such as this one, planning only for the site in question will result in an island of development that has no hope of serving either significant numbers of pedestrians or the residents of the neighboring community. Connectivity with the overall community is an essential element of the TOD, and a narrower, parcel-level planning destroys this important component. This goal can raise the question of responsibility when several owners and stakeholders are involved, and often results in disagreements and finger-pointing. Consensus-building efforts must be sufficiently 
effective to enable the creation and implementation of a cohesive areawide plan.

\section{Acknowledgments}

The authors would like to thank Dan Cohen at the city of Atlanta Bureau of Planning and the Turner Foundation for providing funding for the study on which this article is based. A special thanks is given to the students that were in the city planning studio course at Georgia Tech, which conducted some of the early analysis of the Lindbergh Station area. These students were Lakey Broderius, Alicia Corral, Mary Darby, Johnny Dunning, Philip Harris, Dorita Herd, Kiesha Johnson, Brian Leary, Beth Prins, Bratten Thomason, and Douglas Wolf.

\section{Endnotes}

1. The Atlanta Regional Commission (the area's federally designated metropolitan planning organization) has recently conducted a "Land Use Sensitivity Analysis" to test the comparative effects on travel choice associated with focusing growth into MARTA station areas (Atlanta Regional Commission, Land Use Task Force Results 1999). The results of this analysis, with a 2020 planning horizon, was a 31.6 percent increase in home-based work and a 17.9 percent increase in homebased, nonwork trips via transit. However, the same analysis did not reveal similar reductions in SOV travel.

2. One of the more creative and exhaustive fund-raising efforts for transit station area redevelopment can be found in association with the Fruitvale Bay Area Rapid Transit Station, for which a wide variety of private and public monies have been pooled to implement an areawide redevelopment plan.

3. The current site of the Lindbergh Station area redevelopment was formerly an international market.

4. This practice requires unique circumstances where an alternative right-of-way is available for separating directional travel into one-way pairs. Such a practice would be used to address negative impacts of pass-through travel often associated with state-owned routes.

5. MARTA received a grant from the FTA through the Livable Communities Initiative Program for the redevelopment of the Lindbergh Station area.

6. A great deal of these units are part of the post-Lindbergh development, which is adjacent to the Lindbergh Station. 
7. Home ownership was also found to vary systematically with income and race.

8. Housing values in this central portion of the Atlanta region have risen dramatically since the time these data were collected.

9. The Lindbergh Station is the location along the north-south MARTA alignment where two lines from the north (Dunwoody [along I-400 north] to Doraville [northeast]) merge into one heading south.

10. It is possible that these streets need not be one way but could rather serve to distribute the north-south flow through the station area, enabling Piedmont Road itself to become less of a barrier for pedestrian movement. One-way streets have been found to increase travel speed and are often difficult from an economic development perspective.

11. The City of Atlanta has requested enhancement funds under Transportation Equity Act for the 21st Century (TEA-21) for several of these needed pedestrian improvements.

12. These capture rates are conservative. They are based on historical trends within the residential market area defined above.

13. Governor Roy Barnes recently signed into law an act that establishes the Georgia Regional Transportation Authority (GRTA). The authority will have significant oversight concerning transportation funding and its relationship with major local land-use actions. GRTA will have the capacity to support projects such as the Lindbergh Station area redevelopment that have significant potential to improve air quality and offset automobile dependence. In particular, GRTA may have the financial capacity to leverage federal funding required to establish pedestrian linkages required for a successful redevelopment effort.

14. TEA-21 makes several new provisions for the funding of transit-supportive development including new funds for creating environmentally sustainable communities that include the Transportation and Community System Preservation Pilot Program.

\section{References}

Antoniou, James. January 1971. Planning for pedestrians. Traffic Quarterly.

Berechman, Joseph. 1995. Transport infrastructure investment and land use. In Transport and Urban Development. David Banister, ed. London: E \& FN Spon. Bernick, Michael, and Robert Cervero. 1997. Transit villages in the 21st century. McGraw Hill. 
Burchell, Robert, and D. Listoken. 1974. The costs of sprawl: Environmental and economic costs of alternative residential development patterns at the urban fringe. Washington, DC: U.S. Government Printing Office, Council on Environmental Quality.

Calthorpe, Peter. 1993. The next american metropolis: Ecology, community, and the American dream. Princeton: Princeton Architectural Press.

Cervero, R, and R. Gorham. 1995. Commuting in transit versus automobile neighborhoods. Journal of the American Planning Association 61 (2):210-225.

Cervero, Robert, and Kara Kockelman. 1997. Travel demand and the 3Ds: Density, diversity, and design. Transportation Research Part D 2 (3):199-219.

City of Portland. 1980. Downtown design standards.

Ewing, R., P. Haliyur, and G. W. Page. 1994. Getting around a traditional city, a suburban PUD, and everything in-between. Transportation Research Record 1466.

Florida Department of Transportation. 1995. Walkable communities. State Safety Office, Pedestrian/Bicycle Program.

Frank, Lawrence. 1998. Reducing vehicle emissions through growth management and travel reduction strategies. Journal of Urban Planning and Development 124 (1):11-32.

Frank, Lawrence D. January 1999 (forthcoming). Land use and transportation interation: Health and quality of life implications. Journal of Planning Education and Research.

Frank, Lawrence, and Gary Pivo. 1994. Relationships between land use and travel behavior in the Puget Sound region, Final Summary Report, Washington State Transportation Center.

Metro. 1997. Metro regional street design handbook. Portland, Oregon.

Moudon, A., P. Hess, and M. Snyder. 1996. Effects of site design on pedestrian travel in mixed-use, medium-density environments. Paper submitted to 75th Annual Meeting of the Transportation Research Board, Washington, DC.

Newman, Peter, and Jeffrey R. Kenworthy. 1996. The land-use transport connection. Land Use Policy 13 (1): 1-22.

Parsons, Brinckerhoff, Quade, and Douglas Inc., with Cambridge Systematics Inc., and Calthorpe Associates. 1993. LUTRAQ-Making the land use transportation air quality connection: The pedestrian environment. Portland, OR: 1000 Friends of Oregon.

Pushkarev, B. S., J. M. Zupan, and R. S. Cumella. 1982. Urban rail in America: An exploration of criteria for fixed-guideway bus. Report Number UMTA-NY-060061-80-1, U.S. Department of Transportation. Urban Mass Transportation Administration. 
Schimek, Paul. 1996. Household motor vehicle ownership and use: How much does residential density matter? Transportation Research Record 1552.

Untermann, Richard K. 1984. Accommodating the pedestrian: Adapting towns and neighborhoods for walking and bicycling. New York: Van Nostrand Reinhold Company, Inc.

U.S. Department of Transportation. December 1989. A guide to land use and public transportation.

\section{About the Authors}

LaWrence D. Frank is an assistant professor in the City Planning Program at the Georgia Institute of Technology. He is a Registered Landscape Architect, and holds a master's degree in civil engineering transportation planning and a Ph.D. in urban design and planning from the University of Washington. Dr. Frank does research and writes on the relationships between land development, travel choice, vehicle emissions, and household physical activity levels. He recently authored the Project XL proposal to the Environmental Protection Agency for the redevelopment of the 138-acre Atlantic Steel brownfield in Atlanta into a 12 million square foot transit-oriented community.

Mollie STEPHENSON SMith is a senior transportation planner at CRA Associated, Inc., in Atlanta, and holds a master's degree from the City Planning Program at Georgia Institute of Technology. Ms. Smith has worked on a variety of projects that involve multimodal transportation concerns.

ELEANOR Q. MATTHEws is the principal of MARKETEK, Inc., which specializes in the assessment of consumer demand for various real estate products. MARKETEK, is involved in a variety of projects throughout the southeastern and central portions of the nation. Ms. Matthews is a graduate of the City Planning Program at the Georgia Institute of Technology. 


\title{
Environmental Responsiveness in Australia's Bus and Coach Supply Chain
}

\author{
Ann M. Brewer \\ Institute of Transport Studies, The University of Sydney
}

\begin{abstract}
The responsiveness of business enterprises to the natural environment is of great concern to both the government and industrial sectors in Australia. A key question emerges as to which industries are environmentally more responsive than others. This article examines transportation's contribution to greenhouse gas (GHG) emissions. It identifies and describes environmental responsiveness within Australia's bus and coach sector, a major operator of passenger transport. This sector is defined in the full context of the supply chain; that is, the integration of business processes from manufacturers and suppliers of vehicles and fuel to the providers of services and information for the benefit and value of customers.

The article focuses on the perceptions that bus and coach operators have about environmental opportunities and associated risks. Twenty-six key stakeholders were invited to participate in either a survey or case study designed to ascertain energy and waste management practices. Environmental responsiveness occurs when it has the greatest potential impact on the "bottom line" of both the environment and the business. While operators initiated waste and energy management programs to be socially responsible, the continuation of these practices depended on their cost effectiveness to the business. A number of specific actions are warranted based on the study's findings.
\end{abstract}




\section{Introduction}

In the 1990s, there has been an increase in worldwide public awareness of environmental issues and the necessity for their management (Bhate and Lawler 1997). A strategic concern of both government and industry in Australia has been the extent of responsiveness of businesses across all industries to the natural environment. Protecting the environment essentially involves reconciling ecological issues and values with economic interests and business responsibilities.

The rise in GHG emissions is due primarily to the burning of fossil fuels and deforestation. GHG contributes to global warming, which, in turn, increases the potential incidence of catastrophes such as potent and frequent windstorms, rainfall, floods, mud slides, hailstorms, drought, crop damage, and wildfire (Mills 1998). Each of these catastrophes presents massive costs to society. Industrial activities are also having a detrimental impact on the environment, as demonstrated by the increase in the atmospheric concentrations of GHG, accumulation of wastes, and pollution of ground and surface water. Many of these environmental changes are happening swiftly, and some are irrevocable.

What was thought to be critical management of the natural environment in the 1970s may not be the case today. More so than ever before, the environment has to become a significant factor in shaping business practice as management develops policies, programs, and tools to address environmental pressures. A key question emerges as to which industries are environmentally more responsive than others. This article examines transportation's contribution to GHG emissions, specifically the responsiveness among bus and coach operators. The article addresses five themes that represent the central tenets of environmental commitment in the bus and coach industry:

1. Key influences on vehicle purchases

2. Types of operations perceived as factors in GHG emissions production

3. Nature of energy and waste management programs

4. Environmental auditing

5. Industry outlook in the supply chain 


\section{Australia's Bus and Coach Industry}

Australia's bus and coach sector integrates business processes from manufacturers and suppliers of vehicles and fuel to the providers of services and information. Table 1 lists the key players in the supply chain of the bus and coach transport sector as well as their energy and waste generation characteristics.

The potential impact on energy and waste efficiency by bus and coach operators should not be overlooked. From 1994 to 1995 , the transport sector contributed 12 percent of all GHG emissions, of which the bus sector accounted for only 0.9 percent (Apelbaum Consulting Group 1997). During the same period, bus and coach operators consumed 4.7 percent (398 megaliters) of the total fuel

\begin{tabular}{|c|c|c|c|c|c|c|}
\hline \multicolumn{7}{|c|}{$\begin{array}{c}\text { Table } 1 \\
\text { SCM by Energy/Waste Generation Characteristics }\end{array}$} \\
\hline $\begin{array}{l}\text { Energy/Waste Generation } \\
\text { Characteristics }\end{array}$ & $\begin{array}{l}\text { Chassis } \\
\text { Suppliers }\end{array}$ & $\begin{array}{l}\text { Body- } \\
\text { builders }\end{array}$ & $\begin{array}{l}\text { Vehicle } \\
\text { Component } \\
\text { Suppliers }\end{array}$ & $\begin{array}{c}\text { Fuel } \\
\text { Suppliers }\end{array}$ & $\begin{array}{l}\text { Bus and } \\
\text { Coach } \\
\text { Operators }\end{array}$ & $\begin{array}{c}\text { Commercial } \\
\text { Waste } \\
\text { Companies }\end{array}$ \\
\hline $\begin{array}{l}\text { Manufacture of components- } \\
\text { production system }\end{array}$ & $\sqrt{ }$ & & $\sqrt{ }$ & & & \\
\hline \multicolumn{7}{|l|}{ Materials selection } \\
\hline Testing of components' quality & & & $\sqrt{ }$ & $\sqrt{ }$ & & \\
\hline Production of chassis & $\sqrt{ }$ & & & & & \\
\hline Fuel cracking & & & & $\sqrt{ }$ & & \\
\hline Fuel refining & & & & $\sqrt{ }$ & & \\
\hline Fuel testing & & & & $\sqrt{ }$ & $\sqrt{ }$ & \\
\hline Fuel storage and maintenance & $\sqrt{ }$ & $\sqrt{ }$ & & $\sqrt{ }$ & $\sqrt{ }$ & \\
\hline Depot/plant design & $\sqrt{ }$ & $\sqrt{ }$ & $\sqrt{ }$ & $\sqrt{ }$ & $\sqrt{ }$ & \\
\hline Materials used in depot/plant & $\sqrt{ }$ & $\sqrt{ }$ & $\sqrt{ }$ & $\sqrt{ }$ & $\sqrt{ }$ & \\
\hline Painting & $\sqrt{ }$ & $\sqrt{ }$ & $\checkmark$ & & $\sqrt{ }$ & \\
\hline Vehicle maintenance & & & & & $\sqrt{ }$ & \\
\hline Depot maintenance & & & & & $\sqrt{ }$ & \\
\hline Waste disposal methods_fuels & $\sqrt{ }$ & $\sqrt{ }$ & $\sqrt{ }$ & $\sqrt{ }$ & $\sqrt{ }$ & $\sqrt{ }$ \\
\hline Waste disposal methods-solids & $\sqrt{ }$ & $\sqrt{ }$ & $\sqrt{ }$ & $\sqrt{ }$ & $\sqrt{ }$ & $\sqrt{ }$ \\
\hline $\begin{array}{l}\text { Waste disposal methods-- } \\
\text { other liquids }\end{array}$ & $\sqrt{ }$ & $\sqrt{ }$ & $\sqrt{ }$ & $\sqrt{ }$ & $\sqrt{ }$ & $\sqrt{ }$ \\
\hline
\end{tabular}

Hensher, D. A., A. M. Brewer, J. King, and M. Coulson. 1998. Scoping study, greenhouse gas emissionsbus and coach sector. Report prepared for the Greenhouse Challenge Office. Institute of Transport Studies, the University of Sydney, p. 15.

Vol. 2, No. 3, 1999 
used by the transport industry. In the year 1995 to 1996, buses (public and private) represented 38 percent of the urban public transport task in terms of passenger kilometers and 54 percent of urban public transport task in terms of number of passengers (BTCE 1996). The bus and coach sector delivers long-distance services to 15 percent of the total private and public transport users and tour/hotel shuttle services to 47 percent of the total international visitors to Australia (Bureau of Tourism Research 1996). In 1998, fleet size was estimated at 15,578, and the number of private operators at about 2,456 (ABCA 1998).

Supply Chain Management (SCM) is the effective control of all business processes occurring within and among enterprises. The ability of bus and coach operators to manage the full extent of the supply chain is contingent on the consequence of each component activity to their business as well as their managerial capability to do so. The principal processes of SCM for bus and coach operators include:

- acquiring vehicles, fuel, and labor,

- making efficient use of inputs (finance, people, technology, time, information) relative to outputs,

- producing outputs of services,

- conducting maintenance and administrative processes effectively,

- investing in appropriate technologies and services,

- conforming to regulations and rules governing the industry in which they operate, and

- $\quad$ satisfying the interests of primary stakeholders.

Careful review of these activities suggests that, in order for bus and coach operators to achieve organizational effectiveness, a balanced distribution of resources across each of these processes is needed. A business remains effective as long as it strives continuously to use its resources in an efficient manner and contributes to the wider system, which requires recognizing environmental opportunities and risks. Environmental responsiveness arises from the processes and arrangements that management use to take action (mostly requiring 
extraordinary effort and investment) to deal with various environmental pressures that confront operators in conducting their business (Brewer 1994).

Moreover, environmental responsiveness leads to appropriate actions mostly in situations where it costs the operator little. From the operator's perspective, isolated managerial action will be less effective because improvement in environmental quality requires concerted industry action. While environmental responsiveness can be measured by operators' activities, it is essentially a philosophical stance that industry holds in relation to the environment that influences managerial practices, which in turn, impact philosophy.

In general, management needs to optimize two, often conflicting, objectives: organizational effectiveness and the minimization of environmental risks. Little is known about how bus and coach operators perceive their natural environment and respond to changes (including regulatory) within it. This article focuses on three issues:

1. Are bus and coach operators taking the necessary steps toward managing the environment?

2. In this regard, what influences their decisions?

3. In order to promote effective environmental responsiveness, an essential first step is to appreciate the factors perceived by operators to be important enough for them to engage in strategies that sustain the natural environment.

\section{The Study}

A project investigating the perceptions of bus and coach operators in understanding environmental opportunities and risks was undertaken. Twentysix key stakeholders (chassis manufacturers, bodybuilders, oil companies, government/regulators, bus and coach operators, and industry associations) representing the main subsectors of the industry were also invited to participate in either a survey or case study designed to elicit information about perception and strategies for managing energy and waste. A fax out/fax back self-administered survey was designed.' The response rate was 69 percent.

In addition, interviews were held with management and workshop supervisors of one private and one public operator in Sydney. An on-site tour of 
depots and workshops of each operator was conducted to review both energy and waste management procedures in operation. Figure 1 presents a profile of the survey respondents from the bus and coach sector.

\section{Findings}

This section summarizes key issues identified that may facilitate or impede the environmental responsiveness of bus and coach operators. Each theme represents a major business decision by operators in running their enterprises.

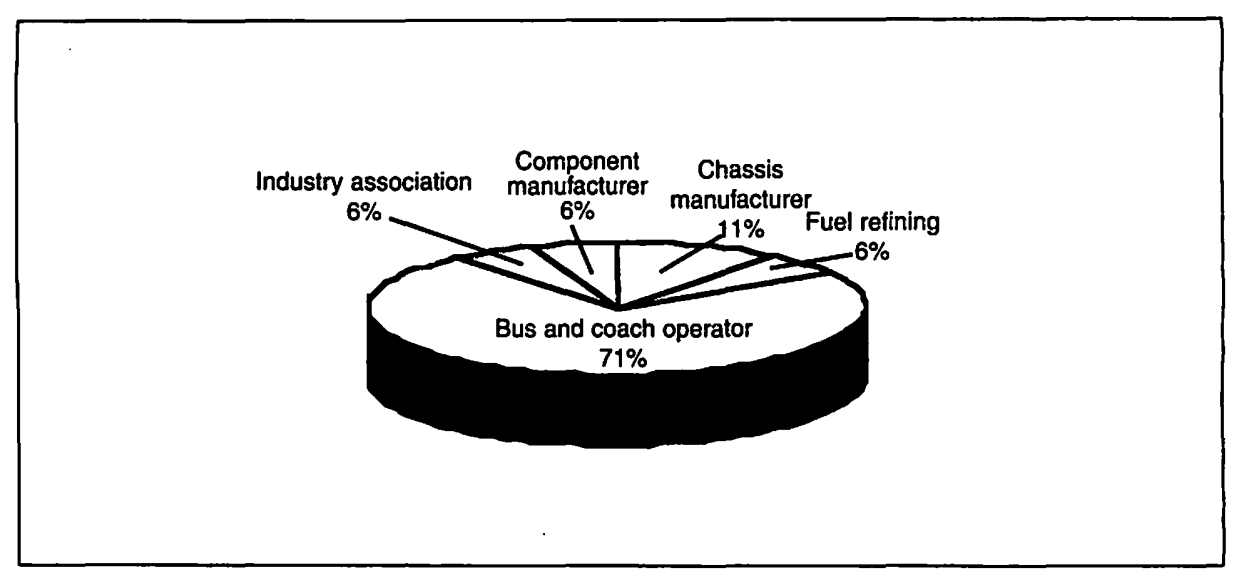

Figure 1. Profile of survey respondents

\section{Key Influences on Vehicle Purchases}

The key influences in vehicle purchase decisions made by operators are shown in Figure 2. The decision to purchase one vehicle or augment an existing fleet is a complex interaction of factors. The most important factors in the vehicle purchase decision are vehicle reliability, purchase price, vehicle specifications, and fuel consumption. These factors are rated ahead of vehicle resale value. The decision-making process varies for operators depending on whether they are government, private, family-owned, large or small enterprises, and physical location of the depot.

In terms of policy, operators are consumers, and this fact provides governments with an opportunity to intervene in the marketing of products by suppliers. The question arises as to the nature of government intervention. 


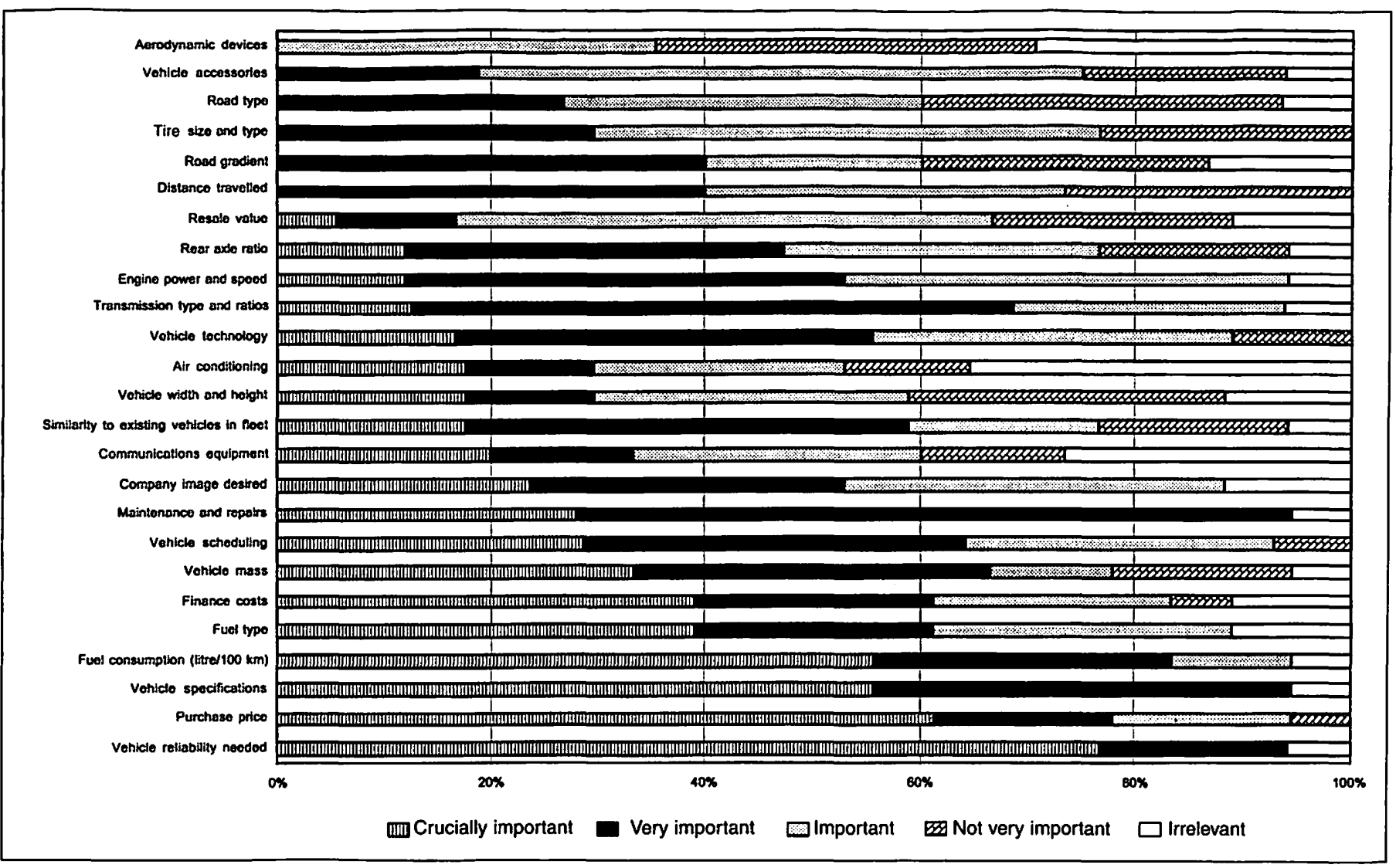

Figure 2. Survey results summary: Key influences on vehicle purchases (ranked) 
Information is one way to disseminate data to operators about the environmental advantages and disadvantages of different types of purchasing outcomes. For example, when purchasing a vehicle, bus and coach operators trusted that they were provided with highly reliable information on total vehicle fuel economy and associated environmental benefits. This was not always the case. In addition to being able to rely on manufacturers' and suppliers' information, operators wanted opportunities to discuss issues, such as vehicle and fuel efficiency, with experts and key industry players. The decision to purchase a vehicle has long-term impacts as it influences fleet type and maintenance contracts. This is a major operational constraint for operators.

\section{Types of Operations Perceived as Factors in GHG Emissions Production}

The most important factors in emissions production are vehicle technology, fuel type, fuel consumption, maintenance and repairs, vehicle reliability, and similarity to existing vehicles in the fleet (Figure 3). Interestingly, these factors contrast with those perceived as important in vehicle purchasing (Figure 2). The distinction lies mainly in the perceived importance of purchase price associated with vehicle purchases by operators. Purchase price acts as a proxy and may be confounded by other factors in the decision-making process. Also noteworthy is the fact that engine power and speed and distance traveled ranked lower in terms of the importance of perceived factors in emissions production. The case studies showed that driver training was also an important factor in reinforcing the way driving patterns influence emissions production.

Emission controls, according to Taylor (1988), are the most efficient means to prevent global warming. On this basis, operators rated a list of sources of GHG emissions according to what they believed are the greatest and least potential gains in managing them (Figure 4). The most important factors in managing emissions production include exhaust emissions, storm water, leakage of fuel storage systems, used paper, brake fluid, paint waste, solvents/thinners, and used batteries. Engine parts was seen as the least important factor in emissions production. Overall, operators were undecided as to the greatest and least potential gain from the management of sources of GHG emissions. This finding suggests a greater need for information not only about sources of GHG emissions but also their management in the workplace. 


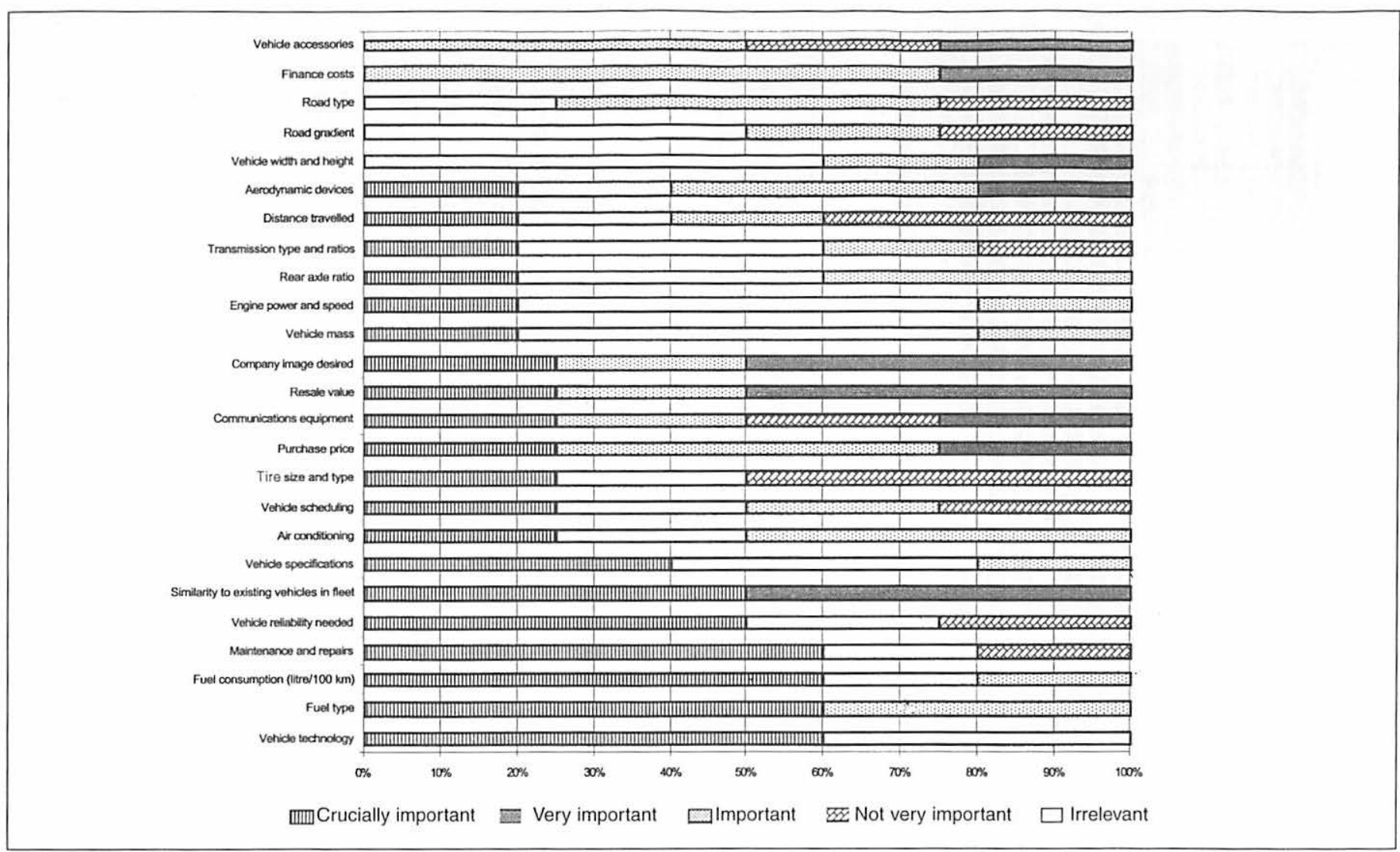

Figure 3. Survey results summary:

Importance of various factors in emissions production (ranked) 


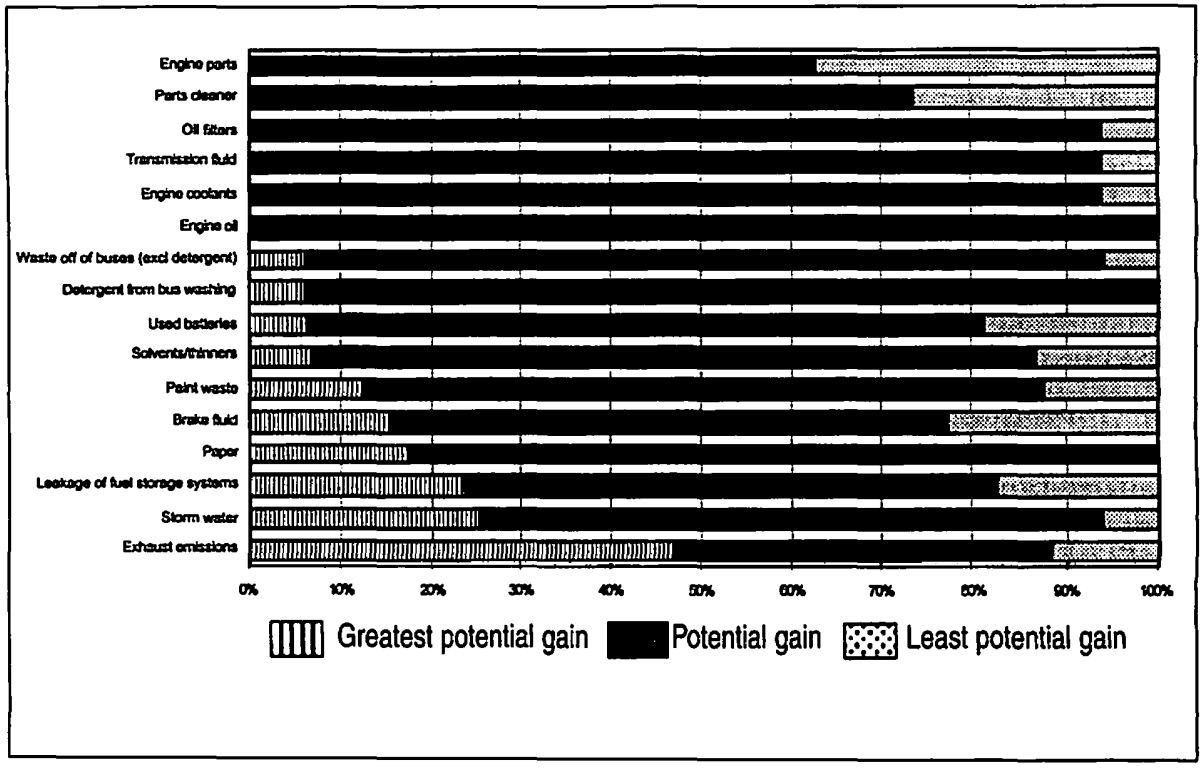

Figure 4. Survey results summary: Sources of GHG emissions (ranked)

\section{Nature of Energy and Waste Management Programs}

Bus and coach operators were asked to list six operational processes that they believed contributed to either the generation or release of GHG emissions. Identifying these activities was not straightforward for most operators. The most frequently listed activities included operating buses, painting (spray, etc.), use of diesel fuel engines, washing and cleaning of buses, and electricity usage.

The two case studies confirmed that it is difficult for public and private operators to get high-quality information about sources of GHG emissions. Notwithstanding operational constraints, not the least of which is cost, operators report that they are trying to reduce energy use and improve waste management. However, little information is available from either government or industry about the types of activities, products, or by-products that contribute directly or indirectly to GHGs or any other negative environmental outcome within the bus and coach sector. 
Bus and coach operators were asked to identify three energy/emission programs that they believed contributed to industry best practices. The most frequently named energy management programs in use were: compressed natural gas (CNG) bus trials/use of CNG engines, fuel improvement programs, recycling of bus washing water, treatment of waste, use of better/higher specified engines (e.g., Euro II diesel engine), reduced electricity usage, and energy management.

Operators examine their energy bills carefully, making comparisons with previous billing periods, and generally look for information on how to conserve energy in their business. To cut back on the use of electricity, for example, some operators have put skylights in the depots, installed improved lighting technology, and added timers to switches. The use of tinted windows has reduced air-conditioning in buses and coaches and also has resulted in the use of more effective "refrigerants" in equipment.

Despite these measures, there is generally not a good understanding of what is energy intensive in the workplace, particularly in back-office areas. The problem is that most information and search tools that operators rely on are insufficient for the purpose. Operators believe it is difficult to acquire information about the type and nature of energy management programs in use in the industry. It is up to individual operators to network with each other and gain access to each other's depots-not an easy process in a competitive situation.

While operators accept products upstream on the supply chain, they pass waste and costs downstream. For example, oil sludge, old oil, dry waste, shredded paper, paint and thinners, and worn-out batteries and tires are collected by commercial operators who dispose of or recycle them. Operators identified the major waste activities using fossil fuel-derived energy as electricity usage and operation of vehicles, computers, offices, and depots. Most operators attempt to recycle oil, water, and tires to minimize costs and landfill deposits. Some have installed their own irrigation for washing vehicles to allow wash water and run off to be recycled for further use. Others have engaged in procedures that maximize the use of recycled materials such as paper and toner cartridges for printers. 
Waste management, including prevention, is widely appreciated by bus and coach operators, but is seen essentially as an added cost, incurred through inspection, maintenance, rework, and liability risk. Recycling does not guarantee a direct payoff for operators since waste collection and its dispatch is a costly exercise. Consequently, a key issue for environmental management is what commercial operators do with waste.

\section{Environmental Auditing}

Information about environmental auditing assists in understanding the impediments to energy and waste management as well as the quality of the auditing process. Bus and coach operators were asked to identify examples of environmental auditing that specifically focused on reducing GHG emissions in each phase of the supply chain. Some examples of environmental auditing are listed in Table 2. Overall, maintenance was the main approach to auditing, which meant that isolated aspects of operations were frequently monitored. This approach is piecemeal. An auditing process should reflect a more integrated and total quality approach.

In contrast to chassis manufacturers, fuel refining plants, and the public operator, the auditing process among private operators is largely ad hoc. Table 2 depicts the level of awareness of bus and coach operators in terms of environmental auditing processes that explicitly look at ways to reduce GHG emissions. However, there is no indication that these auditing processes are administered as part of bus and coach operations. On the whole, operators do not maintain audit databases so there is little opportunity at present to survey audit systems for important sources of information about energy and waste management programs. If energy and waste management are to have a significant impact on GHG emissions, their impact should be traceable through audit data, transforming audit databases into tools for evaluating environmental responsiveness. Auditing has the additional advantage of providing useful information to operators about outcomes of the energy strategies implemented.

Implementing more efficient forms of environmental auditing is a major challenge facing most enterprises. However, having an efficient management information system does not necessarily translate into good environmental prac- 


\section{Table 2}

Survey Results Summary: Examples of Environmental Auditing in Bus and Coach Operations

\begin{tabular}{lcc}
\hline Item (listed in order of highest number of incidence) & Frequency: Count & Percent \\
\hline Regular preventive maintenance & 4 & 20 \\
Monitor fuel consumption via transponder & 2 & 10 \\
Check periodically that operation complies to relevant laws & 1 & 5 \\
Audit fuel usage & 1 & 5 \\
Audit electricity usage & 1 & 5 \\
Use better gearbox and engine technology & 1 & 5 \\
Routine servicing to reduce oil and fuel leakage & 1 & 5 \\
Bus lanes and priority measures & 1 & 5 \\
Bus idling at terminals & 1 & 5 \\
Vehicle testing of emissions & 1 & 5 \\
Better fuel usage & 1 & 5 \\
Six weekly visual emissions checks on all & 1 & 5 \\
Route planning & 1 & 5 \\
Driver training & 1 & 5 \\
Maintenance of equipment and consumables & 1 & 5 \\
Reduce exhaust emissions & 1 & 5 \\
Total & 20 & $\mathbf{1 0 0}$
\end{tabular}

tices. This can be attributed to ad hoc decision-making by management and lack of resources to evaluate compiled data, as well as the lack of implementation of good environmental practices either through ignorance, lack of expediency, or because energy and waste are not viewed as strategic business processes.

\section{Industry Outlook in the Supply Chain}

Table 3 shows the extent to which stakeholders (i.e., all members in the supply chain) can be considered environmentally responsive. It presents the most frequent statements that gained agreement and disagreement. At the top of the list, most respondents believe that as vehicles age they will be replaced by more fuel-efficient vehicles. There is strong agreement with the need to improve the quality of diesel/distillate in order to reduce GHGs. However, respondents do not believe that the conversion to CNG saves up to 50 percent 
in operating costs, as claimed in the technical literature (Erdos 1998). They do believe that the bus and coach sector is bereft of information about energy and emission management programs. The industry is optimistic that Euro II, the emission standard in Europe, is achievable by 2002. The introduction of bus infrastructure, such as bus priority systems and more flexible time-tabling coupled with minibuses, will also impact the reduction of GHG emissions.

While not opposed to the use of CNG vehicles, there is some concern about the introduction of these vehicles into the private bus sector. Stakeholder disagreement centers around fuel efficiency and a perception that diesel/distillate contributes to GHG emissions. Respondents are not optimistic about the penetration of alternative fuels. A report by Dickson-Simpson (1998) suggests that studies by London Buses demonstrated that a diesel bus with a catalytic exhaust is the only cost-effective way to become environmentally friendly. The report stated, "The ECS catalyzer works on today's ordinary diesel fuel with up to 0.05 percent ( 500 parts per million [PPM]) sulfur. London Transport uses it in conjunction with ultra-low sulfur fuel (less than 50 PPM). The reason is that this light fuel has been effective in particulates reduction-cutting them by 32 percent. Adding the ECS catalyzer as well cuts particulates by up to 54 percent."

In addition, $\mathrm{CNG}$ poses a space problem for passengers, thereby impacting the number of $\mathrm{CNG}$ vehicles required to replace one diesel vehicle equivalent. This issue needs to be analyzed in the context of real-life operations in order to assess patronage levels, vehicle replacement trends, and vehicle deployment.

Commitment to the environment might be judged by the fact that the majority of respondents (94\%) believe that energy and waste management is an important part of the business strategy for the industry. For example, waste management is a legislated component of the occupational health and safety program for operators in Australia. About 50 percent of management conduct regular (i.e., weekly or monthly) depot audits (unofficial) to ensure efficient energy and waste practices. For example, they may perform regular checks on fuel efficiency in order to identify leaks. Reviewing energy costs is also a high priority. While 
Table 3

Survey Results Summary: Stakeholder Views

\begin{tabular}{|c|c|c|c|}
\hline $\begin{array}{c}\text { Strong Agreement } \\
\text { (Percentage of "totally agree" responses) }\end{array}$ & Rank & $\begin{array}{c}\text { Strong Disagreement } \\
\text { (Percentage of "disagree" responses) }\end{array}$ & Rank \\
\hline $\begin{array}{l}\text { As vehicles are replaced, the replacement } \\
\text { is much more fuel efficient than the } \\
\text { disposed vehicle }\end{array}$ & $\begin{array}{c}1 \\
77 \%\end{array}$ & $\begin{array}{l}\text { Private bus companies are not taking } \\
\text { up the opportunity to use CNG buses } \\
\text { simply because the success of the } \\
\text { technology in penetrating that } \\
\text { market is very slow }\end{array}$ & $\begin{array}{c}1 \\
66 \%\end{array}$ \\
\hline $\begin{array}{l}\text { Staff in the industry generally have little } \\
\text { idea of what an energy/emissions } \\
\text { management program is }\end{array}$ & $\begin{array}{c}1 \\
77 \%\end{array}$ & $\begin{array}{l}\text { The conversion to CNG saves up } \\
\text { to } 50 \% \text { in operating costs }\end{array}$ & $\begin{array}{c}2 \\
56 \%\end{array}$ \\
\hline $\begin{array}{l}\text { Establishing ways of improving the quality } \\
\text { of diesel/distillate content to reduce sulfur } \\
\text { content and GHG emissions is a priority issue }\end{array}$ & $\begin{array}{c}2 \\
65 \%\end{array}$ & $\begin{array}{l}\text { Private bus and coach operators are } \\
\text { generally opposed to alternatively } \\
\text { fueled vehicles (e.g., CNG) }\end{array}$ & $\begin{array}{c}3 \\
50 \%\end{array}$ \\
\hline $\begin{array}{l}\text { Better infrastructure for bus movements } \\
\text { will reduce GHG emissions from bus } \\
\text { operators }\end{array}$ & $\begin{array}{c}3 \\
61 \%\end{array}$ & $\begin{array}{l}\text { Having CNG tanks in a bus and coach } \\
\text { depot takes up too much space }\end{array}$ & $\begin{array}{c}4 \\
44 \%\end{array}$ \\
\hline $\begin{array}{l}\text { Staff in the industry generally have little } \\
\text { idea of what a waste management program is }\end{array}$ & $\begin{array}{c}4 \\
56 \%\end{array}$ & $\begin{array}{l}\text { An impediment to the take-up of } \\
\text { alternative fuels is the small market } \\
\text { for new buses and coaches in Australia }\end{array}$ & $\begin{array}{c}5 \\
39 \%\end{array}$ \\
\hline $\begin{array}{l}\text { An impediment to the take-up of alternative } \\
\text { fuels is the small market for new buses and } \\
\text { coaches in Australia }\end{array}$ & $\begin{array}{c}4 \\
56 \%\end{array}$ & $\begin{array}{l}\text { Using smaller vehicles such as } \\
\text { minibuses will enable operators to } \\
\text { provide more flexible time-tabling } \\
\text { of services }\end{array}$ & $\begin{array}{c}5 \\
39 \%\end{array}$ \\
\hline $\begin{array}{l}\text { To have Euro Il or U.S. } 98 \text { standards by } \\
2002 \text { is achievable }\end{array}$ & $\begin{array}{c}4 \\
56 \%\end{array}$ & $\begin{array}{l}\text { The diesel/distillate supplied to the bus } \\
\text { and coach operators is the major } \\
\text { culprit in producing GHG emissions } \\
\text { in end-use operations }\end{array}$ & $\begin{array}{c}6 \\
35 \%\end{array}$ \\
\hline $\begin{array}{l}\text { If government introduced more stringent } \\
\text { regulations and fines on levels of sulfur in } \\
\text { diesel, then the oil companies may finally } \\
\text { sort out this major pollutant problem }\end{array}$ & $\begin{array}{c}5 \\
53 \%\end{array}$ & $\begin{array}{l}\text { Most bus and coach operators are not } \\
\text { prepared to invest in CNG vehicles } \\
\text { until fuel prices are as attractive } \\
\text { as conventional fuel prices }\end{array}$ & $\begin{array}{c}6 \\
35 \%\end{array}$ \\
\hline $\begin{array}{l}\text { Bus and coach operators are committed to } \\
\text { reducing GHG emissions }\end{array}$ & $\begin{array}{c}6 \\
50 \%\end{array}$ & $\begin{array}{l}\text { My industry sector does take } \\
\text { environmental protection seriously } \\
\text { enough }\end{array}$ & $\begin{array}{c}7 \\
33 \%\end{array}$ \\
\hline $\begin{array}{l}\text { Most bus and coach operators are not } \\
\text { prepared to invest in CNG vehicles until } \\
\text { fuel prices are as attractive as conventional } \\
\text { fuel prices }\end{array}$ & $\begin{array}{c}7 \\
41 \%\end{array}$ & $\begin{array}{l}\text { The regulatory environment under } \\
\text { which we operate imposes a major } \\
\text { constraint on our industry's ability } \\
\text { to reduce GHG emissions }\end{array}$ & $\begin{array}{c}7 \\
33 \%\end{array}$ \\
\hline
\end{tabular}

Vol. 2, No. 3, 1999 
commitment to the environment is reflected in the survey findings, these perceptions are not mirrored in operators' official communications (once or twice a year) to or the training of staff (less than a third). In time, this will be reflected in how customers view the quality of service as it is modified to meet effective environmental business policy. Service indicators that are potentially modified by environmental responsiveness include vehicle specification and reliability, response time, staff competence, and communications with customers.

In summary, there is a high level of industry support for enhanced management of energy and waste. However, it is one thing to observe how to improve energy and waste efficiency and it is another to implement mitigating actions to address environmental issues. Drawing on the study's findings, the most appropriate means for achieving this is through integrating energy and waste management (e.g., the auditing process, benchmarking, driver training, and education programs for operators) with the business strategy.

Table 4 summarizes suggestions for regulatory changes that will assist operators in becoming more environmentally responsive. The highest priority is education, followed by implementing bus priority measures (by road authorities), minimizing vehicle mass limits. Education is also a priority due to the lack of knowledge about alternative energy sources and environmental best practices. The imposition of government regulations does not guarantee that operators will comply with or understand these rules. Justification for other regulatory changes such as increased incentives or taxes on car use must be based on social benefits not already reflected in other pricing structures. Alternatively, it may be preferable to choose some other means of having environmental factors influence operator choices about energy and waste management.

\section{Conclusions}

Environmental responsiveness occurs when it has the greatest potential impact on the bottom line of both the environment and the business. Operators will initiate waste and energy management programs so as to be socially responsible and continue with them providing they are cost effective. A number of specific actions are warranted based on the study's findings, including: 
Table 4

Survey Results Summary: Regulatory Changes Assisting the Industry

\begin{tabular}{lcc}
\hline Item (listed in order of highest number of incidence) & Frequency: Count & Percent \\
\hline Education (more information on how to achieve more responsible & & \\
environmental practices) & 2 & 6.7 \\
Introduce more bus priority measures & 2 & 6.7 \\
Vehicle mass limits (greater mass limits for buses and coaches) & 2 & 6.7 \\
Testing of vehicles for pollution & 1 & 3.3 \\
Give incentives to pollute less & 1 & 3.3 \\
Taxing car usage in urban areas & 1 & 3.3 \\
Legislate excise on CNG-“NIL EXCISE" & 1 & 3.3 \\
Remove all excises from fuel for bus fleets & 1 & 3.3 \\
Introduce Euro Il & 1 & 3.3 \\
Financial incentives for use of CNG & 1 & 3.3 \\
Better control of emissions on motor vehicles & 1 & 3.3 \\
Diesel fuel standard CEC (500 PPM) maximum & 1 & 3.3 \\
Reduced tax on low-sulfur fuel & 1 & 3.3 \\
Focus should be on Euro standards (EPA current reliance on & & 3.3 \\
California standards) & 1 & 3.3 \\
Government to take holistic approach to oil industry & 1 & 3.3 \\
Price deregulation and removal of sites act to allow competition & 1 & 3.3 \\
Give assistance to operators with older buses modified to meet Euro standards & 1 & 3.3 \\
Low-sulfur fuel & 1 & 3.3 \\
Maintain no excise on natural gas & 1 & 3.3 \\
Tax relief for CNG use & 1 & 3.3 \\
Better planning of road networks & 1 & 3.3 \\
Tax incentives to increase patronage & 1 & 3.3 \\
Funding needed to change capital to benefit environment & 1 & 3.3 \\
Review fuel suppliers' quality of fuel & 1 & 3.3 \\
Financial assistance based on emissions & 1 & 3.3 \\
Remove all speed humps on bus routes & 1 & 3.3 \\
Minimize car or truck use in poorly planned areas & 30 & \\
Total & & \\
\hline
\end{tabular}

- educating operators to enable them to integrate environmental responsiveness within their business strategy,

- switching from polluting and resource-degrading vehicles and fuels to efficient, environmentally effective vehicles and fuels,

- providing better information systems and auditing of operational processes in relation to energy conservation and waste management, and

- involving and training employees to ensure that individual businesses can extract pertinent and specific information about everyone's perception regarding the enterprise's responsibility to the environment. 
Stakeholders in the bus and coach supply chain acknowledge the significance of adopting a positive attitude toward conserving the environment, albeit that their industry contributes a relatively small percentage to GHG emissions. The switch to improved fuel and vehicle technologies and information management industrywide will lessen the impact of the bus and coach industry on the natural environment. More efficient practices and better use of information could potentially reduce environmental degradation. The main perceived obstacle in stakeholders becoming more environmentally responsive is a general lack of information and data about the efficiency of vehicles and fuel (and to minimize conflicting evidence about this). More importantly, operators must be made aware of the direct benefits of environmental management to the profit of their enterprise.

Many of the strategies examined in this study fit a "pro-enterprise" perspective whereby individual operators accept products from upstream in the supply chain and pass waste and costs downstream. This economic rationalist approach is primarily enterprise focused and short term rather than environmentally based and long term (Stern and Dietz 1994). To minimize a pro-enterprise stance and to enhance enterprise relationships with the environment requires an improved understanding of environmental responsiveness. Environmental responsiveness embodies knowledge, attitude, and strategic action (Figure 5).

One of the major impediments to responsible environmental responsiveness is a lack of knowledge about issues and a subsequent inability to develop and mobilize strategic action to manage the environment. Lack of knowledge may add to the perception of complexity associated with protecting the environment. That is, operators want to be environmentally responsive but do not have the know-how. Conversely, some operators may have the knowledge but not the expertise or the financial capacity to take sustainable environmental action. Other operators may be concerned that, as a single enterprise, their action will not make a difference to the environment so their potential investment will be dissipated. 


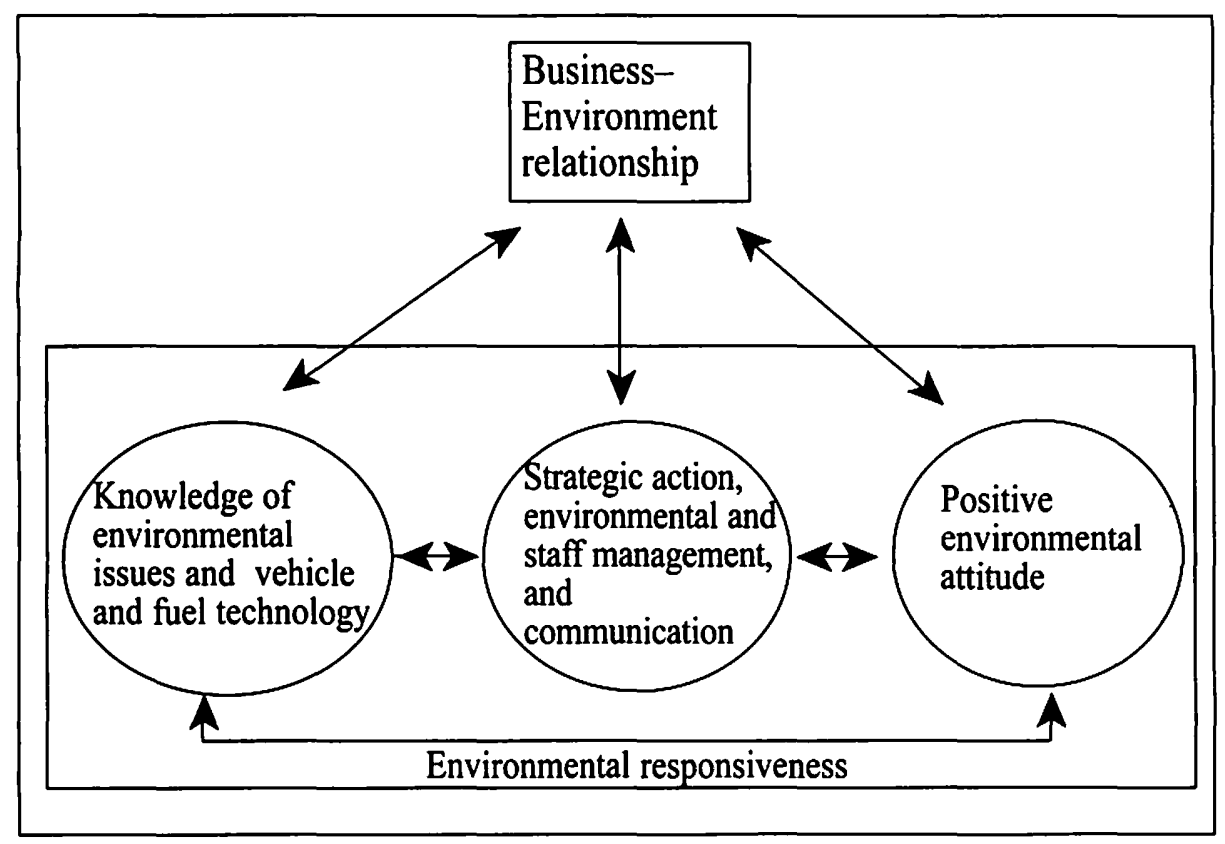

Figure 5. Factors contributing to environmental responsiveness

Schein's (1984 p. 3) frequently quoted definition of culture assists in understanding the basis of environmental responsiveness. Culture is the pattern of basic assumptions that a business has invented, discovered, or developed logically in learning to manage environmental issues. Culturally, environmental responsiveness diffuses throughout a business, affecting all people and facets of operation and business practice. As suggested in Figure 5, maintaining a business-environment relationship requires knowledge and a convergence of attitudes between pro-enterprise and pro-environment, as well as behavior that leads to environmental responsiveness (Rannikko 1996). Communication with and the training of staff to understand the "correct" way to perceive, think, and feel in relation to these problems is essential for an enterprise to become fully responsive to the needs of the environment.

Becoming environmentally responsive is a complex process for any enterprise. In addition to the enforcement of environmental regulations and subsequent monitoring of compliance, it involves engendering moral responsibility (Hines et al. 1987) or what might be termed "good citizenship," understanding 
the processes of social diffusion of industry knowledge (Manzo and Weinstein 1990), and as managing strategically. If environmental issues are officially recognized by management through integration in the business strategy, the likelihood of employees and customers being more receptive to environmental issues and activities increases. Unfortunately, operators do not know how to integrate environmental expenditure into their planning and budgets, nor is there a systematic process of environmental auditing in place. The need for businesses to engage in industrywide education and networking is of foremost importance in order for them to become environmentally responsive. Training and benchmarking are among the most effective routes to improve energy and waste management in the bus and coach industry.

All of these recommendations require a policy change for the bus and coach industry. Governments need to view operators in the bus and coach industry as conservative consumers. By focusing on the improvement of processes, it is necessary to identify the (often competing) interests of business and environmental objectives and seek realignment of a common objective. The policy change has to be an approach that seeks to change attitudes and business strategies by addressing the costs of not doing things by operators in relationship to the environment, and by identifying typical problems and preventive management programs.

\section{Acknowledgments}

The project reported in this article was conducted by the Institute of Transport Studies and sponsored by the Greenhouse Gas Studies Challenge Unit (GCU), Canberra, Australia.

The author wishes to thank Professor David Hensher for his comments on an earlier draft of this article and his contribution to the GCU study. The author also acknowledges Jenny King and Michelle Coulson for their contributions to the GCU study. Thanks are also due to two anonymous reviewers of this article for their valuable comments. 


\section{Endnote}

1. For a copy of the survey, contact Professor Brewer at the Institute of Transport Studies, C37, University of Sydney, NSW2006, Australia; phone: 6129351 0071; fax: 6129351 0088; email: itsinfo@itsusyd.edu.au.

\section{References}

ABCA. 1998. Australian bus and coach association membership list. Unpublished data.

Apelbaum Consulting Group. 1997. The Australian transport task, energy consumed and greenhouse gas emissions, Report prepared for the Department of Primary Industries and Energy, Volume B-Report, Canberra, September.

Bhate, S., and K. Lawler. 1997. Environmentally friendly products: Factors that influence their adoption. Technovation 17 (8): 457-465.

Brewer, A. M. 1994. The responsive employee: The road towards organisational citizenship in the workplace. Sydney: Allen and Unwin.

BTCE. 1996. Estimates of the urban transport task. Unpublished data, Canberra.

Bureau of Tourism Research. International visitor survey, Table 39.

Dickson-Simpson, J. 1998. How diesel can get clean away from gas. $B C A$ (NSW) Bulletin, April: 34-36.

Erdos, G. 1998. TransAdelaide. Personal communication.

Hines, J. M., H. R. Hungerford, and A. N. Tomera. 1987. Analysis and synthesis of research on responsible environmental behavior: A meta-analysis. Journal of Environmental Education 18: 1-8.

Manzo, L. C., and M. D. Weinstein. 1990. Behavioral commitment to environmental protection: A study of active and nonactive members of the Sierra Club. Environment and Behavior 19: 673-694.

Mills, E. 1998. The coming storm: Global warming and risk management. Risk Management 45 (5): 20-27.

Rannikko, P. 1996. Local environmental conflicts and the change in environmental consciousness. Acta Sociologica 39 (1): 57-72.

Schein, E. 1984. Organizational culture and leadership. San Francisco: Jossey Bass.

Stern, P. C., and T. Dietz. 1994. The value basis of environmental concern. Journal of Social Issues 50: 65-84. 
Taylor, J. 1998. Global warming: The anatomy of a debate. Vital Speeches of the Day 64 (11): 335-340.

\section{About the Author}

ANN M. BREWER is an associate professor of management at the Institute of Transport Studies, the University of Sydney. She is also the director of ITS Programs in Logistics and Supply Chain Management and Bus and Coach Management in New South Wales and Western Australia. 


\title{
Transit Stations and Commercial Property Values: A Case Study with Policy and Land-Use Implications
}

\author{
Arthur C. Nelson
}

City Planning Program, Georgia Institute of Technology

\begin{abstract}
$\overline{\text { Abstract }}$
There is little research about the association between rail transit station proximity and commercial property values. There is even less research on the role of public policy in influencing commercial property markets near transit stations without resorting to supply-side constraints. The research reported in this article helps close these gaps in research.

This article develops a theory on commercial property value with respect to both transit station proximity and the role of policies that encourage commercial development around transit stations without discouraging commercial development elsewhere. The theory is applied to the universe of commercial property sales in the area of Atlanta known as "Midtown," which is located about 1 kilometer north of the downtown edge. Midtown is served by three heavy rail transit stations operated by the Metropolitan Atlanta Rapid Transit Authority (MARTA). To encourage development around MARTA stations, Atlanta waives parking and floor area ratio requirements in Special Public Interest Districts (SPIDs) located around rail stations. Research shows
\end{abstract}


that commercial property values are influenced positively by both access to rail stations and policies that encourage more intensive development around those stations. This article explores both theoretical and policy implications.

\section{Introduction}

For the better part of a century, rail transportation systems have influenced urban land-use patterns. Shortly after the Civil War, streetcar networks were laid out in many northeastern and midwestern industrial cities, enabling affluent households to live away from cities along rail lines (Muller 1975; Newton 1971). Later in the 19th century, subterranean rail systems were installed in the largest northeastern cities, having the effect of dispersing both residential and employment activity from downtowns or their nearby neighborhoods. The 20th century through the end of the second world war saw the maturing of streetcar and subway systems, and, despite the introduction of mass produced automobiles, urban development patterns were aligned closely with rail networks (Hoyt 1939). Urban property markets reflected the role of rail transit in establishing value. The earliest studies of property values show that property value rises the closer it is to rail transportation stations (Spengler 1930). To analysts of the early twentieth century, rail facilities decreased the "friction" of distance, thereby allowing more efficient economic interactions (Hurd 1903).

The postwar period gave rise to new suburbs that became inhabited by millions of families whose chief mode of transportation was the automobile. Since then rail transit patronage as a share of all modes has fallen steadily (although total ridership has changed little in the past few decades). The movement of families to suburbs initially called into question whether property markets continued to value accessibility to rail systems. Even more dramatic has been the rise in the past two decades of polycentric urban patterns such as edge cities, many of which rival or exceed traditional downtowns in terms of employment and shopping space. Indeed, vacancy rates of many downtowns with rail transit access have risen in recent years while those of suburban centers dependent on only highways have dropped or remain lower than for downtowns. Very few suburban activity centers owe their existence to rail, and newer ones certainly do not. The logical question is: Does rail still matter for commercial property? 
In particular, does the commercial property market value proximity to rail facilities?

\section{Theory}

Two theoretical dimensions-improvements in accessibility and policy intervention-address whether and to what extent commercial property values may be influenced by proximity to rail stations.

\section{Improved Accessibility Effects}

If transit stations improve the accessibility of property to all parts of an urban area, there will be a positive association between transit station location and property value. Thus, the closer property is to transit stations, the more valuable it is. If this relationship is not found, it could lead to the conclusion that rail transportation facilities have little or no influence on urban development patterns. Studies into the association between property values and rail facility accessibility fall cleanly into residential and office commercial categories.

Much of the literature on the association between residential property values and rail transit accessibility dates from the 1970s, a time during which several new rail systems were being planned or under construction (e.g., Washington's Metro, the Bay Area's Bay Area Rapid Transit Authority, and Atlanta's MARTA). Research by Boyce et al. (1972), for example, found that the largest gains in residential property value accrued to those properties located farthest from downtown Philadelphia along the Philadelphia-Lindenwood high-speed line, presumably indicating that when rail enters a new area, property values escalate higher than the regional mean. (They also found that residential property adjoining highway exits increased as much as that of property adjoining transit stations.) Allen et al. (1986) also showed that residential property values in the Philadelphia region rose about 7 percent higher than the regional mean for similar property. Voith (1991) found that residential properties in Philadelphia census tracts (between 1979 and 1988) accessed by commuter rail rose from 4 to 10 percent over property not served by rail. Similar findings have been made in other metropolitan areas such as Boston (Armstrong 1994), Portland (Al-Mosaind et al. 1993), Washington, D.C. 
(Rybeck 1981), San Francisco (Landis et al. 1995), and Atlanta (Nelson and McClesky 1992).

The evidence on office commercial price effects is considerably more sketchy. Dyett et al. (1979) and Fejarang (1994) found that commercial property values near the planned rail systems of BART and Los Angeles appreciated faster than similar property away from the systems, indicating only speculative effects but not long-term market effects. Washington, D.C.--area commercial brokers interviewed by Damm et al. (1980) and the Rice Center (1987) indicated that rents ranged about $\$ 30$ to $\$ 50$ (in 1994 dollars) higher per square meter for commercial property adjacent to station entries rather than a few blocks away, a phenomenon found also by Cervero et al. (1994) during interviews of commercial brokers in the upscale Buckhead area of Atlanta. Those studies are not statistically rigorous, however, and other factors may explain differences in values. Landis et al. (1995) did not find conclusive evidence showing that rail system accessibility improved commercial property value significantly. It seems that the evidence on whether and the extent commercial property markets value proximity to transit stations is surprisingly sketchy.

\section{Policy Intervention Effects}

More sketchy is the association of commercial property prices with respect to policy levers that attempt to focus commercial development around transit stations. There is certainly no limit to policy approaches, ranging from increasing densities around transit stations while decreasing densities elsewhere, to subsidizing development around stations, to stimulating urban renewal policies through tax increment financing and public partnerships with private redevelopment. In many cases these efforts can be considered supply side; that is, the ability of the commercial property market to operate near transit stations is made considerably more attractive than development away from those stations. Although the literature does not clearly show this, one would expect that commercial property values will be influenced positively when these kinds of policies are present. On the other hand, if those policies have the effect of shifting commercial development from centralized urban locations to decentralized suburban locations, perhaps there may be perverse outcomes. 
Another kind of policy approach is much less benign by simply encouraging commercial development near transit stations. Such policies may relax certain development constraints but do not dramatically change development regulations affecting other land nearby or public subsidies to private development. Because they encourage development around transit stations but do not discourage such development elsewhere, these policies may not distort commercial property markets to the extent that supply-side policies might.

There is another consideration. If parking requirements are eliminated near transit stations, decked parking spaces may be reduced in number, if not eliminated altogether. In current market conditions, tilt-up parking can cost $\$ 15,000$ per space. Offering to delete this requirement may affect the decision of where to build.

Can public policy make a difference in how rail systems affect commercial property values? Parsons Brinckerhoff (1996) speculates but does not necessarily conclude that "rail transit investments must be accompanied by careful planning and supportive public policies to maximize benefits" (p. 28). The question comes down to the extent that the market places a premium on accessibility. Measuring capitalization effects helps to quantify the benefits conferred by transit. If there are such benefits, policy tools may be used to encourage a shift in commercial development toward transit stations. If capitalization effects are not seen, policy tools intended to shape urban form, in part by shifting commercial development location, may be seen as essentially futile and a waste of scarce public resources.

\section{Study Area}

Proper evaluation of the research question requires that several criteria be met. First, the study area must be large enough to supply sufficient variation in price effects across space. This is needed so that influences may be detectable with some degree of certainty. Second, the study area must be reasonably homogeneous in terrain, accessibility, and land-use patterns to assure that variation in price effects is not attributable to differences in elevation, major highways, and different land uses that can have either positive or negative influences on nearby properties (e.g., a downtown high-rise jail facility on nearby 
residential property values). Third, the rail system must have been in place during the entire study period, and the study period must be sufficiently long to generate an adequate number of commercial property sales for statistical evaluation. These criteria were met for the speculative influences observed by Dyett et al. (1979) and Fejarang (1994), and for the unscientifically demonstrated influences reported by Damm et al. (1980), the Rice Center (1987), and Cervero et al. (1994).

A fourth criterion concerns policy intervention in the form of supply-side constraints, which make location around transit stations more attractive than elsewhere by simply preventing development elsewhere or offering considerable subsidies or inducements that merely encourage development around stations without necessarily subsidizing such development or discouraging it elsewhere.

The Midtown area of Atlanta, Georgia, meets all criteria. Midtown, located about 1 kilometer from the edge of Atlanta's historic downtown, is about 4.0 kilometers north to south and about 1.0 kilometer east to west. The area is not only sufficiently large but has three similarly-sized MARTA stations placed roughly equidistant from each other. The terrain is flat; has uniform access to Interstate 75/85 along its northern, western, and southern borders; and is not beset by blight or noxious land uses. It is buffered on the east by a major urban park (Piedmont Park) and by high-density, urban residential neighborhoods located generally north and south of the park. MARTA's rail stations opened in Midtown during the early 1980s and, with sales of approximately 30 commercial buildings between then and 1994, there are reasonably sufficient data with which to conduct statistical analysis.

One policy dimension is also met. The City of Atlanta encourages development near MARTA stations in the Midtown area but does not use supply-side constraints to do so. It promotes development within SPIDs but does not discourage development outside SPIDs. Buildings located inside SPIDs need not provide parking facilities and can be developed more intensively than buildings located outside SPIDs. Buildings constructed outside SPIDs must meet pre-SPID policies that require at least two parking stalls for about every 100 square meters of gross leasable area, and limit development to about 30 floors in height. 
SPIDs measure about 0.64 kilometer on a side, resulting in an approximate radius from SPID edges to the station center of about 0.32 kilometer. Some research indicates that most people are willing to walk this distance to access transit (Untermann 1984; Stringham 1982; Cervero 1993b), although many are willing to walk farther.

To appreciate the subtlety of this effort, one must understand that MARTA operates in the nation's most sprawled metropolitan area (Nelson 1999). The metropolitan area includes 20 counties stretching between the South Carolina and Alabama borders. It is the nation's second fastest growing metropolitan area in population, after Phoenix, but it leads the nation in land absorbed for development (Nelson 1999). It will grow from 3 million in 1990 to more than 5 million in 2010 , or about 1 million people per decade.

This study provides the opportunity to gain insights in two important ways. First, if transit stations influence property values, then values must rise the closer property is to stations. This finding could confirm what others have not. Second, if price effects can be detected with regard to SPIDs all other factors considered, this finding could confirm the effectiveness of policies that are not supply-side oriented.

\section{Model and Data}

The general form model used to evaluate the research question is:

$$
\text { PRICE }_{i}=a_{o}+\Sigma b_{1} E_{j i}+b_{2} \text { TRANSIT-ACCESS }_{i}+w ;
$$

where:

PRICE $_{\mathrm{i}}=$ the sales price per square meter of commercial building, $i$, sold since SPID policies were adopted;

$\Sigma b_{1} E_{j i}=$ the sum vector of control variables, $j$, characterizing each parcel $i$

TRANSIT-ACCESS $_{i}=$ the categorical experimental variable operationalized as either the distance of a building, $i$, to the nearest transit station or its location inside (1) or outside (0) a special public interest district; $w=$ the stochastic disturbance. 
The model is applied to all sales of commercial buildings during the study period. Rents were considered but found to be problematic for several reasons. First, access to tenant leases is confidential. Second, advertised rents do not reflect rents actually contracted. Third, rent concessions for initial lease-up followed by rent escalation makes valuing of advertised rents essentially impossible. Fourth, advertised rents are almost always a range reflecting the range in amount of space and amenities available (such as elevation above street level). It is perhaps for these and other reasons that studies on the relationship between transit station accessibility and rents are often hearsay based on local commercial broker accounts (see, for example, Damm et al. 1980; Rice Center 1987; and Cervero et al. 1994). Sale prices are based on the capitalized value of leases plus assumptions of future market conditions made by the purchaser.

The dependent variable is the sales price adjusted for inflation using 1994 constant dollars based on the consumer price index deflator as published in the Statistical Abstract of the United States. The experimental variables are defined as location inside or outside SPIDs (1 or 0) or Euclidian distance from the centroid of a subject building to the centroid of the nearest station using census Tiger line files in Atlas-GIS.

Control variables customarily used in analyses of commercial building value may include building area, land area, age, amenities, construction quality, and number and type of parking spaces (surface or deck, underground or aboveground). Because of renovations to older buildings and uniform construction (based on tax assessor records), the influences of building age, amenities, and apparent uniform construction quality are considered negligible. In intensely developed areas such as Midtown Atlanta, land area is capitalized into building area, with the exception that land devoted to parking may have an incremental value. The parking ratio (the ratio of parking stalls per unit of building area) does a better job of capturing surplus land area influences. Because some buildings have insufficient land for surface parking, decked or covered parking is used. The combination of parking ratio and covered parking is a better proxy for land area than the land area itself. To control for economies of scale in building value, the remaining extraneous variable is building area. 
In sum, the variables used in this evaluation are defined below.

$P R I C E=$ price per square meter.

$B U I L D I N G-A R E A=$ the enclosed floor space in square meters. Because of economies of scale that relate to price per unit of space, a negative association may be expected between price and building area.

FLOORS $=$ the number of floors of a subject building. This variable helps to account for the higher price per unit of construction, especially along tall buildings and that tall buildings receive a premium in the market especially for offices on the higher levels. A positive association is expected between number of floors and the price per square meter.

FLOOR-AREA-RATIO (FAR) = the total building area divided by total land area. It is a measure of land-use intensity and also accounts for economies of scale inherent in more intense use of land. FAR is not the same as number of floors, although both are measures of building features. A high FAR may be associated with a low-rise building that trades off horizontal over vertical configuration (e.g., buildings in downtown Washington, D.C., which face height limits). A low FAR may be associated with a high-rise building that trades off vertical space over horizontal space (e.g., buildings in downtown Dallas and Houston, many of which are surrounded by large plazas). A positive association is expected between FAR and price per square meter.

PARKING-RATIO = the number of parking stalls per 100 square meters. Because commercial buildings usually need parking to satisfy customer and employee needs, price should be positively associated with parking ratio.

COVERED-PARKING = a binary variable indicating the presence of covered parking. Covered parking is the most expensive of all parking types. Yet because fees charged rarely cover costs, a negative association is expected between price and covered parking. 
CITY-CENTER-DISTANCE = the distance in meters from a subject building to the center of downtown Atlanta. Although one would normally expect building prices to fall away from the downtown center, during much of the study period it was Midtown that blossomed, with the downtown witnessing rising vacancy rates. A negative association is expected between price per meter and distance to the city center.

MARTA-STATION-DISTANCE $=$ the distance in meters from the nearest MARTA station. If the market for office commercial space views proximity to rail transit stations as an improvement in accessibility for its employees and customers, it should capitalize this value. Distance from transit stations should be negatively associated with price.

SPID-LOCATION = a binary variable indicating whether a subject building is inside a SPID. If policies aimed at encouraging development around SPIDs work as intended, price should be positively associated with location inside SPIDs.

Data for the evaluation are arms-length sales' of all office commercial property with buildings sold in the study area during the 1980s through 1994. There were 30 such sales; they comprise the universe. Sales and building attribute data come from the Fulton County Assessor's office. Distance of the property centroid to the centroid of the nearest MARTA transit station was computed using the census Tiger line file in Atlas-GIS. Other variables were considered and rejected. Age of building was rejected because old buildings are renovated periodically and, in this study area, no high-rise buildings (more than 10 floors) were constructed in the study area before the study period. Building floors is thus a proxy for recently constructed buildings. Building class, such as Class A and Class B (using Class $\mathrm{C}$ as a potential referent), was rejected because it is associated with building floors (higher buildings are the most recently constructed and most prestigious in the market). There is always the danger that with a small $n$, more variables than absolutely necessary to 
reveal central tendencies with experimental variables may confound analysis, not improve it. The danger essentially comes down to underspecification. Over time, as this and other study areas build a history of sales, large numbers of sales can allow one to expand the number of variables used.

\section{Results and Interpretation}

Table 1 presents results of ordinary least squares regression for all cases $(n=30$ ), in the first column showing the association of price with respect to transit station distance and in the second column with respect to SPID location. The third column reports results only for sales located outside SPIDs showing price with respect to transit station distance. The coefficient of determination $\left(R_{2}\right)$ is .561 , which seems reassuring given the relatively small sample size. The $F$-ratio is reasonable. The correlation matrix (not reported for brevity) reveals no problematic colinearities, while the casewise plots of standardized residuals against the dependent variable do not reveal systematic bias (also not reported for brevity).

The coefficients of all control variables (BUILDING-AREA, FLOORS, FLOOR-AREA-RATIO, PARKING-RATIO, COVERED-PARKING, and CITY-CENTER-DISTANCE) possess the expected signs, have reasonable magnitudes, and are mostly significant around the .10 level of the one-tailed $t$ test $^{2}$ (because directions of association are predicted). ${ }^{3}$ The experimental variables, MARTA-STATION-DISTANCE and SPID-LOCATION, possess the signs expected from theory, have reasonable magnitudes, and are significant at the .01 level of the one-tailed $t$-test. In particular, the price per square meter falls by $\$ 75$ for each meter away from the center of transit stations and rises by $\$ 443$ for location within SPIDs. The increment in building value with respect to SPID location is roughly equivalent in annualized rent to $\$ 44$ per square meter, which is within the range commercial brokers in Washington, D.C., and elsewhere in Atlanta reported to interviewers (Damm et al. 1980; Rice Center 1987; Cervero et al. 1994).

\section{Implications for Theory and Policy}

The evaluation poses interesting theoretical and policy implications. 
Table 1

Regression Results

Price Effects of Transit Station and SPID Policy on Midtown Atlanta Commercial Property Sales, 1980-1994

\begin{tabular}{lccr}
\hline Variable & $\begin{array}{c}\text { Regression } \\
\text { Coefficient }\end{array}$ & $\begin{array}{c}\text { Statistical } \\
\text { Indicator }\end{array}$ & $\begin{array}{r}\text { Standard Error } \\
\text { (one-tailed } p\end{array}$ \\
\hline BUILDING-AREA & -0.305 & & {$[0.017]^{p<0.05}$} \\
FLOORS & 62.062 & & {$[41.132]^{p<0.10}$} \\
FLOOR-AREA-RATIO & 0.449 & & {$[0.392]^{\mathrm{p}<0.15}$} \\
PARKING-RATIO & 91.044 & & {$[61.460]^{\mathrm{p}<0.10}$} \\
PARKING-COVERED PARKING & -889.542 & & {$[307.975]^{\mathrm{p}<0.05}$} \\
CITY-CENTER-DISTANCE & 0.228 & & {$[0.182]^{\mathrm{p}<0.15}$} \\
MARTA-STATION-DISTANCE & -0.748 & & {$[0.484]^{\mathrm{p}<0.10}$} \\
SPID-LOCATION & 443.205 & & {$[299.278]^{\mathrm{p}<0.10}$} \\
CONSTANT & 40.075 & & \\
& & & \\
$R_{2}$ & & 0.561 & \\
Standard Error & & 450.010 & \\
F-ratio & & 3.357 & \\
Number of cases & & 30 & \\
\hline
\end{tabular}

\section{Theoretical Implications}

For the present and given contemporary technology, theory on the association between transit station access and building value seems to hold. This is especially interesting since theory seems to hold where policies do not discourage development away from transit stations. What is not known and cannot be derived from this or other studies, because there are no baselines by which to compare price effects longitudinally, is whether the magnitude of association is falling over time because of employment deconcentration and/or technological advances that reduce the advantages of central location.

Perhaps theory holds for only the more centralized locations such as Midtown Atlanta but not for more suburban locations. This alternative theoretical consideration is based on work by Landis et al. (1995) who found limited evidence of some price effects for commercial properties located near BART stations in urbanized Alameda County (Oakland area) but not for suburban 
Contra Costa County (Walnut Creek and Concord). This alternative should be the subject of future research.

\section{Policy Implications}

Atlanta has attempted to influence development patterns to increase transit ridership especially in the Midtown area. Its SPID policy waives parking requirements for development around rail transit stations while also relaxing FAR requirements, thereby allowing for taller, more intensively developed buildings. Outside SPIDs, new buildings must meet minimum parking ratios and are restricted to less intensively developed buildings-both conditions predating the SPID policy. Atlanta's approach to influencing parking supply and increasing transit ridership is solely based on incentives; there are no disincentives or mandatory conditions imposed on new development inside or outside SPIDs.

Atlanta's policy to encourage commercial development within SPIDs seems effective, at least to some degree. MARTA's investment in its rail system and transit stations appears to attract commercial development. The regression equation shows that distance from transit stations is associated with declining value per square meter of office space. Policies to stimulate commercial clustering around transit stations also appear somewhat effective, principally by reducing parking facility requirements within SPIDs. The price per square meter of office space rises with location inside SPIDs; in addition, the presence of decked parking is associated with lower value per square meter of office space, further signaling market response to the costs of parking.

Given the favorable response by the office market, is Atlanta's SPID policy enough? Atlanta can probably do little more than it already is doing with its SPID policy. If the City unilaterally engaged in supply-side measures, it would either heavily subsidize commercial development around transit stations or prohibit commercial development elsewhere, but its policies would apply to only its incorporated city limits. Atlanta accounts for only 10 percent of the entire region's population. Suburban locations enjoy lower land prices, accessibility to larger pools of more highly educated labor, lower congestion (at least until recent years), and willingness by suburban governments to diversify their 
tax base. Given this, how can central cities such as Atlanta attract development, direct such development to areas served by rail transit, and encourage commuters if not customers to use transit? Mandatory requirements such as restricting new high-density development to areas near transit stations and restricting parking may seem reasonable but could have the effect of discouraging commercial development, causing even more commercial development in the suburbs.

In the present political climate, metropolitan Atlanta may be better advised to expand the city's SPID approach to encompass transit stations recently built or under construction in suburban areas. Indeed, SPID policies may be more effective in suburban communities than in places such as Midtown, because although local governments covet the diversification to local tax bases that commercial development offers, citizens are opposing more effectively commercial encroachments into established residential neighborhoods. SPIDs drawn around suburban stations may be even more effective in influencing development if they are combined with land-use policies restricting commercial and high-density housing outside SPIDs. Suburban governments would have their commercial development while mollifying citizen groups, too.

To accommodate the growing demand for commercial space, especially in suburban activity centers, the design of Atlanta's SPIDs could be reconsidered. The Midtown SPIDs are only about 0.64 kilometer on a side with an approximate radius half that distance and thus contain land area averaging about 0.41 square kilometer. This area is probably insufficient to accommodate more than a small share of total commercial and high-density housing demand in suburban areas. Although research suggests that most people are willing to access transit within this distance (Untermann 1984; Stringham 1982), other literature suggests that people are willing to walk a radius of up to 1.25 kilometers especially at the work-trip end (Parsons Brinckerhoff 1996). Suburban SPIDs designed with longer radii can be as large as 2.4 kilometers on a side or 5.8 square kilometers-an area more than 10 times larger than Atlanta's Midtown SPIDs. With a localized trolley system, the SPID area may be expanded somewhat more but probably only if density warrants. 


\section{Generalizability}

Atlanta's experience with SPIDs may be generalizable to other metropolitan areas that are constructing or plan to construct new or expanded rail systems. Even in the absence of regional planning that directs commercial development to areas such as SPIDs, this research indicates that the commercial market in centralized locations, such as Midtown, will be attracted to locations near transit stations. Although SPID-like inducements may increase development, the mere presence of transit stations apparently influences location behavior. Will these outcomes hold for suburban locations? In growing suburban areas that have or will soon have rail transit access, SPID-like policies can be used to accommodate commercial development needs while also protecting nearby residential neighborhoods from commercial encroachment. Whether such policies will be effective in suburban locations is an open question, however, and one deserving of rigorous research.

\section{Acknowledgment}

Partial support for research reported in this article was provided by the Transit Cooperative Research Program, TCRP-H3, under a subcontract with Portland State University. The views expressed herein are those of the author and do not necessarily reflect those of the National Academy of Sciences, National Research Council, Transportation Research Board, Transit Cooperative Research Program, Georgia Institute of Technology, Portland State University, or Growth Management Analysts, Inc.

\section{Endnotes}

1. Arms-length sales are those not between people related by kin or business.

2. Significance for some coefficients is at the .15 level. The reader may decide whether to accept or reject those outcomes. Because (1) of the small sample size, (2) directions were as predicted, and (3) the affected coefficients are merely control, whether the reader accepts or rejects those outcomes is immaterial to statistical interpretation.

3. Those associations indicate generally that sales price per square meter falls by about $\$ 0.03$ per square meter above the mean ( $\$ 674 /$ square meter), rises by $\$ 62$ for each floor above the mean ( 5 floors), rises $\$ 0.44$ for each point increase in FAR above the 
mean (266), rises $\$ 91$ for each point increase in the parking ratio mean (1.75 per 100 square meters), falls by $\$ 889$ for the presence of a parking garage, and rises by $\$ 23$ for every kilometer away from the city center mean ( 3.78 kilometers).

\section{References and Selected Bibliography}

Allen, Bruce W., and Robert Mudge. 1974. The impact of rapid transit on urban development. Rand Corporation Paper P-5246.

Allen, W. R., et al. 1986. The impact of rapid transit on suburban residental property values and land development. Philadelphia, PA: University of Pennsylvania, Wharton School.

Al-Mosaind, M. A., K. J. Dueker, and J. G. Strathman. 1993. Light rail systems and property value. Transportation Research Record, 1400:90-94.

Armstrong, R. J., Jr. 1994. Impacts of commuter rail service as reflected in singlefamily residential property values. Paper presented at the 73rd Annual Meeting of the Transportation Research Board, Washington, DC.

Black, J. Thomas, Donal O'Connell, and Michael Morina. 1982. Downtown office growth and the role of public transit. Washington, DC: The Urban Land Institute.

Beesley, M. E., and C. D. Foster. 1973. Estimating the social benefit of constructing an underground railway in London. Urban Transport, 1-97.

Bell, D. 1991. Office location: City or suburb? Transportation 18: 239-259.

Boyce, David, Bruce Allen, Richard Mudge, Paul B. Slater, and Andrew M. Isserman.

1972. The impact of rapid rail on suburban residential property values and land development analysis of the Philadelphia high-speed line. Philadelphia: Regional Science Department, Wharton School, University of Pennsylvania.

Burkhardt, Ross. 1976. Summary of research: Joint development study. New York: The Administration and Managerial Research Association of New York City.

Cambridge Systematics. 1988. The impacts of UMTA programs. Washington: UMTA. Cervero, Robert. 1993a. Ridership impact of transit focused development in California. University of California (Berkeley).

Cervero, Robert. 1993b. Rail transit and joint development: Land market impacts in Washington, DC, and Atlanta. Journal of the American Planning Association 60 (1): 83-94.

Cervero, R., M. Bernick, and J. Gilbert. 1994. Market opportunities and barriers to transit-based development in California. Institute of Urban and Regional Development, University of California (Berkeley). 
Cervero, R. M. et al. 1994. Market opportunities and barriers to transit-based development in California. Berkeley, CA: Institute of Urban and Regional Development, University of California.

Damm, et al. 1980. Response of urban real estate values in anticipation of the Washington metro. Journal of Transport Economics and Policy (September): 315-35.

Davies, Frederick W. 1970. Proximity to a rapid transit station as a factor in residential property values. Appraisal Journal 38:554-572.

Davies, Gordon W. 1972. The effect of a subway on the spatial distribution of population. Journal of Transport Economics and Policy, 126-136.

Dornbusch, David M. 1975. BART-induced changes in property values and rents. Land Use and Urban Development Projects, Phase I, BART. Working Papers. WP 21-5-76. Washington, DC: U.S. Department of Transportation; U.S. Department of Housing and Urban Development.

Downing, Paul B. 1973. Factors affecting commercial land values. Land Economics 49:44-56.

Dyett, M., et. al. 1979. The impact of BART on land use and urban development: Interpretative summary of the final report. Washington, DC: U.S. Department of Transportation, Urban Mass Transportation Administration.

Goldberg, Michael A. 1970. Transportation, land values, and rents: A synthesis. Land Economics 44, 2: 153-62.

Hilton, G. 1968. Rail transit and the pattern of cities. Traffic Quarterly 67: 379-93. Hoyt, Homer. 1939. The structure and growth of residential neighborhoods in American cities. Washington, DC: Federal Housing Administration.

Hurd, Richard M. 1903. Principles of city land values. New York: The Record and Guide.

John Blayney Associates/David M. Dornbusch and Co., Inc. 1979. Land use and urban development impacts of BART. San Francisco: Metropolitan Transportation Commission.

Landis, John. 1995. Rail transit investments, real estate values, and land-use change: A comparative analysis of five California rail transit systems. Berkeley, CA: Institute of Urban and Regional Development, University of California.

Landis, J., et al. 1995 Rail transit investments, real estate values, and land use change.

Berkeley, CA: Institute of Urban and Regional Development, University of California. 
Langfield, S. C. 1971. The balanced and orderly development of the site in close proximity to a metro station as a contributor to a more healthy and economically viable urban environment in the Washington metropolitan area. Washington, DC: Urban Transportation Center.

Lee, Douglass B., and C. P. Averous. 1973. Land use and transportation. Environment and Behavior 2: 491-502.

Lee, Douglass B., et al. 1973. Case studies and impacts of BART on prices of singlefamily residences. Institute of Urban and Regional Development, University of California (Berkeley).

Lerman, Stephen R., David Damm, Eva Lerner-Lamm, and Jeffrey Young. 1978. The effect of the Washington Metro on urban property values. Washington, DC: U.S. Department of Transportation, Urban Mass Transportation Administration.

Muller, Peter O. 1975. The outer city. Washington, DC: Association of American Geographers.

Nelson, Arthur C. 1992. Price effects of elevated rail transit facilities on home values with respect to class. Transportation Research Record 1359, 127-132.

Nelson, Arthur C., and Susan J. McClesky. 1990. Improving elevated transit station influences on neighborhoods: Some evidence of desirable effects of elevated transit stations designed to minimize adverse impact on single-family home values in adjacent neighborhoods. Transportation Research Record 1266, 173-180. Nelson, A. C., and S. J. McClesky. 1992. Improving the effects of elevated transit stations on neighborhoods. Transportation Reserch Record, 1266.

Newman, P., and J. Kenworthy. 1989. Cities and automobile dependency. Aldershot, Australia: Avebury Technical.

Newton, Norman T. 1971. Design on the land. Cambridge, MA: Harvard University Press.

Nowlan, D., and G. Stewart. 1991. Downtown population growth and commuting trips. Journal of the American Planning Association 65: 165-182.

Parsons Brinckerhoff. 1996. Transit and urban form. Washington, DC: National Transit Cooperative Research Program, Project TCRP-H1.

Rice Cener for Urban Mobility Research. Assessment of changes in property values in transit areas. Houston, TX: Rice Center.

Rybeck, W. 1981. Metrorail impacts on Washington area land values. Washington, DC: Subcommittee on the City, Committee on Banking, Finance, and Urban Affairs, U.S. House of Representatives. 
Spengler, E. H. 1930. Land values in New York in relation to transit facilities. New York: Columbia University Press.

Stringham, M. 1982. Travel behavior associated with land uses adjacent to rapid transit stations. ITE Journal 52 (4): 18-22.

Untermann, Richard. 1984. Adapting neighborhoods for walking and bicycling. Accommodating the pedestrian. New York: Van Nostrand Reinhold.

Voith, Richard. 1991. Transportation, sorting, and house values. American Real Estate and Urban Economics Association Journal 19 (2): 117-137.

\section{About the Author}

ARThuR C. Nelson is professor of city planning in the College of Architecture and public policy in the College of Management at the Georgia Institute of Technology. He is also a member of the Transportation Research and Education Center faculty of the College of Engineering. 


\title{
Modeling Senior Travelers' Acceptance of New Transit Systems
}

\author{
Mohamed A. Abdel-Aty \\ University of Central Florida
}

\section{$\overline{\text { Abstract }}$}

This article examines the findings of an investigation of senior travelers ' willingness to use several advanced transit systems. Elderly travelers were surveyed to evaluate their acceptance of a real-time paratransit and several transit information systems. The likelihood of using each system was estimated using the binary probit modeling methodology. The analysis showed that gender, income, age, type of trips recently made, and several perception-related variables are among the factors that affect the decision to accept the new transportation systems. The study also showed the important potential of several transportation technologies to increase the mobility and alleviate the transportation difficulties of the elderly population. In addition, the results illustrated the willingness of many groups of senior travelers to use new transportation systems in an attempt to reduce their travel problems.

\section{Introduction}

The elderly are a rapidly growing segment of the U.S. population. The 1990 census shows that individuals more than 65 years old constitute 12.6 percent of the population, and that this segment continues to grow. The Nationwide Personal Transportation Survey (NPTS) shows that although today's elderly 
rely more on the automobile than in the past, individuals more than 75 years old experience driving difficulties that lead to a decline in their mobility, and are looking for alternative transportation modes (U.S. Department of Transportation 1992; Transportation Research Board 1988).

In a paper by Abdel-Aty and Jovanis (1998), a survey of elderly travelers in California was introduced. The survey showed that the elderly are taking, and are willing to take, many trips for different purposes. The results also uncovered many problems and difficulties experienced by the elderly, which oftenlead to missing some important trips such as medical appointments.

Intelligent Transportation Systems (ITS), particularly those tailored to meet the needs of elderly travelers dealing with transit and paratransit, are envisioned as potential solutions for the elderly's improved mobility and the reduction of their transportation-related problems.

Not much is available in the literature about the elderly's acceptance of new technologies. Geehan and Suen (1993) explored the acceptance of Advanced Traveler Information Systems (ATIS) by the elderly and disabled. They found that special groups generally prefer in-vehicle information systems over both pretrip and in-terminal information. Suen and Parviainen (1993) discussed a conceptual framework of advanced travel accessibility systems for the elderly and disabled. Suen and Rutenberg (1994) reviewed the ATIS in Canadian transportation terminals. Guthrie and Phillips (1994) discussed the market opportunities of ITS for elderly and disabled travelers. Schweiger and McGrane (1994) reviewed the different Advanced Public Transportation Systems (APTS) that could directly and indirectly affect elderly and disabled travelers. They also addressed the challenges for developing and implementing APTS for the elderly and disabled. Although most of these studies noted that the private vehicle is the most favored transportation mode for the elderly, they indicated that satisfying the informational requirements of the elderly is very important, and that the demand for pretrip and en route information systems for the elderly continues to grow. Although many previous studies have addressed the elderly's travel behavior and mobility (e.g., Witkowski and Buick 1985), or estimated models of mode choice or demand for public transportation by senior 
citizens (Parolin 1988; Lago and Burkhardt 1980), very limited research has attempted to estimate models of the elderly's acceptance of advanced transportation systems.

This article presents models of the elderly's willingness to use transit or paratransit given the availability of several new transportation systems. The data used in this modeling effort were collected using a Computer-Aided Telephone Interview (CATI). Abdel-Aty and Jovanis (1998) describe in detail the CATI survey, general descriptive statistics of the sample group, physical capabilities of the elderly, and their travel characteristics.

\section{The Senior's Survey}

A CATI survey, conducted in August 1996, targeted a random sample of the elderly population in the Sacramento area in northern California. The CATI was limited to respondents 65 years old and above, and yielded a sample of 260 respondents. The main objectives of the survey were to define the characteristics and travel behavior of the elderly, and to test their acceptance of new transportation technologies and the technologies' potential for improving mobility.

The survey contained 105 questions and took 13 minutes to complete. Three callbacks were attempted to each potential respondent until the desired sample size was reached. Respondents who were unable to respond to the survey when initially contacted were offered the option of a callback at a more convenient time. Respondents who found it difficult to answer questions for a long period of time were given the opportunity to call on a toll-free number to complete the survey at their convenience.

Of the total sample group, 48.1 percent were males and 51.9 percent were females. This is very comparable to the 1990 census for the national male/female percentage more than 65 years old $(48.4 \%$ male and $51.6 \%$ female). About 23.6 percent of the sample were 65 to 69 years old; 62.8 percent, 70 to $79 ; 13.2$ percent, 80 to 89 ; only 1 respondent was in the 90 or above age category. The majority, as expected, were in the first two age categories (65 to 79 years old).

Most respondents had relatively low to middle incomes. The largest percentage, about 17.8 percent, were in the $\$ 10,000$ to $\$ 19,999$ income group; 
15.1 percent and 16.7 percent had incomes of $\$ 20,000$ to $\$ 29,999$, and $\$ 30,000$ to $\$ 39,999$, respectively. Of the total respondents, $36.4 \%$ completed some college, while 17.1 percent had a four-year college degree. Most respondents (68.6\%) were married, 19.4 percent widowed, and 12 percent were single or divorced. The majority lived in two-person households (67.1\%); the remainder (26\%) lived in one-person households.

The distribution of car ownership per household shows that the majority of the respondents owned one vehicle (48.5\%). Only 4.3 percent lived in households that did not own any vehicle. About 36.6 percent lived in households with only one licensed driver; 58.2 percent lived in households with two licensed drivers. Most respondents were retired (94.6\%). Of the 11 respondents (4.3\%) who were employed, only 5 were employed full time; the remaining 6 were employed part time. Two respondents went to school part-time.

These descriptive statistics indicate several characteristics of the elderly population. They tend to be nonworking and to have relatively low incomes. Thus, the elderly need a low-cost transportation service that is convenient and serves destinations of activities other than work (e.g., medical, recreational, etc.). Although a small percentage, some elderly neither own a car nor have a driver's license, which again indicates their need for public transportation.

The majority of the respondents ( $95 \%$ ) usually had a car available to them for use, but only 88.8 percent said they currently drive. Of the 29 respondents $(11.3 \%)$ who did not drive, 10 said their disability or age prevented them from driving; 6 preferred not to drive; 5 respondents did not learn how or never got a license; and 3 had medical conditions that prohibited them from driving. Of those who did not drive, 51.7 percent are disabled, compared to only 12.7 percent who were disabled and drove $\left(x^{2}=27.763 ; \mathrm{df}=1 ;\right.$ Prob. $\left.=0\right)$. Also, the reasons for not driving were related to the disability, with most of the disabled citing either medical advice or disability/age as why they did not drive $\left(\mathrm{x}^{2}=\right.$ 23.393; $\mathrm{df}=7$ Prob;. = 0.0015).

The majority of the respondents $(70.9 \%)$ rode a bus "more than a year ago," and only 5.8 percent rode a bus "this month." In addition, 65.5 percent rode a train or trolley more than one year ago, and only 2 percent rode one last 
month. About 18 percent of the respondents never rode a public transit bus. The corresponding percentages for door-to-door paratransit service are only 5.8 and 0 percent for riding more than a year ago, and this month, respectively. This low percentage for paratransit could be attributed to the fact that 92.3 percent of the respondents "never" used a paratransit door-to-door service, although 17.3 percent are disabled.

The overall results of the survey show that very few elderly are using public transportation, and that there is a vital need for public transit improvements to accommodate their needs for accessibility and mobility.

Abdel-Aty and Jovanis (1998) describe the initial investigation of the effect and acceptance of new technologies on the elderly. They found that some actions, such as walking or standing for some time, are considered impossible or extremely difficult to a considerable number of the elderly. They also report that the elderly generally take trips frequently.

Elderly females rated several actions/situations as impossible or difficult more often than males. They more likely required assistance from another person to get in and/or out of a standing car, truck, van, or transit vehicle. Females were more apt to not have a car available to them everyday, and they currently drove less than males. Females grocery shopped more frequently than males. Some indicated they were recently unable to make a grocery shopping trip because of a transportation problem. Also, more females noted that they were recently unable to keep a medical appointment because of a transportation problem. These results show several physical and transportation problems for elderly females, beside less car availability. In addition, the results point to a need to look more carefully at the transportation requirements of elderly females and to find solutions. This issue was confirmed when testing for the association between gender and the acceptance of transportation technologies addressed in the survey. Females consistently expressed willingness to use such systems and to use transit and/or paratransit systems.

\section{Advanced Transportation Systems}

The survey proposed five advanced transportation technologies to test the elderly's acceptance and potential use of such systems: 
- Onboard transit information

- Information kiosks

- Real-time paratransit services

- In-home information systems

- Personal information systems

The initial analysis shows that a real-time paratransit system would have the most effect on encouraging people to use paratransit. This is followed by the significant effect of in-home information on using real-time paratransit, and the positive effect of personal information systems also on using real-time paratransit. The results also indicate that the other systems encourage the use of transit or paratransit, but as mentioned above, real-time paratransit seems to be the most favored system if information is available.

The main objective of this study is to propose alternative technological solutions and to evaluate elderly travelers' perceptions and acceptance of such systems. In the survey, respondents were presented with the statement: "I am going to ask your opinion about the usefulness of several new transportation technologies." Then, questions related to each of the technologies were presented.

\section{On-Board Transit Information}

On-board transit information was described in the interview. Respondents were told:

Suppose transit buses and light-rail trains had information systems located on them. These would be electronic bulletin boards that could display information. The types of information would include:

- the name and location of the vehicle's next stop;

- the expected arrival time at the next stop;

- information about any transfers you might have to make to reach your final destination, including the expected arrival time of the next vehicle to which you would be transferring; and

- emergency phone numbers.

About 40 percent of the respondents who reported previously in the sur- 
vey that the last time they rode a public transit bus, transit train, or trolley was either "more than one year ago" or "never" (i.e., nonregular transit users), said that if on-vehicle information was available they would be more likely to use public transit.

As for respondents who said that the last time they rode public transit was less than one year ago (i.e., transit users), 60 percent said that on-vehicle information would make the trips they are already taking easier. About 30 percent said they would make more trips, and 10.6 percent indicated that such a system would have allowed them to make a trip that they recently missed (Figure 1).

\section{Information Kiosks}

Information kiosks were described as:

... an electronic bulletin board that not only displays information, but

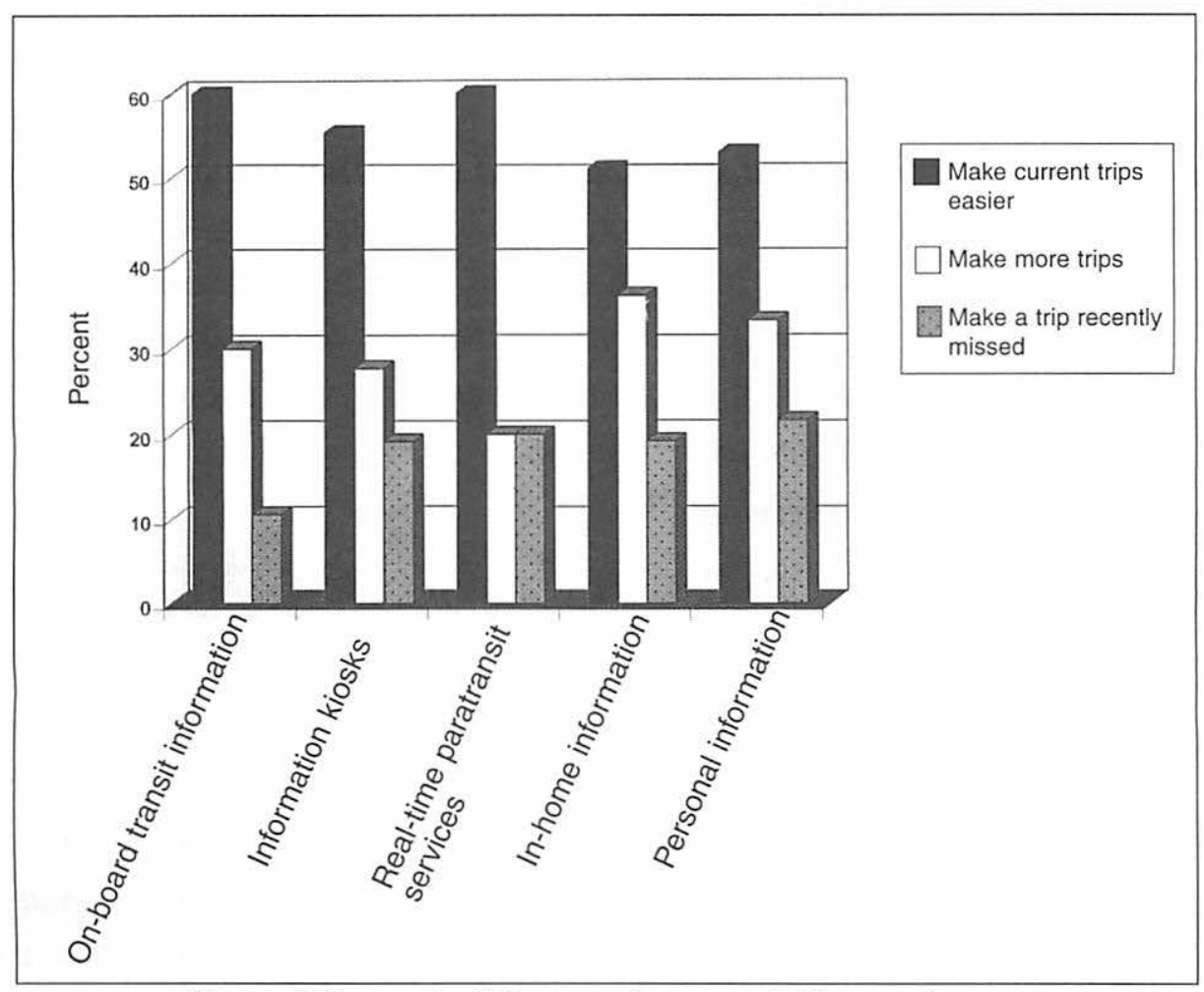

Figure 1. Impact of the new transportation systems 
also allows you to choose the type of information. The types of information available to you would be:

- the map of the transit route, including the stops nearest your actual destination,

- up-to-the-minute information on the expected arrival time of the next transit vehicle,

- the exact fare for your trip,

- the number and location of any transfers you might have to make to reach your destination,

- whether a wheelchair lift is available on the next arriving vehicle, and

- emergency phone numbers.

Suppose such information kiosks were located at light-rail transit stops and at major bus stops where transfers are made from one bus route to another.

About 44 percent of the nonregular transit users stated that if information kiosks were available, they would more likely use public transit. As for transit users, 55.3 percent said that information kiosks would make the trips they are already taking easier. About 27.7 percent said that they would make more trips, and 19.2 percent indicated that such a system would have allowed them to make a trip they recently missed (Figure 1).

\section{Real-Time Paratransit Services}

The interviewees were told:

Real-time paratransit is like the paratransit services you may have heard of or may now be using. A van would provide you with a "door-to-door" ride between your home and your destinations. You would likely be sharing this vehicle at least once in a while. Real-time paratransit systems would allow you to make a reservation on the day of a local trip you wanted to make, rather than requiring several days' advance reservation as with today's paratransit. 
About 56.9 percent of the nonregular paratransit users said that if realtime paratransit was available, they would more likely use paratransit. Of the paratransit users, 60 percent indicated that real-time paratransit service would make the trips they are already taking easier, 20 percent would make more trips, and 20 percent would have been able to make a trip that they recently missed (Figure 1).

Real-time paratransit is a door-to-door service, therefore it is convenient and does not require going to a transit stop that might be considered a difficulty by many senior travelers. Real-time paratransit is also attractive and efficient because it provides same-day service. Therefore, it is not surprising that respondents would be more enthusiastic about this service.

\section{In-Home Information Systems}

Respondents were told that in-home information systems:

...would deliver the same types of information to you at home as the information kiosk provides at transit stops. That is, it would tell you:

- the location of transit stops nearest your actual destination,

- a schedule of the regular arrival and departure times for transit vehicles at the stops nearest both the starting point and ending point of your trip,

- updated information on the actual expected arrival time of the next transit vehicle,

- the exact fare for your trip,

- the number and location of any transfers you might have to make to reach your destination, and

- whether a wheelchair lift is available on the next arriving vehicle.

In addition, the in-home system would provide you with information about ordinary paratransit that requires several days of advanced reservation, and real-time paratransit services such as we just discussed. This information might be delivered to you through your television or through a home computer. 
Respondents were asked if such a system would make them more likely to use public transit, paratransit, or real-time paratransit. About 43.6 percent, 45 percent, and 51.7 percent indicated that an in-home information system would make them more likely to use public transit, paratransit, and real-time paratransit, respectively. Compared to on-board and kiosk information, these percentages might show a slight preference for real-time paratransit for the elderly if provided with pretrip information.

As for respondents who indicated that the last time they rode public transit/paratransit was less than one year ago, 51 percent said that in-home information would make the trips they are already taking easier. About 36.2 percent said that they would make more trips, and 19.2 percent indicated that such a system would have allowed them to make a trip they recently missed (Figure 1).

\section{Personal Information Systems}

Interviewees were told that personal information systems:

...would provide you with all the information available to you in the inhome information system. However, it would be a small device that you could carry with you. It would tell you about:

- the location of transit stops nearest your actual destination,

- a schedule of the regular arrival and departure times for transit vehicles at the stops nearest both the starting point and ending point of your trip,

- updated information on the actual expected arrival time of the next transit vehicle,

- the exact fare for your trip,

- the number and location of any transfers you might have to make to reach your destination,

- whether a wheelchair lift is available on the next arriving vehicle, and

- whether any seats are available on the next arriving vehicle. 
Also, the personal system would provide you with information about ordinary paratransit that requires several days of advanced notice, and realtime paratransit services for which you could make reservations for doorto-door travel. You could access this information from wherever you happened to be within the city or region you live. Additionally, the personal information system would allow you to access a real-time paratransit provider from wherever you happen to be and make a reservation for later in the day.

About 40.1 percent of the respondents indicated that a personal information system would make them more likely to use public transit; 39.1, paratransit; and 48.3, real-time paratransit. Again, these percentages might show a slight preference of real-time paratransit for the elderly if provided with the personal information system. Also, it shows a slight preference for in-home information systems over personal information systems. This might be attributed to the fact that a personal information system could be perceived as a hitech gadget that is difficult to use. Such a resistance to new equipment is natural, particularly by the elderly.

As for transit/paratransit users, 52.9 percent said that a personal information system would make the trips they are already taking easier. About 33.3 percent said they would make more trips (about $65 \%$ said they would make such additional trips by transit, $29 \%$ using real-time paratransit, and only $6 \%$ by conventional paratransit). About 21.6 percent indicated that such a system would have allowed them to make a trip they recently missed (Figure 1).

\section{Evaluation of New Transportation Technologies}

In general, the results show that a real-time paratransit system would have the most effect on encouraging the elderly to use paratransit. This is followed by the significant effect of in-home information on using real-time paratransit, and the positive effect of personal information systems on also using real-time paratransit.

Figure 1 shows that both on-board information and real-time paratransit were chosen more frequently by current transit and paratransit users as the sys- 
tems that would make current trips easier. The figure also indicates that in-home information, followed by personal information systems, would have the greatest effect on encouraging the elderly to make more trips (increased mobility).

The respondents' perceptions of the usefulness of each of the information systems is presented in Figure 2. Real-time paratransit was seen as the most useful by 29.5 percent of the respondents. This was followed by personal information systems (26\%) and in-home information systems (26\%). Information kiosks and on-board transit information were chosen by 12.8 percent and 5.4 percent of the respondents, respectively.

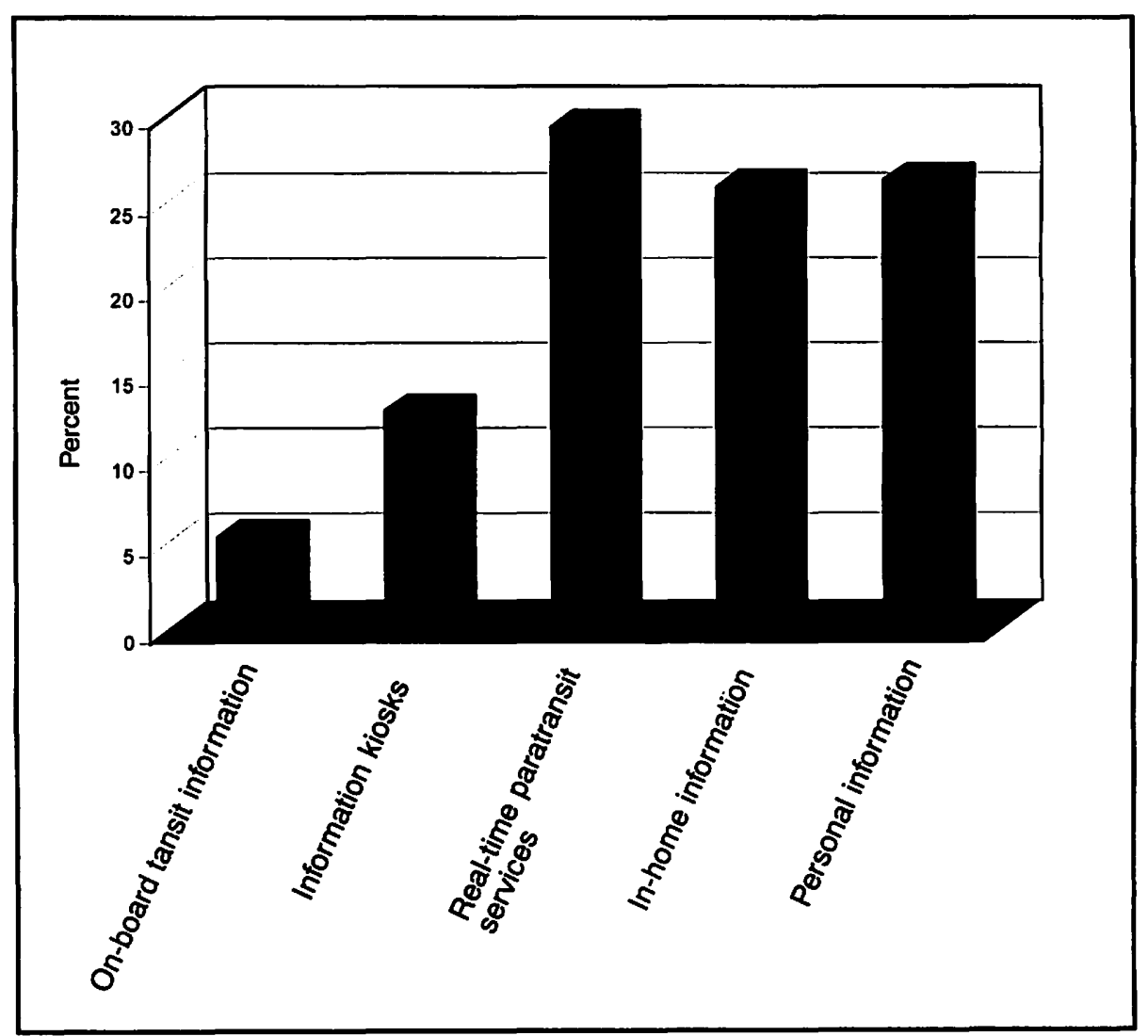

Figure 2. Respondents' selection of the most useful transportation technology 


\section{Modeling Seniors' Acceptance of Advanced Transportation Technologies}

This section described a modeling effort (in a multivariate context) of the elderly's acceptance of the different advanced transit systems proposed in the survey. The purpose of this modeling effort was to identify the factors that influence the elderly's choice to use transit or paratransit, given the availability of one of the proposed advanced systems. The approach pursued here uses the binary probit model formulation. It assumes that an individual's perceived utility for a specific choice is a function of the perceived attributes of the alternative and the individual's characteristics.

\section{Methodological Approach}

The random utility theory was used in estimating the models. The theory assumes that an individual's choice is based on the utility gain experienced by the individual for a particular choice. If an individual perceives a certain gain by using a certain mode of travel, then the perceived utility of this choice is larger than that of the alternative. A binary probit model was used to estimate the respondent's likelihood of using transit/paratransit if certain a new system was available as opposed to the alternative of not choosing this mode.

Suppose $\varepsilon_{i n}$ and $\varepsilon_{j n}$ are both normal with zero means and variances $\sigma^{2}{ }_{i}$ and $\sigma^{2}$, respectively. Suppose further that they have covariance $\sigma_{i j}$. Under these assumptions, the term $\varepsilon_{i n}-\varepsilon_{j n}$ is also normally distributed with mean zero but with variances $\sigma^{2} i+\sigma^{2}{ }_{j}-2 \sigma_{i j}=\sigma^{2}$. This result can be used to solve for the choice probabilities as follows (Ben-Akiva and Lerman 1985; Daganzo 1979):

$$
\begin{aligned}
& P_{n}(i)=\operatorname{Pr}\left(\varepsilon_{j n}-\varepsilon_{i n} \leq V_{i n}-V_{j n}\right) \\
& =\int_{\varepsilon}^{V_{i n}}-V_{j n} \frac{1}{\sqrt{2 \pi \sigma}} \exp \left[\frac{-1}{2}\left(\frac{\varepsilon^{2}}{\sigma}\right)\right] d \varepsilon, \sigma>0, \\
& =\frac{1}{\sqrt{2 \pi}} \int_{-\infty}^{\left(V_{i n}-V_{j n}\right) / \sigma} \exp \left[\frac{-1}{2} u^{2}\right] d u=\Phi\left(\frac{V_{i n}-V_{j n}}{\sigma}\right),
\end{aligned}
$$

where: $\Phi($ ) denotes the standardized cumulative normal distribution. 
In the case where $V_{i n}=\beta^{\prime} x_{i n}\left(\beta^{\prime}\right.$ is the vector of estimated coefficients, and $\mathrm{x}_{i n}$ explanatory variables) and $V_{j n}=\beta^{\prime} \mathrm{x}_{j n}$,

$$
P n(i)=\Phi\left(\frac{\beta^{\prime}\left(X_{i n}-X_{j n}\right)}{\sigma}\right)
$$

In this case, $1 / \sigma$ is the scale of the utility function, which can be set to an arbitrary positive value, usually 1 . The binary probit choice probabilities depend only on $\sigma$, not on $\sigma_{i}^{2}, \sigma 2_{j}$, and $\sigma_{i j}$. Thus, the variances and covariance of the two disturbances are irrelevant to the choice probabilities.

\section{Estimation Results}

In all, seven models were estimated to address the acceptance of the ITS systems proposed in this study. Only four complete models are presented due to space limitations. Table 1 summarizes the results of all seven.

Information Kiosks. A model of whether a respondent would be more likely to use public transit, if information kiosks were available, was estimated using the binary probit formulation (Table 2). Numerous variable combinations were attempted before reaching the final model presented in Table 2. Although not all the variables that were entered into the final model are significant at the 95 percent confidence level (i.e., $t$-stat. $\geq 1.96$ ), all the variables had the appropriate sign, and had a rational interpretation. Also, this combination of variables achieved the best overall fit of the model.

The model shows that females are more likely to use transit if information kiosks are available. This might be an expected finding since earlier results indicated that females have greater transportation problems (Abdel-Aty and Jovanis $1998)$. Middle-income respondents $(\$ 20,000-\$ 49,999)$ are more likely to use transit. This group is probably educated and willing to use information. Respondents with lower incomes might be using transit already, while respondents with higher incomes are not ready to change their current mode (private car). The respondent's age was found to affect the choice to use transit. The younger group of elderly (65-69 years old) are more likely to use transit, while the older-age group (more than age 80) are less likely to use transit given the availability of information kiosks when compared to the 65- to 69-year-old 


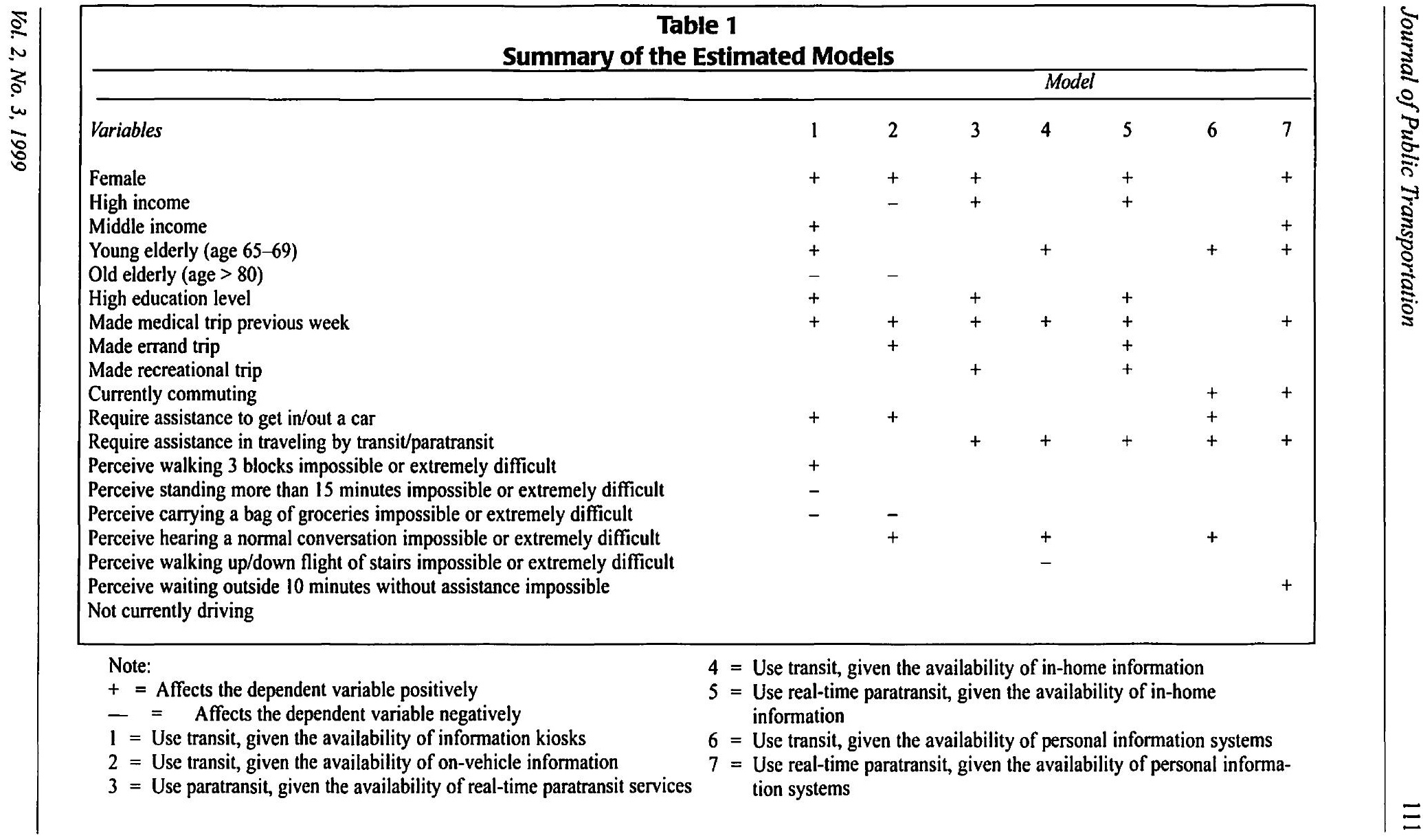




\begin{tabular}{|c|c|c|}
\hline \multicolumn{3}{|c|}{$\begin{array}{l}\text { Table } 2 \\
\text { Probit Model of the Likelihood of Using Transit, Given Information } \\
\text { Kiosks Are Available }\end{array}$} \\
\hline & $\beta$ & i-statistic \\
\hline$\beta_{0}$ Use transit constant & -0.652 & -3.428 \\
\hline$X_{1}$ Female dummy variable & 0.376 & 2.116 \\
\hline $\begin{array}{l}X_{2} \text { Middle-income dummy variable } \\
\text { (1 if income } \$ 20,000-\$ 49,999)\end{array}$ & 0.299 & 1.726 \\
\hline $\begin{array}{l}X_{3} \text { Younger-age dummy variable } \\
\text { (1 if age } 65-69,0 \text { otherwise) }\end{array}$ & 0.318 & 1.581 \\
\hline $\begin{array}{l}X_{4} \text { Older-age dummy variable } \\
\text { (1 if age } \geq 80,0 \text { otherwise) }\end{array}$ & -0.415 & -1.543 \\
\hline $\begin{array}{l}\mathrm{X}_{5} \text { High education-level dummy variable } \\
\text { (1 if graduate degree, } 0 \text { otherwise) }\end{array}$ & 0.822 & 2.910 \\
\hline $\mathrm{X}_{6}$ Require assistance to get in/out of car & 0.514 & 1.411 \\
\hline $\mathrm{X}_{7}$ Made clinic/hospital/medical trip last week & 0.248 & 1.390 \\
\hline $\begin{array}{l}\mathrm{X}_{8} \text { Perceive walking } 3 \text { blocks without resting as } \\
\text { impossible or extremely difficult, dummy variable }\end{array}$ & 0.580 & 2.029 \\
\hline $\begin{array}{l}\mathrm{X}_{9} \text { Perceive standing for more than } 15 \text { minutes } \\
\text { impossible or extremely difficult, dummy variable }\end{array}$ & -0.652 & -1.893 \\
\hline $\begin{array}{l}\mathrm{X}_{10} \text { Perceive carrying a bag of groceries as } \\
\text { impossible or extremely difficult, dummy variable }\end{array}$ & -0.525 & -1.202 \\
\hline $\begin{array}{l}\text { Summary Statistics } \\
\text { Log likelihood at } 0=-187.0304 \\
\text { Log likelihood at convergence }=-156.8336 \\
\text { Likelihood ratio index around } 0=0.161 \\
\text { Number of observations }=248\end{array}$ & & \\
\hline
\end{tabular}

Note: Variables are defined for the alternative of choosing to use transit if the information kiosks were available. 
group. As travelers age, regular transit buses might be difficult to use, even if information was available. Respondents who have a graduate degree are also more likely to use transit. The well-educated elderly are more apt to use different technologies including information kiosks.

Elderly people who require assistance to get in/out of a car are more likely to use transit, indicating their desire for more independence. Those who responded that they made a medical-related trip in the week prior to the survey, are more likely to use transit given the availability of information kiosks. This was the only trip purpose found significant, indicating the necessity of such trips and that the elderly need reliable transportation for such trips.

Several perception-related variables representing the respondents' physical capabilities were entered into the model. Respondents perceiving walking three blocks to be impossible or extremely difficult, are more likely to choose transit, given the availability of information kiosks. These respondents probably associate their capabilities with the modes or transportation systems they currently use, and their need to a system that facilitates the effort they exert. However, respondents that perceive standing for 15 minutes and/or carrying a bag of groceries as impossible or extremely difficult are less likely to use transit.

On-board Transit Information. Table 3 presents a binary probit model of whether the respondents are more likely to use public transit if on-board vehicle information systems were available. The estimation results show, as in the previous model, that females are more likely to use transit (although this variable is not significant at the $95 \%$ level as in the previous model). Highincome respondents (household income between $\$ 70,000-\$ 89,999$ ) are less likely to use transit, given the availability of on-board information. Highincome respondents are probably not willing to change their mode of travel from the private car to transit because they have the financial ability to have a good car and assistance if needed. Also, the older group (more than 80 years) is less likely to use transit, possibly because of the perceived difficulty associated with using this mode (i.e., walking to bus stops, waiting, etc.).

As in the previous model, if respondents require assistance to get in or out of private vehicles, then they would be more likely to use transit, although it is 


\begin{tabular}{|c|c|c|}
\hline \multicolumn{3}{|c|}{$\begin{array}{c}\text { Table } 3 \\
\text { Probit Model of the Likelihood of Using Transit Given the Availability } \\
\text { of On-Vehicle Information }\end{array}$} \\
\hline & $\beta$ & t-statistic \\
\hline$\beta_{0}$ Use transit constant & -0.563 & -2.389 \\
\hline $\mathrm{X}_{1}$ Female dummy variable & 0.267 & 1.570 \\
\hline$X_{2}$ High-income dummy variable ( 1 if income $\$ 70,000-\$ 89,999$ ) & -0.827 & -1.363 \\
\hline$X_{3}$ Older-age dummy variable ( 1 if age $\geq 80,0$ otherwise) & -0.405 & -1.490 \\
\hline $\mathrm{X}_{4}$ Require assistance to get in/out of a car & 0.783 & 2.117 \\
\hline $\mathrm{X}_{5}$ Made clinic/hospital/medical trip last week & 0.246 & 1.397 \\
\hline $\begin{array}{l}\mathrm{X}_{6} \text { Perceive carrying a bag of groceries as impossible or } \\
\text { extremely difficult, dummy variable }\end{array}$ & -1.175 & -2.463 \\
\hline \multicolumn{3}{|l|}{$\mathrm{X}_{7}$ Perceive hearing a normal conversation as impossible or extremely } \\
\hline difficult, dummy variable & 0.675 & 1.514 \\
\hline $\mathrm{X}_{8}$ Made an errand trip last week & 0.260 & 1.222 \\
\hline $\begin{array}{l}\text { Summary Statistics } \\
\text { Log likelihood at } 0=-191.1275 \\
\text { Log likelihood at convergence }=-158.3695 \\
\text { Likelihood ratio index around } 0=0.171 \\
\text { Number of observations }=247\end{array}$ & & \\
\hline
\end{tabular}

Note: Variables are defined for the alternative of choosing to use transit if on-vehicle information was available.

unlikely that a senior traveler that requires assistance would use transit. This variable has consistently been significant, probably indicating the high level of frustration of this group of elderly, and the need to address their mobility problems. Also, respondents that made a medical-related trip or ran an errand during the week prior to the survey were more likely to choose transit. Although the running errand variable is only significant at the 78 percent level, it was included because it improved the overall fit of the model. Therefore, medical trips, as discussed above, are considered the most important type of trip for the elderly.

Perceiving hearing a normal conversation as impossible or extremely difficult affects positively the likelihood of using transit, given the availability of on-board information. This indicates that the elderly with communication 
problems would seek information because it saves them the embarrassment of asking the driver or another passenger for help. Perceiving carrying a bag of groceries as impossible or extremely difficult negatively affects the likelihood of using transit (i.e., if carrying the groceries is a problem, then riding the bus is a problem).

Real-Time Paratransit Services. A binary probit model of whether respondents are more likely to use paratransit if real-time paratransit services were available was estimated. The estimation results show, as in the previous models, that females are more likely to use paratransit. High-income respondents (household income greater than $\$ 70,000$ ) are more likely to use paratransit given the availability of real-time systems. In comparing the income variable with the previous two models, high-income respondents were shown to prefer paratransit over transit, probably a tendency to use more private modes of transportation.

Respondents with a graduate or four-year college degree are more likely to use real-time paratransit. Also, respondents who require assistance in traveling by transit or paratransit are more likely to consider real-time paratransit.

In terms of trip type, making a medical trip the week before the survey positively influences the likelihood of using paratransit. This is consistently a significant variable in all the estimated models, indicating the importance of this type of trip. Making recreational/leisure trips, although marginally significant in this model, shows that real-time paratransit could improve the elderly's mobility and hence encourage those who usually make such trips to use real-time paratransit.

In-Home Information Systems. Two models were developed to investigate the potential effect of in-home information systems. The first is a binary probit model of whether respondents would be more likely to use public transit if in-home information systems were available (Table 4). The second is a binary probit model of whether respondents would be more likely to use realtime paratransit if in-home information systems were available (Table 5). The first model is the only model estimated that does not show any gender effect. All the previous models showed that females have a likelihood to use transit or 


\section{Table 4}

\section{Probit Model of the Likelihood of Using Public Transit If In-Home Information Was Available}

\begin{tabular}{lrr}
\hline & $\beta$ & $t$-statistic \\
\hline$\beta 0$ Use transit constant & -0.413 & -3.358 \\
$X_{1}$ Younger-age dummy variable (1 if age 65-69, 0 otherwise) & 0.373 & 1.912 \\
$X_{2}$ Respondent not currently driving a vehicle & -0.487 & -1.563 \\
$X_{3}$ Made clinic/hospital/medical trip last week & 0.318 & 1.812 \\
$X_{4}$ Perceive walking up or down a flight of stairs as impossible or extremely & & \\
difficult, dummy variable & -0.933 & -2.584 \\
$X_{5}$ Perceive hearing what is said in a normal conversation as impossible or & & \\
extremely difficult, dummy variable & 1.041 & 2.333 \\
$X_{6}$ Require assistance while traveling by transit or paratransit & 0.815 & 2.386 \\
& & \\
Summary Statistics & & \\
Log likelihood at $0=-194.2201$ & \\
Log likelihood at convergence $=-158.4135$ & \\
Likelihood ratio index around $0=0.184$ & \\
Number of observations $=249$ & \\
\hline
\end{tabular}

Note: Variables are defined for the alternative of choosing to use transit if in-home information was available.

paratransit given the availability of information, and this was attributed to their transportation difficulties. The second model showed a significant likelihood of females using real-time paratransit. This might indicate that in the event inhome information was available, females prefer paratransit over transit.

The second variable (not driving a vehicle) in the first model (Table 3) unexpectedly has a negative sign, indicating that respondents who currently do not drive are less likely to use transit. However, a closer examination of this group reveals that it is relatively small (29 respondents), and that the respondents probably have physical problems that prevent them from driving. Thus, it can be concluded that physical problems could make transit use difficult as well. Both models show that respondents requiring assistance while traveling by transit or paratransit would be more likely to use the proposed system.

In both models, making a medical-related trip the previous week increased the likelihood of using the proposed system. However, in the second model, making a recreational/leisure or errand trip was entered into the model. 


\begin{tabular}{|c|c|c|}
\hline \multicolumn{3}{|c|}{$\begin{array}{l}\text { Table } 5 \\
\text { Probit Model of the Likelihood of Using Real-Time Paratransit } \\
\text { if In-Home Information Was Available }\end{array}$} \\
\hline & $\beta$ & t-statistic \\
\hline$\beta_{0}$ Use real-time paratransit constant & -0.873 & 3.680 \\
\hline $\mathrm{X}_{1}$ Female dummy variable & 0.308 & 1.863 \\
\hline $\begin{array}{l}X_{2} \text { High level of education dummy variable } \\
\text { ( } 1 \text { if graduate or } 4 \text {-year college degree, } 0 \text { otherwise) }\end{array}$ & 0.450 & 1.625 \\
\hline $\mathrm{X}_{3}$ Made recreational/leisure trip last week & 0.227 & 1.250 \\
\hline $\mathrm{X}_{4}$ Made clinic/hospital/medical trip last week & 0.367 & 2.140 \\
\hline$X_{5}$ Made an errand trip last week & 0.300 & 1.472 \\
\hline $\mathrm{X}_{6}$ Require assistance while traveling by transit/paratransit & 0.729 & 2.433 \\
\hline$X_{7}$ High-income dummy variable ( 1 if income $\$ 70,000-\$ 89,999$ ) & 0.635 & 1.089 \\
\hline $\begin{array}{l}\text { Summary Statistics } \\
\text { Log likelihood at } 0=-193.5583 \\
\text { Log likelihood at convergence }=-165.5845 \\
\text { Likelihood ratio index around } 0=0.145 \\
\text { Number of observations }=256\end{array}$ & & \\
\hline
\end{tabular}

Note: Variables are defined for the alternative of choosing to use real-time paratransit if in-home information was available.

This indicates that real-time paratransit might increase the elderly's mobility by allowing them to make a variety of trip types.

Respondents perceiving walking up or down a flight of stairs as impossible or extremely difficult are less likely to use transit. Respondents who perceive what is said in a normal conversation as impossible or extremely difficult are more likely to use transit if in-home information was available. In this case, in-home information would help these respondents avoid the problem of communicating with others to ask transit-related questions.

Table 3 shows that the younger elderly (age 65-69) are more likely to use transit than older-age groups, given in-home information. Table 5 shows that welleducated respondents (graduate or four-year college degree) are more likely to use real-time paratransit, if in-home information was available. This group is usually familiar with computers, and one of the sources of in-home information would be computers. Also, high-income respondents $(\$ 70,000-\$ 89,999)$ are more likely to use real-time paratransit. 
Personal Information Systems. Two models were developed to investigate the potential effect of personal information systems. The first is a binary probit model of whether respondents would be more likely to use public transit if personal information systems were available. The second is a binary probit model of whether respondents would be more likely to use real-time paratransit if personal information systems were available.

The models are similar to those developed for in-home information (Tables 4 and 5). The significant variables entered in the first model were: younger elderly dummy variable (65-69), requiring assistance to travel, perception of the difficulty of hearing, and commute dummy variable. The second model showed significance of the female dummy variable, younger elderly, requiring assistance, commute, middle income, and medical trips on the likelihood of using real-time paratransit, given the availability of personal information systems.

\section{Summary and Conclusions}

A CATI survey of the elderly, conducted in August 1996, targeted a random sample of the senior population in the Sacramento area. The survey was limited to respondents 65 years old and above and yielded a sample of 260 respondents. The main objectives of the study were to define the characteristics and travel behavior of senior citizens, and to test their acceptance of different new transportation technologies and the technologies' potential for improving their mobility.

A previous study (Abdel-Aty and Jovanis 1998) described the sample and presented the survey design and general descriptive statistics. The results illustrated that the elderly generally perform trips frequently, and pointed to the importance of improving transportation to meet the needs of the elderly.

The survey proposed five advanced transit technologies to test the elderly's acceptance and potential use of such systems.

The binary probit model formulation was used to estimate the elderly's potential use of such systems. Those surveyed were asked whether they would use transit (or paratransit) if one of the suggested technologies was available. The estimation results showed that females consistently try to find solutions to 
their transportation problems. Being a female was always a significant variable in choosing to use transit (or paratransit) when any type of information was available (Table 1). However, if the information system is available for both transit and paratransit (in-home and personal information), females tend to choose real-time paratransit. Sensitivity analysis shows that the gender effect is strongest in the information kiosk and the real-time paratransit models. Highincome respondents were more likely to use real-time paratransit, whether this service was provided by itself or with in-home or personal information. However, the level of significance is higher and the effect of this variable is stronger if the service is provided without personal information. High-income respondents appear satisfied with the service itself without any information. Females and high-income elderly are two potential sociodemographic market groups for real-time paratransit.

The younger group of elderly (age 65-69) is more likely to use transit if information kiosks, in-home information, or personal information is available. However, this group is also more likely to use real-time paratransit if personal information is available. The effect is profound for using transit when in-home or personal information is provided, indicating a preference for transit over paratransit for the younger elderly. This result shows the group's acceptance of information systems that could be perceived as a new device or require familiarity with computers. Well-educated respondents are more likely to use paratransit if this service is available, or if in-home information is available. They are also likely to use transit given the availability of information kiosks (Table 1).

Medical trips are extremely important for the elderly. The models showed that those who made a medical trip the week before the survey were accepting any proposed new transportation system and willing to use it. However, the effect was more significant for real-time paratransit and real-time paratransit associated with in-home information. Respondents who are still commuting generally accepted personal information systems.

Respondents' perceptions of the difficulty of some actions/situations were also significant in the models. One of the most important situations is the ability to hear what is said in a normal conversation. Respondents who considered 
this action as impossible or extremely difficult were more likely to use transit if on-board, in-home, or personal information systems were available (Table 1). This variable indicates that the communication problem experienced by some elderly travelers could be avoided by providing transportation information.

The survey and the analysis illustrated the elderly's difficulties and problems with transportation. They also showed the important potential of several transit technologies to increase the mobility and alleviate the transportation difficulties of the elderly population. The results illustrate the willingness of many groups of senior travelers to use new transportation systems in an attempt to reduce their travel dependence and problems. The study demonstrates that seniors might be willing to change their primary mode of travel from the private vehicle to other public modes if better systems were available.

\section{References}

Abdel-Aty, M., and P. Jovanis. 1998. A survey of the elderly: An assessment of their travel characteristics. Paper presented at the 77th Annual Meeting of the Transportation Research Board, Washington DC (Reprint No. 980001).

Ben-Akiva, M., and S. Lerman. 1985. Discrete choice analysis: Theory and application to travel demand. Cambridge, MA: The MIT Press.

Daganzo, C. 1979. Multinomial probit: The theory and its application to demand forecasting. New York: Academic Press Inc.

Geehan, T., and L. Suen. 1993. User acceptance of advanced traveler information systems for the elderly and disabled travelers in Canada. IEEE-IEE Vehicle Navigation and Information Systems Conference, Ottawa, VNIS '93.

Guthrie, B., and A. Phillips. 1994. Market estimates of Intelligent Transportation Systems for seniors and people with disabilities. Proceedings of the First World Congress on Applications of Transport Telematics and Intelligent VehicleHighway Systems, Paris, France.

Lago, A., and J. Burkhardt. 1980. Predictive models of the demand for public transportation services among the elderly. Transportation Research Record 784, 21-27.

Parolin, B. 1988. Travel mode choice behavior and physical barrier constraints among the elderly and handicapped: An examination of travel mode preferences. Transportation Research Record 1170, 19-28. 
Schweiger, C., and J. McGrane. 1994. The challenge for developing and implementing advanced public transportation systems for elderly and disabled customers. Proceedings of the First World Congress on Applications of Transport Telematics and Intelligent Vehicle-Highway Systems, Paris, France.

Suen, L., and J. Parviainen. 1993. Advanced travel accessibility systems for the elderly and disabled: A conceptual framework. IEEE-IEE Vehicle Navigation and Information Systems Conference, Ottawa, VNIS '93.

Suen, L., and U. Rutenberg. 1994. Advanced transportation information systems for elderly and disabled travelers in transportation terminals. Proceedings of the First World Congress on Applications of Transport Telematics and Intelligent VehicleHighway Systems, Paris, France.

Transportation Research Board. 1988. Transportation in an aging society: Improving mobility and safety for older persons. Special Report 218.

U.S. Department of Transportation. 1992. Travel behavior issues in the '90s, 1990 Nationwide Personal Transportation Survey, Washington, DC: Federal Highway Administration.

Witkowski, J., and T. Buick. 1985. Travel behavior of residents of retirement communities, Transportation Research Record 1018, 13-22.

\section{About the Author}

Mohamed A. AbDel-ATY is an assistant professor of transportation engineering at the University of Central Florida. He received a Ph.D. in transportation engineering from the University of California at Davis in 1995. 
